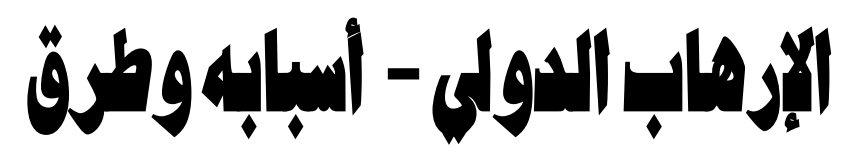

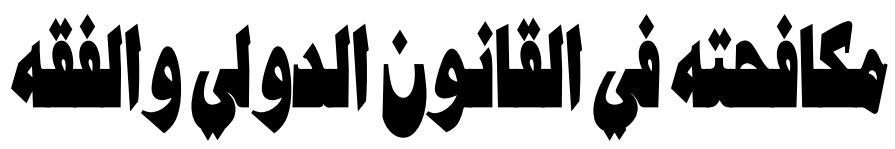

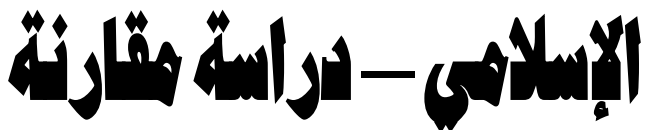

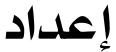 \\ د. شريف عبد الحميد حسن رمخلان
}

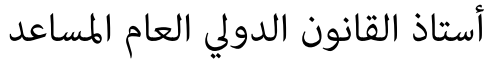

كلية الشريعة والأنظمة - جامعة الطائف ( المملكة العربية السعودية )

\section{الماخص المص}

خلال القرن العشرين ، وبداية القرن الحادي والعشرين شهد المجتمع الدولي العديد

من حو ادث الإرهاب ـ حتى أصبح يأكل الأخضر واليابس ، ويهدد الشعوب ، ويخل بالأمن والاستقرار - بل ويفتت الدول . . وازداد خطر الإرهاب عندما انتقل من العمليات التقليدية غير المنظمة والتخريب والاغتيالات إلى جريمة دولية منظمة تساندها بعض الدول لما لها من قدرة مالية ، وكفاءة في العمليات الإستخبارية - بل أكثر من ذلك لم يعد الإرهاب مقصوراً على استخدام العنف فقد أصبح هناك أنواع أخرى للإرهاب مثل الإرهاب الالكتروني ، والإرهاب الفكري ، والعقائدي ، والإرهاب باستخدام الأجهزة الإعلامية التي تقوم بالتحريض على استخدام العنف . ولما يشكله الإرهاب الدولي من خطورة على المجتمع الدولي • فقد قام المجتمع 
الدولي منذ أوائل القرن العشرين على إيجاد تعاون دولي لمكافحة الإرهاب ، وقامت المنظمات الدولية والإقليمية بالجهود الدولية لمكافحة الإرهاب .كما قامت الدول بسن

$$
\text { التشريعات الوطنية للقضاء على الإرهاب ومكافحته . }
$$

وقد سبقت الشريعة الإسلامية القوانين الوضعية في تحريم الاعتداء على النفس

البشرية ، فاعتبرت النفوس كلها واحدة ، ومن اعتدى على إحداها ، فكأنما اعتدى عليها جميعًا ، ومن قدم خدمة ، أو خيراً لإحداها ، فكأنما قدمه للإنسانية جمعاء ، إذ أن الإسلام يحارب الإرهاب بشتى صوره وأنواعه لأن الإسلام دين السلام ، فالسلام في الإسلام أعمق من أن يكون مجرد رغبة يدعو إلى تحقيقها في الحياة ، إنما هو أصل من أصول عقيدته ، وعنصر من عناصر تربيته ، وهدف يعمق الإحساس به في ضمير الفرد ، وواقع المجتمع ، جسد الأمة.

ومن هذا المنطلق فقد وضعت الشريعة الإسلامية الأسس والمبادئ التي تقضى على

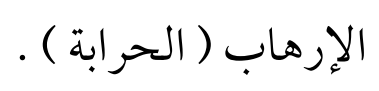

\begin{abstract}
During the twentieth century, and the beginning of the twentieth century atheist and the international community has witnessed many incidents of terrorism. Until it became eats everything and everybody, and threatens peoples, and disturbs the peace and stability - and even crumbling states. The increased threat of terrorism when he moved from traditional operations unregulated, sabotage and assassinations to an international crime organization, backed by some countries because of their financial capacity, the efficiency of the intelligence operations - but more than that terrorism is no longer limited to the use of violence there has become other types of terrorism, such as cyber terrorism and the intellectual and ideological terrorism, and terrorism by using media devices
\end{abstract}


that are inciting the use of violence.

As posed by international terrorism, the danger of the international community. The international community has made since the early twentieth century on international cooperation to combat terrorism, and the international and regional organizations to international efforts to combat terrorism. As the states to enact national legislation to eliminate and combat terrorism.

Islamic law was preceded by man-made laws concerning the prohibition on abuse of the human psyche, Vaattabrt souls are all one, and assaulted one of them, as if he had assaulted them all, and made a service or good for one of them, as if he presented for all mankind, if that Islam is fighting terrorism in all its forms and types because Islam is a religion of peace. peace in Islam deeper than just a desire to be calls to achieve in life, but it is out of the assets of his faith, and the element of his upbringing, and the goal of deepening the sense in the conscience of the individual, and the reality of the community, the body of the nation. Hence the sense of Islamic law has laid the foundations and principles that eliminate terrorism (banditry). 


\section{مقدمة}

أضحى الإرهاب الدولي من أخطر ما يهدد المجتمع الدولي ، فلم يعد الإرهاب

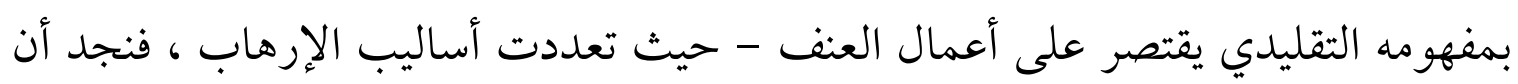

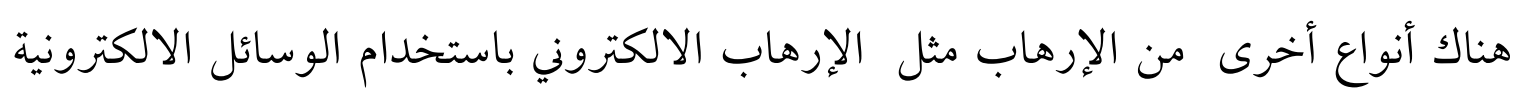

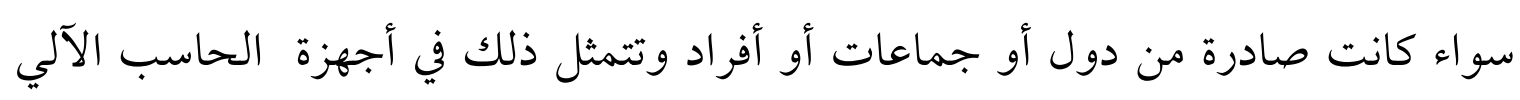

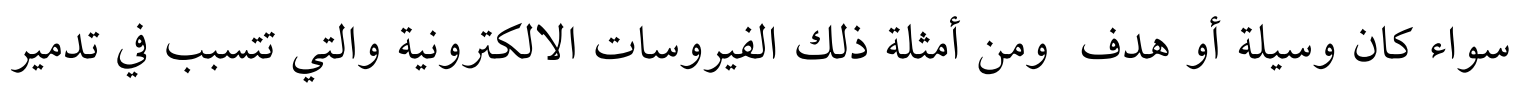

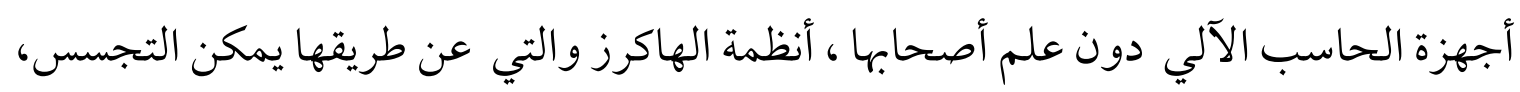

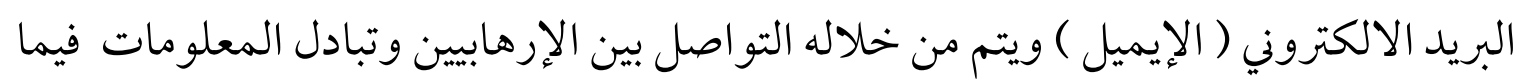
بينهم ونشر وترويج الأفكار ، المواقع على الشبكة العنكبوتية الانترنت - حيث يتم إنشاء

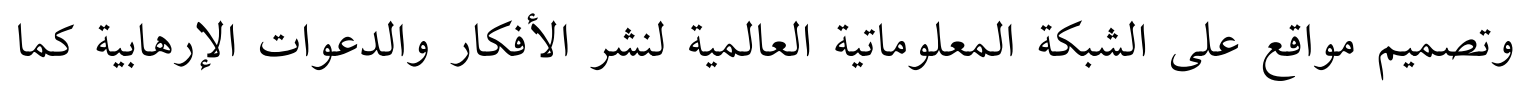

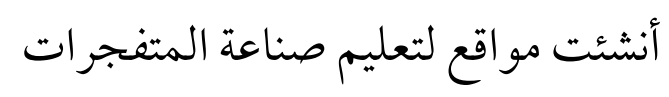

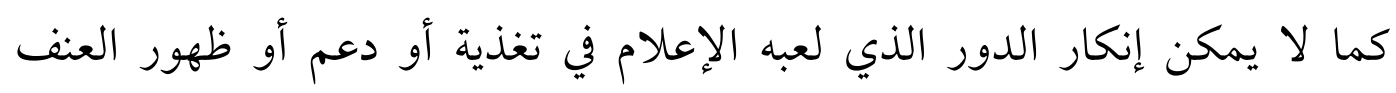

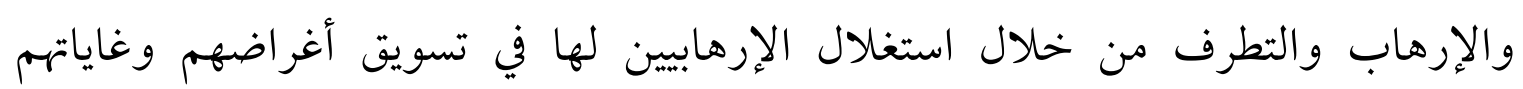
وتوظيفها في تضليل الأجهزة الأمنية واكتساب السيطرة على الرأي العام عن طريق نشر أخبار العمليات الإرهابية التي يقومون بتنفيذها على اعتبار أن الحملات الإعلامية التي تغطي هذه العمليات تساعد على تحقيق واستكمال أهدافهم، حيث يرون في التغطية الإعلامية لجر ائمهم معيار اهاما لقياس مدى نجاح فعلهم الإرهابي ، لدرجة أن البعض منهم اعتبر العمل الإرهابي لعني الذي لا ترافقه تغطية إعلامية عملا فاشلا.

كما أن هناك استخدام نوع آخر من الإرهاب وهو الإشاعات لتهجيج المشاعر

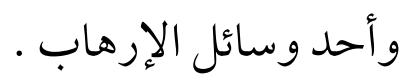
ويوجد كذلك الإرهاب الفكري وذلك لإفساد المعتقدات الدينية سواء عن طريق 
الأجهزة الإعلامية أو الانترنت باستخدام وسائل التواصل الاجتماعي الفيس بوك وتوتير

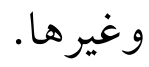

ولذا فقد اهتم المجتمع الدولي بمحاربة ومكافحة الإرهاب منذ النصف الأول

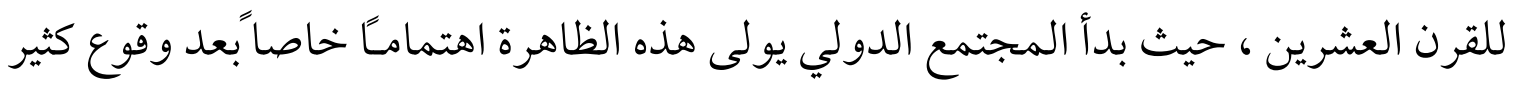

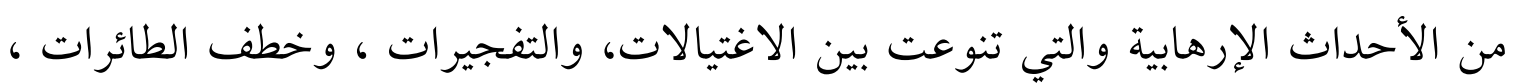
واخذ الرهائن .وتجلى الاهتمام في تناول عصبة الأمم المتحدة هذه المشكلة باتفاقية دولية VTV اوبرتوكول بإنشاء محكمة دولية جنائية لمحاكمة الأفراد المتهمين بالإرهاب ، إلا أن هذه الاتفاقية لم يكتب لها التطبيق بسبب عدم تو افر النصاب الكافي للتصديق عليها ـ إلا انه بدأ بعد ذلك الاهتمام بعقد اتفاقيات دولية لمحاربة الإرهاب في مجالات مختلفة تدرجت

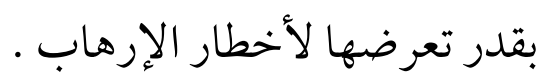

وبعد أحداث الاستمبر r... في الولايات المتحدة الأمريكية تضاعف اهتمام المجتمع الدولي وزاد نشاط الأمم المتحدة في مجال مكافحة الإرهاب من خلال الجمعية العامة ، ومجلس الأمن فصدرت العديد من القرارات ـ كما عقدت كثير من الاتفاقيات والمؤتمرات للتصدي لهذه الظاهرة .

وقد بدء الدين الإسلامي قبل القوانين الوضعية مبادئ تنهى عن كل أنواع الشر

المؤدى إلى الانحراف - ومع ذلك فقد لو حظ في الآونة الأخيرة اتجاه الفكر الغربي بإعلامه لهيل إلى لصق تهمة الإرهاب إلى الإسلام والمسلمين - بل العكس من ذلك فإن الإسلام يرفض الإرهاب ويستنكره ولا يقبل بارتكابه سواء بين المسلمين أنفسهم أو بين المسلمين وغيرهم

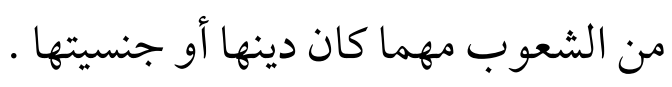

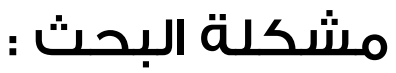

الإرهاب الدولي أصبح خطر يستفحل يوم بعد يوم - بل أصبح الإرهاب بديلا 
للحروب ، وخاصة عندما أصبحت المنظمات الإرهابية في العالم تمتلك العديد من وسائل التقدم التكنولوجي التي تمكنها من تنفيذ عملياتها الإرهابية بدرجة عالية من الدقة والإتقان . حيث أضحى الإرهاب يحصد أرواح الملايين من البشر ، ويتسبب في إحداث العاهات وإصابة الملايين من البشر ، فضلا عن إتلاف وتدمير الممتلكات العامة والخاصة ، بل أكثر من ذلك يعمل الإرهاب على إتلاف العقول عن طريق الغزو الفكري ـ والأخطر من ذلك

يفشى الفوضى بالدول ويعمل على تفتيتها وتجزئتها . أسباب اختيار الموضوع : بوضئ

لموضوع الدراسة أهمية كبرى لما يمثله الإرهاب الدولي من خطر على الأفراد و الممتلكات العامة والخاصة وكيان الدول ـ وهذه الأهمية هي التي دفعتني لكي ابحث في هذا الموضوع حيث يترتب على الإرهاب

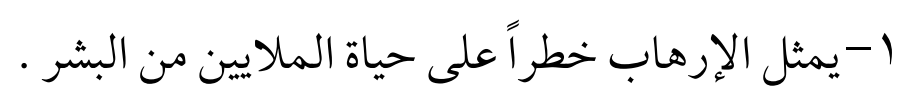
r- يتسبب الإرهاب في إتلاف الممتلكات العامة والخاصة . ب- بدمر الإرهاب البنية التحتية للدول . ع- يعمل الإرهاب على تجزئة الدول وتفتيتها . ه- إيجاد حلول للتصدي ومو اجهة الإرهاب والقضاء عليه .

أهداف الدراسة :

\section{تهدف الدراسة إلى التعرف على :}

1 - مفهوم الإرهاب الدولي وتميزه عن غيره في القانون الدولي والفقه الإسلامي . r- الأسباب والدوافع لظاهرة الإرهاب في القانون الدولي والفقه الإسلامي .

r-بيان الجهود الدولية لمكافحة الإرهاب الدولي سواء عن طريق المنظمات الدولية والإقليمية ، أو الوثائق ، والاتفاقيات الدولية أو التشريعات الوطنية . 


$$
\text { ع - بيان أسس ومبادئ الدين الإسلامي في نبذ الشر والعنف ومكافحة الإرهاب . منهج البحث : }
$$

يعتمد الباحث على المنهج الوصفي التحليلي المقارن بالفقه الإسلامي في بيان مفهوم

الإرهاب الدولي ، وتميزه عن غيره من وسائل القوة المسلحة مثل المقاومة الشعبية ، والدفاع

الشرعي • وبيان أسباب ودو افع الإرهاب ـ وطرق مكافحته .

\section{خطة البحث :}

$$
\text { نقسم هذا الباحث هذا البحث إلى ثلاثة فصول . }
$$

الفصل الأول : ماهية الإرهاب وتميزه في القانون الدولي والفقه الإسلامي .

الفصل الثاني :أسباب الإرهاب الدولي في القانون الدولي والفقه الإسلامي .

الفصل الثالث :طرق مكافحة الإرهاب في القانون الدولي والفقه الإسلامي. 


\section{الفصل الأول \\ ماهية الإرهاب وتميزه في القانون الدولي والفقه الإسلامي تمهيد وتقسيهم :}

إن تعريف الإرهاب الدولي من الصعوبة بمكان الوصول إليه للتحديد مفهوم له ويرجع ذلك إلي أن هذا الاصطلاح ليس له مضمون قانوني محدد ، حيث تعرض هذا الاصطلاح إلي تطور وتغيير معناه منذ بدء استخدامه في أواخر القرن الثامن عشر ـ فقد كان يقصد به في البداية الأعمال والسياسيات الحكومية التي تستهدف الرعب بين المواطنين وصولاً إلي تأمين خضوعهم وانصياعهم لرغبات الحكومة وبتطوره اليوم أصبح يستخدم لو صف أعمال يقوم بها أفراد أو مجموعات من الأفراد لأسباب متعددة ـ ففي الوقت الحاضر يستخدم هذا الاصطلاح للتعبير عن الاستخدام المنظم للعنف لتحقيق هدف سياسي وخاصة الاعتداءات الفردية والجماعية والتخريب وأعمال العنف المختلفة التي تقوم منظمة سياسيه (1) بممارستها علي المو اطنين وخلق جو من الرعب والفزع وعدم الأمان ولقد نبذ الإسلام العنف والإرهاب بجميع أشكاله وألو انه ، وحث المسلمين على الابتعاد عن كل ما يؤدى إلى الوقوع به ، بل أن الإسلام حرم على الإنسان الاعتداء على نفسه

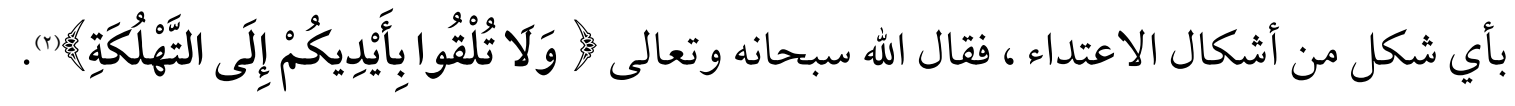
ويختلط مفهوم الإرهاب باعتباره استخدام غير مشروع للقوة ببعض صور القوة الأخرى مثل الدفاع الشرعي،والمقاومة الشعبية المسلحة سواء في القانون الدولي أو الفقه

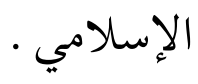

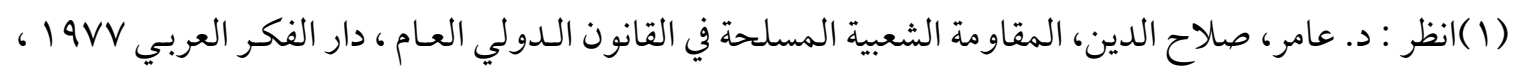
(210 (Y) سور البقرة ، الآية ، 190 . 
وعلي هذا سوف نقسم هذا الفصل إلي ثلاثة مباحث :

المبحث الأول : تعريف الإرهاب في القانون الدولي والفقه الإسلامي .

المبحث الثاني : تميز الإرهاب عن المقاومة الشعبية المسلحة في القانون الدولي

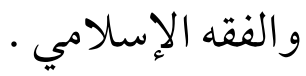

المبحث الثالث : تميز الإرهاب الدولي عن الدفاع الشرعي في القانون الدولي والفقه

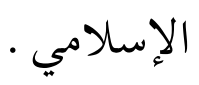

\section{المبحث الأول}

\section{تعريف الإرهاب الاولي في القاتون الاولي والفقه الإسلامي الإني}

اختلف فقهاء القانوني الدولي علي تعريف واحد للإرهاب الدولي حيث أن فريقا

منهم ربط بين الإرهاب وتحقيق الأهداف السياسية،أي ربط بين الإجرام السياسي والإرهاب

بصفة عامة،وفريقًا أخر اهتم في تناوله لمفهوم الإرهاب بالوسائل المستخدمة فيه وبالرعب والفزع،كمصلحة ونتيجة له دون النظر إلي الهدف الكامن وراءه .

كما حاولت العديد من الاتفاقيات الدولة بوضع تعريف محدد للإرهاب الدولي •

وقد جاء الدين الإسلامي للناس كافة لنشر السلام ليحمى كرامة الإنسان ويدافع عن

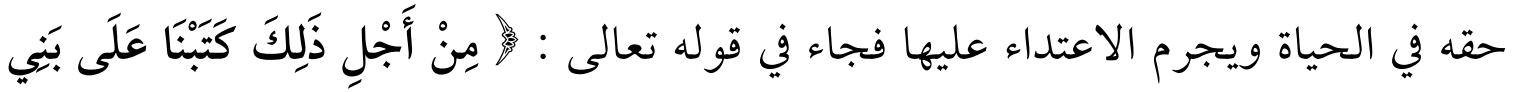

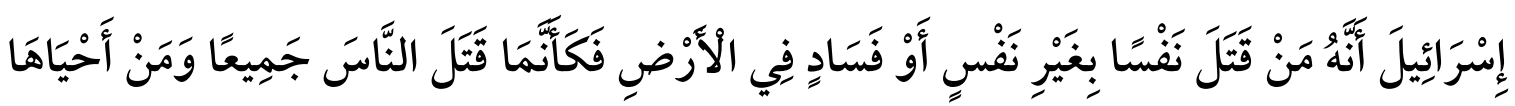

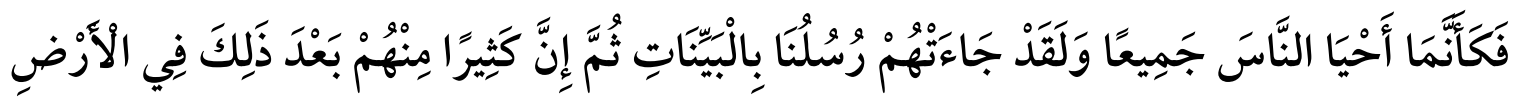
لَمَسْرِفونَ 


$$
\begin{aligned}
& \text { وعلى ذلك سوف نقسم هذا المبحث إلى ثلاثة مطالب : } \\
& \text { المطلب الأول : تعريف الإرهاب في الفقه الدولي . } \\
& \text { المطلب الثاني : تعريف الإرهاب الدولي في الاتفاقيات الدولية . } \\
& \text { المطلب الثالث : تعريف الإرهاب في الفقه الإسلامي . } \\
& \text { المطلب الأول }
\end{aligned}
$$

تعريف الإرهاب في الفقه الدولي

فقد بذلت جهود فقهية عديدة سواء من الفقه الغربي أو الفقه العربي لتعريف الإرهاب.

فقد عرفه "Sottile" سوتيل بأنه (العمل الإجرامي المقترن بالرعب أو العنف أو الفزع بقصد تحقيق لهدف معين) . ويؤخذ علي هذا التعريف بأنه قد اقتصر علي تعريف الإرهاب علي أعمال العنف فقط كما لم يحدد الهدف من الإرهاب (1).

في حين عرفه الفقيه "Saldana" سلدانا في تعريفين أحداهما واسع،و الآخر ضيق فقد عرفه في معناه الواسع بأنه كل "جناية أو جنحة سياسية أو اجتماعية ينتج عن تنفيذها أو التعبير عنها ما يثر الفزع العام لما من طبيعة ينشأ عنها حظر عام" أما المعني الضيق فإن الإرهاب يعني "الأعمال الإجرامية التي يكون هدفها الأساسي نشر الخوف والرعب كعنصر شخصي وذلك باستخدام وسائل من شأنها خلق حالة من الخطر العام كعنصر مادي" (() . ويلاحظ علي هذا التعريف بأن الفقيه "Saldana" قد عرف الإرهاب في معناه الواسع

Sottile A . leterrorisne international R.C.A.O Vol 651938 p.96

Saldana le terrorisne rrevue international de droit penal 1936.P.26 . 
باستخدام تصيف الجرائم من جناية أو جنحة وأن هذا التصنيف يختلف من تشريع إلي أخر فما يعتبر جناية أو جنحة في تشريع لا يعتبر في تشريع أخر .

كما عرفه الفقيه "David Eric" ويفيد إيرك بأنه "كل عمل من أعمال العنف المسلح

$$
\text { يرتكب لتحقيق أهداف سياسية أو فلسفية أو إيديولو جية أو دينية" (1). }
$$

ويلاحظ علي هذا التعريف بأن أغلق باب الاجتهاد فيما يعد هدفًّ من الإرهاب

وكذلك لم يضع في اعتباره ما يستجد من أهداف للإرهاب فقد عدد وحصر الأهداف فقد كان

$$
\text { عليه أن يورد هذه الأهداف علي سبيل المثال وليس علي سبيل الحصر . }
$$

كما عرفه الفقيه "Wilkinson" ويلكنسون إلي أنه نتاج العنف المتطرف الذي يرتكب

من أجل الوصول إلي أهداف سياسية معينة يضحي من أجلها كافة المعتقدات الإنسانية

(r). الأخلاقية

ويلاحظ علي هذا التعريف بأن قد اقتصر فقط علي الأهداف السياسية دون غيرها .

كنا ذهب الفقيه "Walter" ولتر في تعريفه للإرهاب بأنه هو عملية رعب تتألف من

ثلاثة عناصر هي فعل عنيف أو تهديد به،ورده الفعل العاطفية الناجمة عن أقصي درجات

خوف الضحايا والآثار الناجمة عن ذلك التي تمس المجتمع ككل . (r)

ويلاحظ علي هذا التعريف بأنه لم يذكر معيارًا أو أفعال هذا العنف العنيف أو التهديد

: (1) (1) ( )

David eric le terrorisme reue droit in relexionss vr definition et la lepression du terois me editions de iuniversite de - bruxelles bmuxelle p. 25 .

: انظ ( ) ( )

Wilkinsan p. three question terrorisme in coverment and oppositian val .8 na 3 londan 1973 p.292

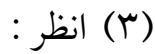

Walter .e.v teror and resistance a study of political viocence with cacese studies : of some paimitue afaican communities of some primitive africem communities of some raimitue afaican communities ax foad university rmess newyamk 1509 . p.3. 
كما عرفه "Bell" بيل بأنه صفة تطلق علي الأعمال غير المشروعة التي تمس

$$
\text { المجتمع وتصيب أفراده بالفزع والترويع · (1) }
$$

ويلاحظ علي هذا التعريف بأنه لم يحدد معياراً لأعمال العنف غير المشروع فأي فعل

$$
\text { مخالف للقانون يعد غير مشروعًَ. . مئ. }
$$

\section{كما تعددت تعريفات الفقه العربي للإرهاب الدولي ·}

فقد عرفه الأستاذ الدكتور / عبد العزيز سرحان بأنه (كل اعتداء علي الأرواح والأموال والممتلكات العامة أو الخاصة بالمخالفة لأحكام القانون الدولي بمصادره المختلفة بما في ذلك المبادئ العامة للقانون بالمعني الذي حددته المادة ^ץ من النظام الأساسي لمحكمة العدل الدولية وهو ما يمكن أن يطلق عليه أنه جريمة دولية أساسها مخالفة

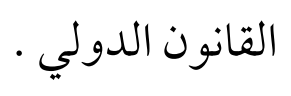

في حين عرفه الأستاذ الدكتور / نبيل حلمي بأنه الاستخدام غير المشروع للعنف أو التهديد به بواسطة فرد أو مجموعة أو دولة ضد فرد أو جماعة أو دولة ينتج عنه رعب يعرض للخطر أروحكً بشرية أو يهدد حريات أساسية ويكون الغرض منه الضغط علي

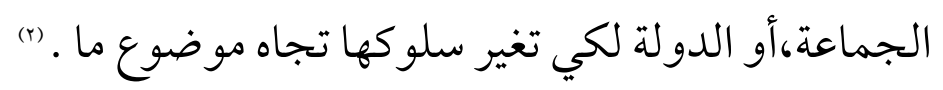
كما عرف الأستاذ الدكتور / أحمد رفعت بأنه استخدام طرق عنيفة كوسيلة الهدف

(1) انظر د. سرحان، عبد العزيز محمدد، حـول تعريف الإرهاب الدولي وتحديد مضمومة - المجلة المصرية

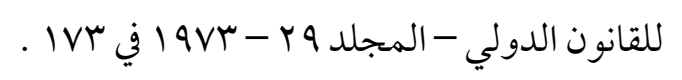

(Y) انظر : د. حلمي، نبيل أحمد الإرهاب الدولي وفقا لقواعد القانون الدولي العام ، دار النهضة العربية ، القاهرة

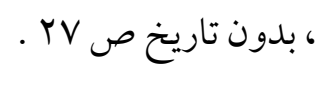


منها نشر الرعب للإجبار علي اتخاذ موقف معين أو الامتناع عن موقف معين . (1) ويرى سيادته أن الإرهاب وسيلة لتحقيق هدف ما،وليس هدفًً أو غاية في حد ذاته، إن لم يكن وسيلة لأصبح هذا العمل من أعمال الفوضوية التي سادت العالم في نهاية القرن التاسع عشر وبداية القرن العشرين،كما يري سيادته أن وسائل الإرهاب عديدة ومتنوعة،ولا يمكن حصرها إلا أنه تتميز جميعها بأنها عنيفة وتخلق حالة من الرعب والفزع،وبين سيادته الغاية من العمل الإرهابي،ويردها في غالبيتها لأسباب وغايات سياسية مثل عدم إقرار حقوق الشعوب في تحقيق مصيرها،وعدم مراعاة حقوق الأقليات إلا أنه ليس ضروريا أن تكون الغاية سياسيه فربما تكون اجتماعية أو تاريخية . كما ذهب الأستاذ الدكتور / محمد عزيز شكري بأنه لعمل عنيف وراءه دافع سياسي أيا كانت وسيلة وهو مخطط بحيث يخلق حاله من الرعب والهلع في قطاع معين من الناس لتحقيق هدف سياسي ·

أو لنشر دعاية أو مظلمة سو اء كان الفاعل يعمل لنفسه بنفسه أو بالنيابة عن مجموعة تمثل شبه دولة أو بالنيابة عن دولة منغمسة بصورة مباشرة أو غير مباشرة في العمل المرتكب شريطة أن يتعدي العمل الموصوف حدود دولة واحدة إلي دولة أخري وسواء ارتكب العمل الموصوف في زمن السلم أوزمن النزاع المسلح · (r)

في حين ذهب الأستاذ الدكتور / عبد العزيز مخيمر في تعريفه أن الإرهاب الدولي لا يختلف عن الإرهاب الداخلي من حيث طبيعته الذاتية فكلاهما عبارة عن استخدام وسائل (1) انظر : د. رفعت ،أحمد محمد ، الإرهاب الدولي في ضوء أحكام القانون الدولي العام والاتفاقيات الدولية

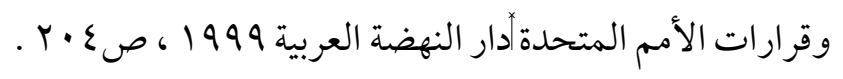

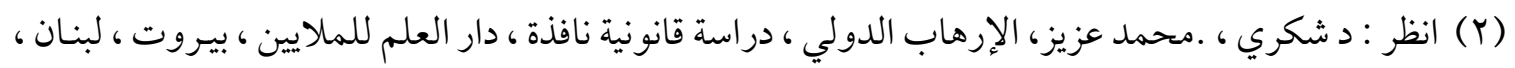
$r \cdot \varepsilon \cdot 199$. 
عنيفة لخلق حالة من الرعب والفزع لدي شخص معين أو مجموعة معنية من الأشخاص أو حتي لدي المجتمع بأسره بغيه تحقيق أهداف معينة أو مؤجلة . (1) ونحن نري في تعريف الإرهاب الدولي بأنه كل فعل سواء كان باستخدام العنف والقوة أو بالتهديد والتحريض باستخدام العنف أو القوة أ أي فعل بالتحريض عن طريقة استخدام وسائل التواصل اجتماعي علي استخدام العنف والتحريض عليه أو ترويج الإشاعات لتهجيج المشاعر أو استخدام الوسائل الإعلامية المسموعة والمقروءة والمرئية للتحريض العنف وتهيج المشاعر سواء كانت هذه الأفعال صادرة من فرد أو جماعة أو دولة ضد فرد أو جماعة أو دولة أو ممتلكات عامة أو خاصة وذلك من أجل تحقيق أغراض سياسية أو أيدلو جية أو دينية أو اجتماعية .

\section{المطلب الثاني تعريف الإرهاب الدولي في الاتفاقيات الدولية}

قامت الحكومات المختلفة أو المنظمات الدولية المعنية بإبرام اتفاقيات دولية ذات طابع عالمي وإقليمي لإيجاد حل لمنع وقمع الإرهاب الدولي وقد تناولت هذه الاتفاقيات تعريف للإرهاب الدولي،نعرفها بعضها . أولاً : تعريف اتفاقية جنيف

هذه الاتفاقية تعتبر أول عمل قانوني يهدف إلي الحد من خطر العمليات الإرهابية عن طريق التعاون الدولي والاتفاق بين الدول لمنع الجريمة ومعاقبة مرتكبيها ـ ومع هذا لم

(1) انظر : د. عبد الهادي ، عبد العزيز مخيمر، الإرهاب الدولي مع دراسة للاتفاقيات الدولية والقرارات الصادرة

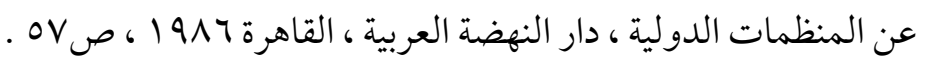
(r) انظر : لـواء دكتور / بو ادي ، حسـين المحمـدي ، الإرهـاب الدولي تجريمـا ومكافحـة ، دار المطبوعـات

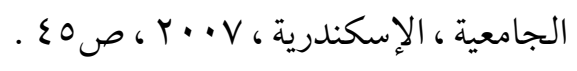


تتناول الاتفاقية إلا شكلاً وحيداً من الإرهاب وهو الإرهاب الثوري والاعتداءات الموجهة ضد حائزي السلطة في الدولة ورغم قصور الاتفاقية إلا أنها تعبر عن إيمان واضعيها بالتعاون الدولي لمكافحته ووضع الأعمال الإرهابية بما يحقق سيادة كل الدول واحترام الأنظمة الدستورية السائدة بها وقد عرفت المادة الأولي من الاتفاقية في فقرتها الثانية أعمال الإرهاب تعني الأعمال الإجرامية الموجهة ضد دولة وتهدف أو تخطط إلي إحداث حالة من الرعب في أخطار أشخاص معيين أو مجوعة من الناس أو لدي العامة. ثانيًا : الاتفاقية الأوربية لقمع الإرهاب عام $19 V V$ :

طالبت الدول الأوربية بضرورة تشديد العقاب علي الإرهابية ورفضت اعتبار فكرة الإرهاب من الجرائم السياسية التي يحظر فيها التسليم،وتم الاتفاق علي وضع اتفاقية جديدة لمكافحة الإرهاب تمت الموافقة عليها في نوفمبر 9V7 (،ووقعت عليها الدول الأوربية في يناير 19VV ـ (19V ودخلت حيز التنفيذ في أغسطس 19V1 ـ ولم تضع هذه الاتفاقية تعريفًا للإرهاب أو الجريمة الإرهابية بل أوضحت مفهوم الإرهاب بطريقة حصرية حيث سردت الأفعال التي تعد أفعالاً إرهابية حيث جاءت المادة الأولي من الاتفاقية بحصر الأفعال التي تعد جرائم إرهابية وهي : 1 - الجرائم التي نصت عليها اتفاقية لاهاي عام 9 1 ـ،و الخاصة بقمع الاستيلاء غير

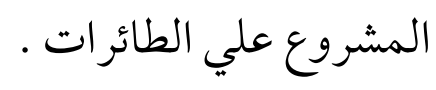

r - الجرائم المنصوص عليها في اتفاقية مونتريال لعام |9V| إل والخاصة بقمع الأفعال غير المشروعة والمو جهة ضد سلامة وأمن الطيران المدني .

(1) انظر : د. حمودة ، متتصر سعيد ، الإرهاب ، جوانبه القانونية ، وسائل مكافحته في القانون الدولي العام والفقـه

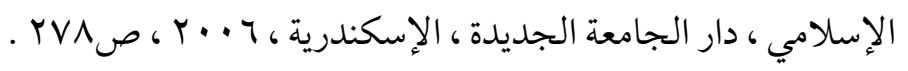


ب- الجرائم الخطيرة التي تشكل اعتداء علي الحياة أو السلامة الجسدية أو حرية المتمتعين بالحماية الدولية بما في ذلك المبعوثين الدبلو ماسيين · ع - الجرائم التي تتضمن الخطف وأخذ الرهائن أو الاحتجاز التعسفي . - - جرائم استعمال المفرقعات والقنابل والأسلحة النارية الآلية والمتفجرات والرسائل الخداعية المتفجرة إذا كان شأن هذا الاستعمال تعريض الأشخاص للخطر . وقد أجازت المادة الثانية من الاتفاقية للدول المتعاقدة سلطات واسعة في التسليم في الجرائم التي لا تعتبر سياسية وذلك في حالتين هما :

الأولي : ارتكاب أي فعل من أفعال العنف الخطيرة ضد الأشخاص أو سلامتهم

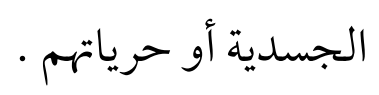

الثانية : ارتكاب أي عمل عنيف ضد الممتلكات إذا كان من شأن ذلك خلق حظر

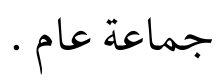

ثالثًا : الاتفاقية العربية لمكافحة الإرهاب لعام 1991 :

صدرت هذه الاتفاقية في القاهرة 9911،عن مجلس وزراء العدل والداخلية العرب،وراعت مبادئ الشريعة الإسلامية والقانون الدولي وميثاق جامعة الدول العربية

$$
\text { وميثاق الأمم المتحدة وهي مكونة من بع مادة . }
$$

وأكدت علي حق الشعوب في الكفاح المسلح ضد الاحتلال الأجنبي من أجل تحرير الأرض وفقـا لمبادئ وقرارات الأمم المتحدة وجاءت مادتها الأولي بتعريف الدول المتعاقدة بأنها كل دولة عضو في جامعة الدول العربية صدقت علي هذه الاتفاقية وأودعت وثائق (1) تصديقها لدي الأمانة العامة للجامعة لئن

(1) انظر د. حمودة ، متتصر سعد، الإرهاب الدولي، جو انبه القانونية ، وسائل مكافحته في القانون الدولي والفقه 
وقد عرفت الاتفاقية الإرهاب تعريفَّ وصفيًا بأنه كل فعل من أفعال العنف أو التهديد

به أيا كانت بو اعثه أو أغراضه يقع تنفيذاً أو تروعيهم بإيذائهم أو تعريض حياتهم أو حريتهم

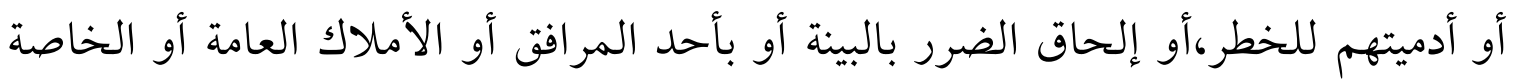

أو احتلالها أو الاستيلاء عليها أو تعريض أحد المو ارد الوطنية للخطر . (1)

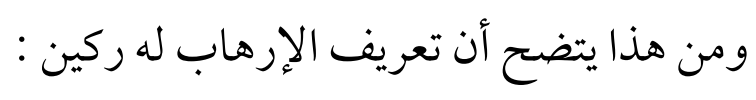

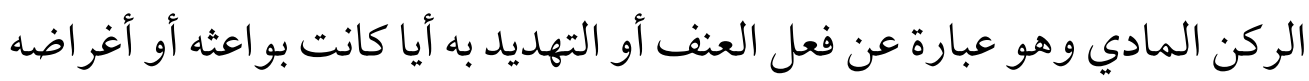

الركن المعنوي : وهو قيام الجاني بإلقاء الرعب بين الناس وترويعهم.

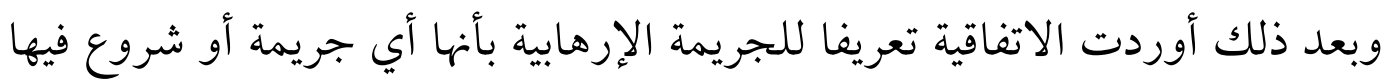
ترتكب تنفيذاً لغرض إرهابي في أي من الدول المتعاقدة سواء علي رعاياها أو ممتلكاتها

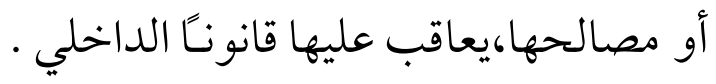

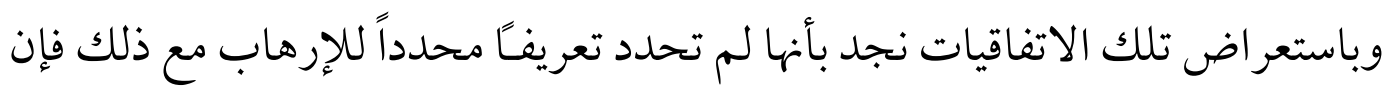
لتلك الاتفاقيات دور رئيس في المساهمة بشكل كبير في تحديد تعريف للجر ائم الإرهابية .

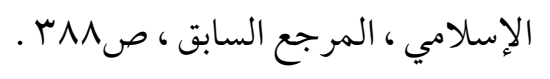

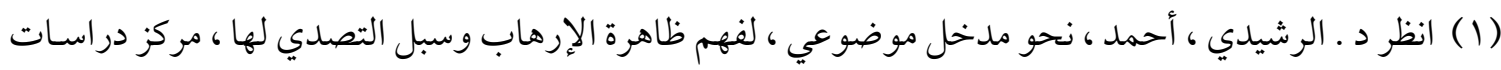

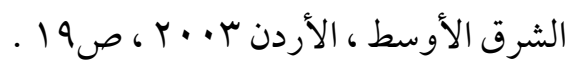




\section{المطلب الثالث \\ تعريف الإرهاب في الغقه الإسلامي}

الشريعة الإسلامية صالحة لكل زمان ومكان ، و الدليل على ذلك وجود أحكامها

عملاً وتطبيقًا لدى قوانين دول لا تعتنق الإسلام ، لذلك فإن كافة الاختلافات الفقهية في كافة القضايا الخلافية دائمكا تجد لها حلاً مناسباً في الفقه الإسلامي - ولذلك فإن تعريف الإرهاب ( الحرابة ) له مفهوم ثابت ومستقر في الفقه الإسلامي ، حيث أنها مجرمة ومعاقب

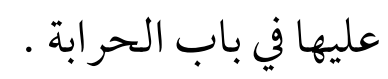

وعلى ذلك سوف نقسم هذا المطلب إلى أربع فروع : الفرع الأول : تعريف الحرابة في الفقه الإسلامي . الفرع الثاني : تعريف الحرابة في اللغة . الفرع الثالث : تعريف الحر ابة في الاصطلاح · الفرع الرابع : جريمة الحرابة في الكتاب والسنة . الفرع الأول

تعريف الحرابة في الفقه الإسلامي

الحرابة هي محظورات شرعية زجر الله عنها بحد ، تعزيزاً أي أنها أفعال محرمة يأتيها الفاعل فيعد مجرمـا وان كان العرف لدى فقهاء المسلمين استقر على أنها هي الذنب بصفة عامة ، والجناية هي الذنب الذي يوجب القصاص أو العقاب( ' ) إلا أن المتفق بين الفقهاء بعيداً عن هذا التعريف أن الجريمة ( هي إتيان فعل محرم معاقب علي فعله أو ترك فعل معاقب على تركه ، أو نصت الشريعة على تحريمه أو العقاب عليه ) .

(1) انظر : د مصطفى الر افعي ، أحكام الجر ائم في الإسلام ، الحدود والقصاص والتعزيز ، الدار الإفريقية العربية ،

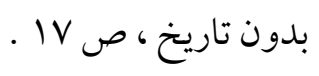


ويقسم الإسلام الجرائم إلى جرائم حدود ، وجرائم قصاص ، وجرائم تعزيرية تقع على أحاد الناس والنوع الأول هو الجرائم التي تمس الدولة الإسلامية في أمنها واستقرارها ونظامها وهى جرائم الحدود الست ـ الردة ، والزنا ، شرب الخمر ، السرقة ،

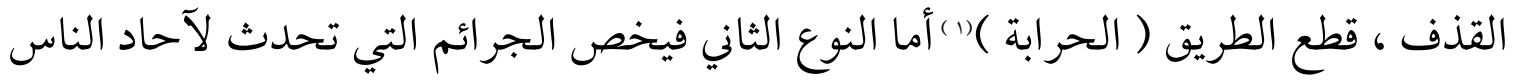

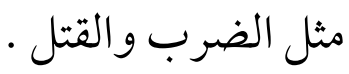

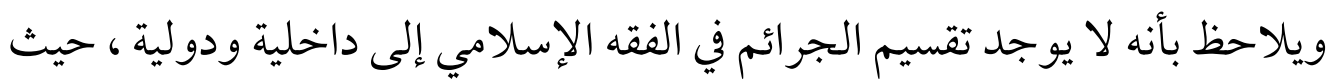
لا يو جد هذا التقسيم في الإسلام لان الأصل أن الإسلام عام لكافة البشر في كل زمان ومكان والأصل أن تكون الأرض دار واحدة هي دار الإسلام ، وترتيبًا على ذلك فان كافة الجرائم التي تقع من المفترض أنها جرائم داخلية .

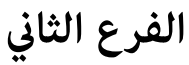 \\ تعريف الحرابة في اللغة}

الحرابة في اللغة من الحرب ، والتي هي نقيض السلم ، وأنا حربُ لمن حارَبني ، أي

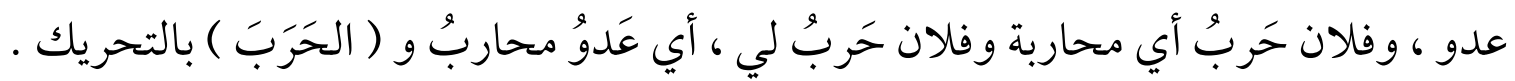

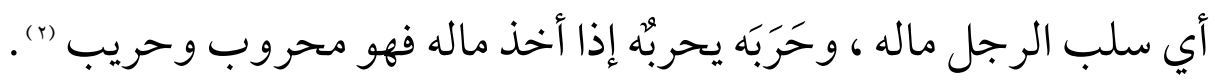

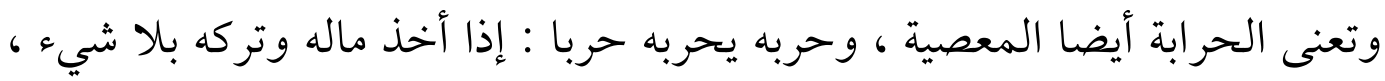

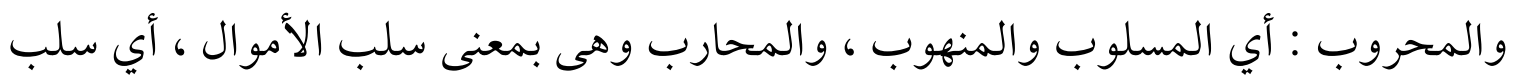

(1) انظر : الإمام محمد أبو زهرة ، الجريمة والعقوبة في الفقه الإسلامي ، الجريمة ، بدون تاريخ ، ص •ع ا - 
الشخص جميع ما يملك "( ). وتأتى المحاربة أيضا بمعنى القتل عندما تقترن بالسلب ، وهو ما يدل على الغصب بمعناه العام ()). فالمعنى اللغوي للحرابة إذاً هو الاعتداء و السلب وإشاعة الخوف محل الأمن ، فهي ليست مرادفة للقتل والمقاتلة ، وإنما الأصل فيها الاعتداء

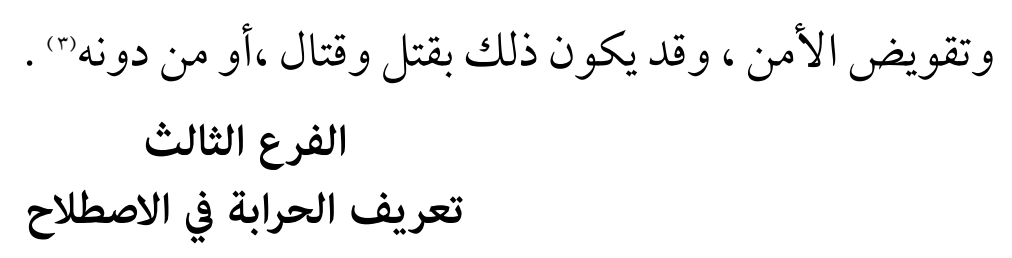

عُرفت الحرابة في المذاهب الفقهية بتعريفات مختلفة ، إلا أنها تتفق جميعها في جوهرها ، فاتفقوا على أن المحاربين هم الخارجون لإخافة المارة من الناس ، وقتل النفوس و أخذ الأموال ، وأي هدف أخر من هؤلاء يكفى لاعتبارهم محاربين ، ما داموا قد خرجوا

$$
\text { لذلك ، ولكنهم اختلفو ا حول الشروط اللازمة لتحقق الحرابة . }
$$

والفقهاء الأحناف يطلقون على الحرابة لفظ ( قطع الطريق ) كما يطلق عليها

$$
\text { البعض منهم لفظ السرقة الكبرى() . (1) }
$$

وعُرفت لديهم بأنها ( قطع الطريق هو الخروج على المارة لأخذ المال على سبيل المغالبة ، على وجه يمنع المارة من الخروج ويقطع سواء كان القطع من جماعة أو من واحد بعد أن يكون له قوة القطع ) . و الكاسانى يرى أيضا بأن الخروج يجب أن يتم عن طريق

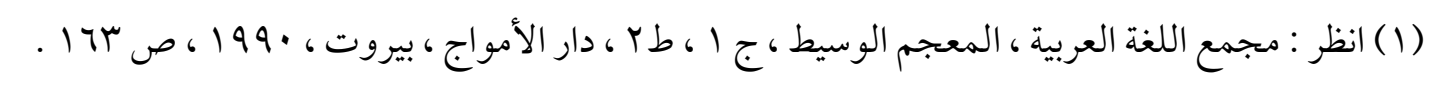

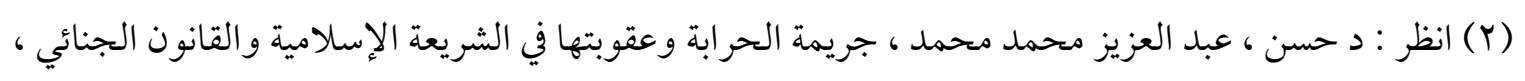

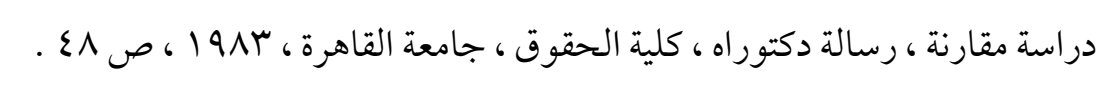

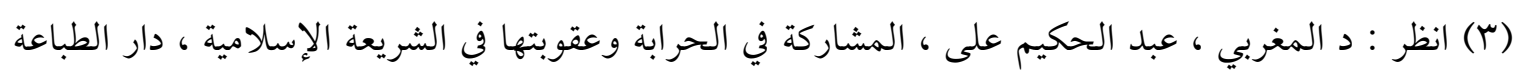

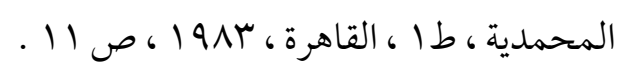

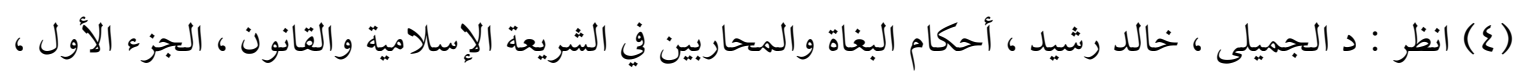

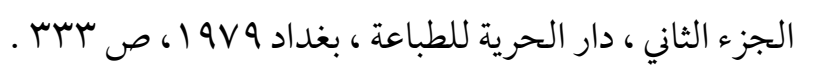


ممكن يكون قادراً عليه ، يقوى على المنعة والمغالبة في قطع الطريق ، وسواء أكان ذلك

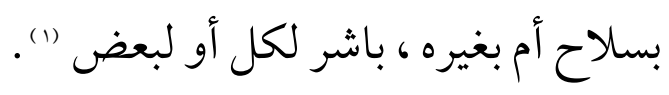
وعُرفت الحرابة عند المالكية بأنها ( قطع الطريق لمنع سلوك المارة ، أو أخذ المال على وجه يتعذر معه الغوث ) (") .و المالكية يتوسعون في تحديد مفهوم الحرابة ، ويعتبرونها

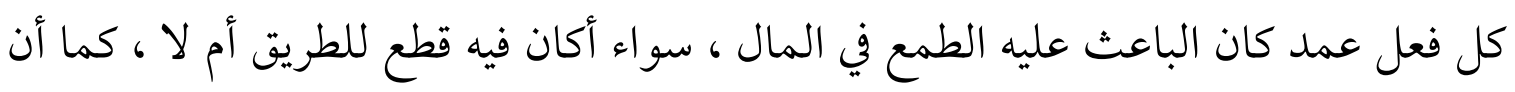
تعريفهم للحرابة يشتمل على تحقها في كل الأماكن ، في الحضر والسفر ، في البر والبحر ، فالأمن والخوف ، وفى القتل غيلة (r). أما عند الشافعية ، فقد عرفت بأنها ( البروز لأخذ مال ، أو لقتل ، أو ارتاب ، مكابرة ، اعتماداً على الشوكة مع البعد عن الغوث )(8) . و الشافعية لا يشترطون أن يكون المحاربون

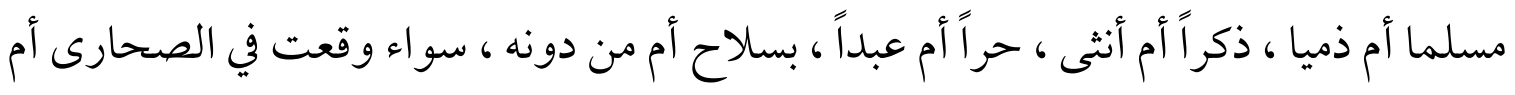

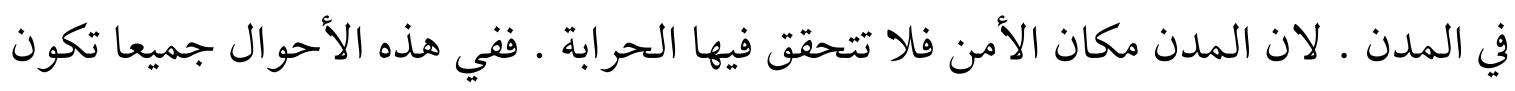
جريمة الحرابة متحققة ، وهم في هذا يتفقون مع المالكية ، وقول أبى يوسف من الحنفية ،

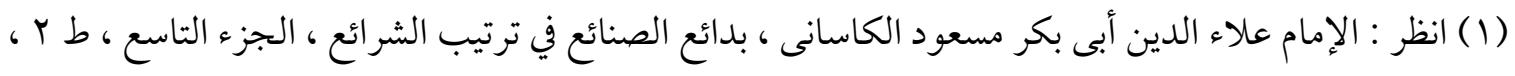

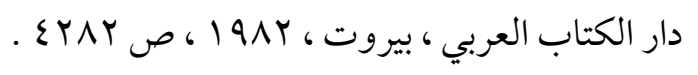

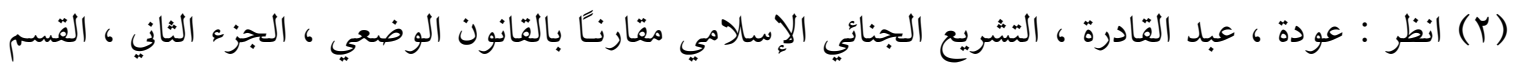

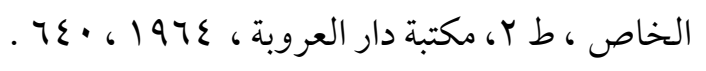

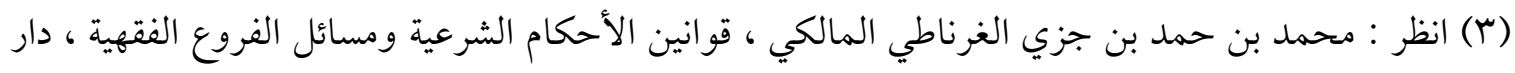

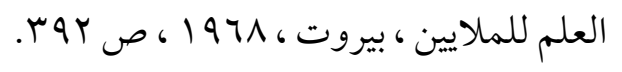

(ع) انظر : شمس الدين محمد بن أبى العباس احمد بن حمزة شهاب الدين الرملي المنوفي المصري الأنصاري

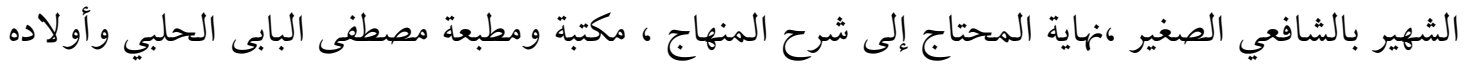

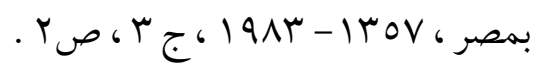




\section{و المشهور عن الحنابلة (1)}

أما عند الحنابلة فقد عرفها بعضهم بأنها ( التعرض للناس في صحراء ، أو بيان ،

أو بحر ، فيغصبونهم أمو الهم قهرا ومجاهرة ، أو يقتلونهم لأموالهم ) (r). أما البعض الآخر ، فقد عرفها بأنها ( خروج الملتزمين المكلفين بالسلاح في الصحراء ، أو البنيان لأخذ أموال الناس مجاهرة ، سواء من الفرد أو من الجماعة ، وبشرط توافر النصاب في السرقة ، سواء أكان في المدن أم في القرى ، في البحر أم في الجو ، وأن يتم ذلك على سبيل المجاهرة ، وأن يكون معهم سلاح ولو عصى ، أو حجارة تقذف بالأيدي ) . وهذا الرأي يتفق مع ما ذهب إليه الأحناف و المالكية و الشافعية (r) ومن جماع ما تقدم يتضح أن جريمة الحرابة في الفقه الإسلامي تتفق مع جريمة الإرهاب في الوقت الحاضر ، ومن عدة أوجه ، وهى بالطبع تحمل صفات الأعمال الإرهابية في غالبيتها ، فمرتكب جريمة الحرابة يقوم باستخدام الأسلحة أيا كان نوعها ، ما دامت تحقق له القوة و المنعة و الشوكة ـ وكذلك الأمر بالنسبة إلى مرتكب الجريمة الإرهابية ، حيث يقوم باستخدام مختلف أنواع الأسلحة التي تعطيه الإمكانية والقوة والقدرة على تحقيق أهدافه ، وأغراضه ، كالمتفجرات ، والمفرقعات ، والأسلحة الخفيفة والثقيلة ، بل وحتى الأسلحة

(1) انظر : احمد ، محمود مطلوب ، د الجميلى ، خالد رشيد ، الفقه الجنائي ، مطبعة جامعة بغداد جامعة بغداد ،

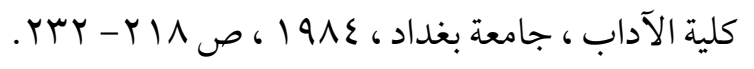

(Y) انظر : شرح الشيخ محمد الخطيب الشربينى على متن منهاج الطالبين للإمام أبى زكريا بن شرف النووي ،

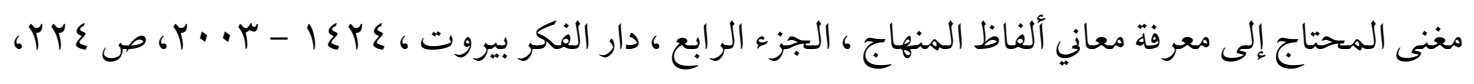

(r) انظر : د حسن ، عبد العزيز محمد محمد ، جريمة الحرابة وعقوبتها في الشريعة الإسلامية والقانون الجنائي ،

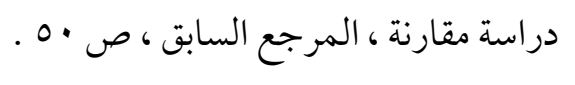


المحرمة دوليا ، كالقنابل النووية والكيمائية ، والتي ثبت امتلاك بعض الجماعات

$$
\text { والعصابات الإرهابية لها . }
$$

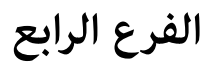

\section{جريمة الحرابة في الكتاب والسنة العرابة}

تعد الشريعة الإسلامية أول تشريع سماوي متكامل ، يصور الجرائم الإرهابية ، ويوصفها توصيفا دقيقا ، من حيث الشروط والأركان ، بما ينسجم مع تعريف الإرهاب وتحديد مفهومه في التشريعات الحديثة ، إذ أن جريمة الحرابة التي وردت في القران الكريم تعد إحدى صور هذا التشريع السماوي ، التي من خلالها يتم تحديد الأغراض الدنيئة ، لمرتكب هذه الجريمة البشعة ، و المضاعفات الخطيرة لها ، وانعكاساتها على بقية أفراد المجتمع ، لما تتضمنه من ترويع الناس الآمنين ، واعتداء على أمو الهم وأعر اضهم ، فضلا عن الخروج على سلطان الدولة (1) . فالإسلام قد جعل الحرابة من الكبائر ، باعتبارها من جرائم الحدود ، ورصد لها أشد العقوبات ، لما فيها من قطع للطريق ، وقتل للناس ، وترويعهم ، وإرهابهم ، وإشاعة الفوضى والاضطراب و الرعب بينهم ، وفى نفوسهم ، فضلا عما تشتمل عليه من عدم إطاعة وعصيان لسلطان الدولة ـ فقد ذكرت المحاربة في موضعين من القران الكريم ، الموضع الأول كان في سورة المائدة ، حيث وضع الحكم الشرعي تجريما وعقابا بحق مرتكب هذه الجريمة ، أما الموضع الثاني ، فكان في سورة التوبة ، كإشارة لقوم يحاربون الله ورسوله ،

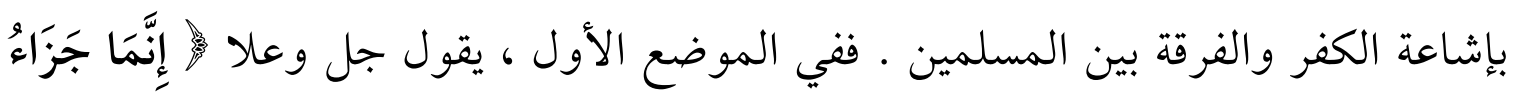

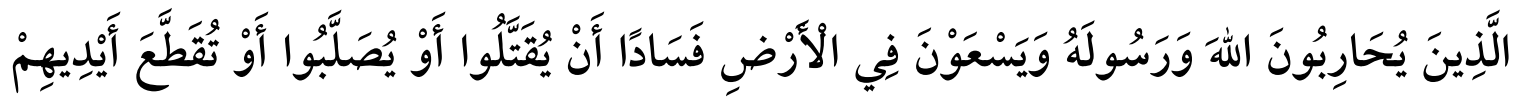




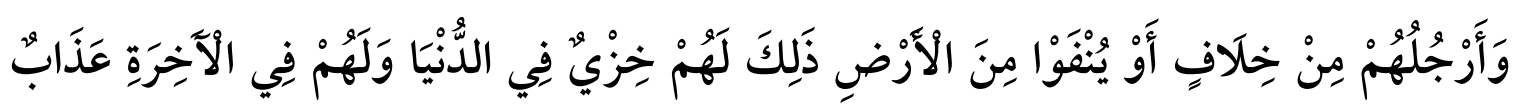

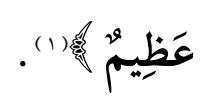

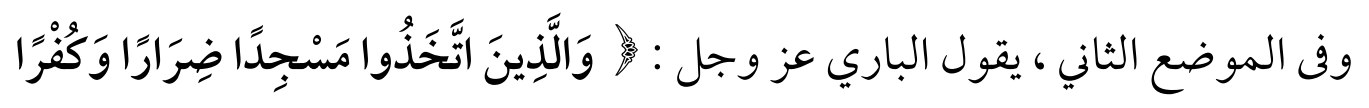

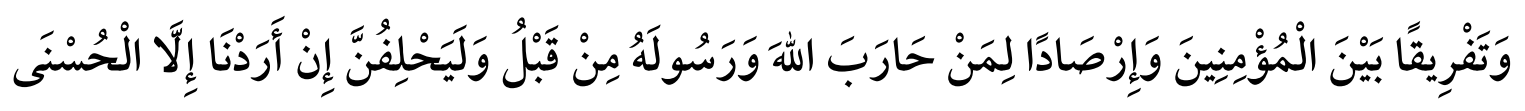

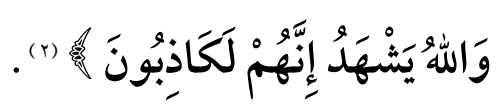

أما في السنة النبوية المطهرة ، فقد روى عن أبى هريرة رضي الله عنه أن رسول الله صلى الله عليه وسلم قال : " من خرج من الطاعة ، وفارق الجماعة ، فمات ، مات ميتة جاهلية ... ومن قاتل تحت راية عميه ، يغضب لعصبية ، أو ينصر عصبية فقتل ، فقتلته جاهلية ، ومن خرج على أمتي ، يضرب برها وفاجرها ، ولا يتحاشى مؤمنا ، ولا يفي بعهد ذي عهد ، فليس منى ولست منه" (r) . ع

فالمحارب الذي يخرج ويقطع الطريق على الناس ، ويسلب أموالهم ، ويقوم

بقتلهم إذا اقتضى الأمر ، وأحيانا يمثل بجثثهم ، لا شك في أنه قد خرج على طاعة ولى الأمر ، وقد فارق ائتلاف الجماعة التي تربطه بهم رابطة الإسلام إذا كان مسلما ، أو عقد الأمان إذا كان ذميا أو مستأمنا ، ومن ثم فان خروجه عن هاتين الرابطين . طاعة ولى الأمر وائتلاف الجماعة وإخلاله لأحكامها ، يكون مستحقا في هذه الحالة لوصف المحارب ، ومن ثم تطبيق

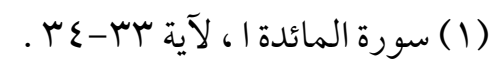

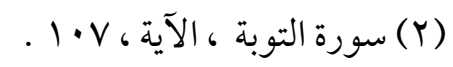

(r) انظر : سنن النسائي بشرح الحافظ جلال الدين السيوطي وحاشية الإمام السندى ، الجزء السابع ، دار البشائر

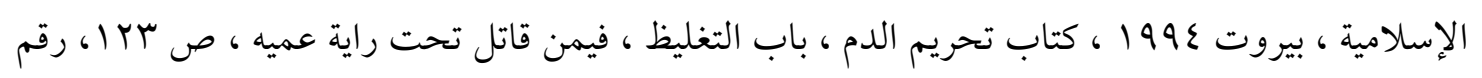

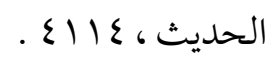


أحكام الحرابة بحقه (1)، لذلك فان الرسول سيدنا محمد صلى الله عليه وسلم روى عنه أنه قال : " أنه ستكون هنات وهنات ، فمن أراد أن يفرق أمر هذه الأمة وهى جميع ، فاضربوه بالسيف كائنا من كان " (")وما رواه ابن عمر رضي الله عنهما أن رسول الله سلم الله عليه وسلم قال( من حمل علينا السلاح فليس منا )(").

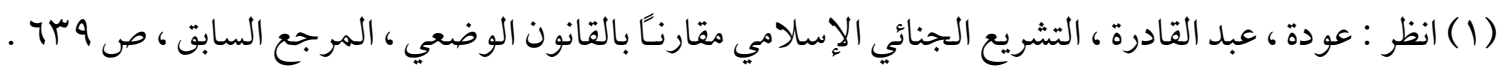

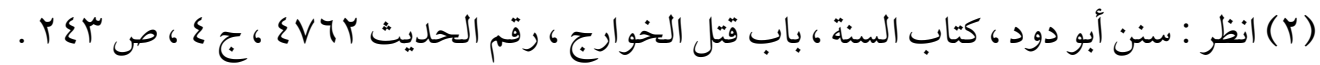

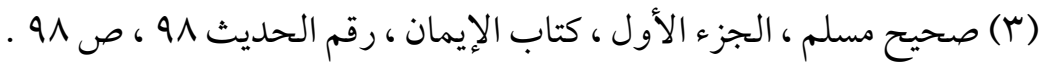




\section{المبحثب الثناني \\ ثميز الإرهاب الدولي عن المقاومهة الثعبية في القانون الدولي والفقه الإسلامي}

إذا كان الإرهاب الدولي يعتمد علي استخدام القوة فإن قد يختلط بأنواع أخري من

$$
\text { الأفعال التي تستخدم فيها القوة ولكنها مشروعة . }
$$

فهناك المقاومة الشعبية المسلحة والتي تستخدم فيها القوة ولكنها مشروعة وذلك

لنيل الشعوب المستعمرة حقها في تقرير مصيرها ـ وهناك الدفاع الشرعي الذي يستخدم فيه

$$
\text { القوة ولكنها مشروعة ومباحة لرد الاعتداء. }
$$

وشرعه الإسلام في هذا الصدد بنص القرآن حيث قال تعالى في محكم كتابه

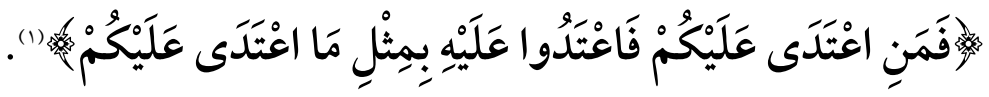

$$
\begin{aligned}
& \text { وعلى ذلك سوف نقسم هذا المبحث إلى مطلبين : }
\end{aligned}
$$

المطلب الأول : تميز الإرهاب الدولي عن المقاومة الشعبية المسلحة في القانون

المطلب الثاني : تميز الإرهاب الدولي عن المقاومة الشعبية المسلحة في الفقه الإسلامي .

\section{المطلب الأول تميز الإرهاب الدولي عن المقاومة الشعبية المسلحة في الثرلي القانون الدولي}

يختلط الأمر كثيراً بين الإرهاب الدولي والمقاومة الشعبية المسلحة من أجل تقرير المصير ويرجع ذلك إلي المصالح الدولية بين الدول ـ حيث تري بعض الدول في أن المقاومة 
الشعبية عملاً إرهابيًا وتري بعض الدول الأخرى أنه عملاً مشروعَّ يجب تأييده ومساندته .

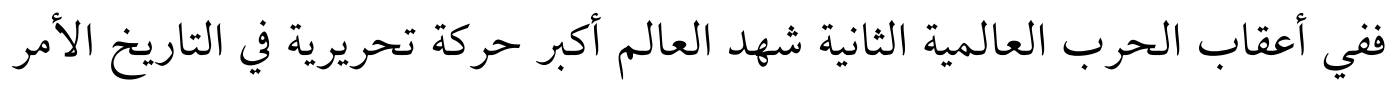
الذي أوجد علي الساحة الدولية مجموعة من الدول المستقلة حديثـأستطاعت أن تلعب

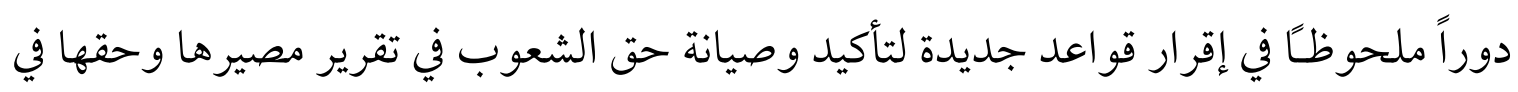
التحرر والحياة الكريمة وساعدها في ذلك ما تمتعت به من أغلبية عددية في المجالس والهيئات الدولية وتوجهت جهودها بإعلان منح الاستقلال للبلاد والشعوب المستعمرة الذي صدر عن الجمعية العامة في دورتها الخامسة عشر في ع أ كانون أول ديسمبر 197 ــ ومنذ هذا التاريخ أضحت المقاومة الشعبية المسلحة تأخذ مفهومَّ واسعًَ بحيث أصبح النضال

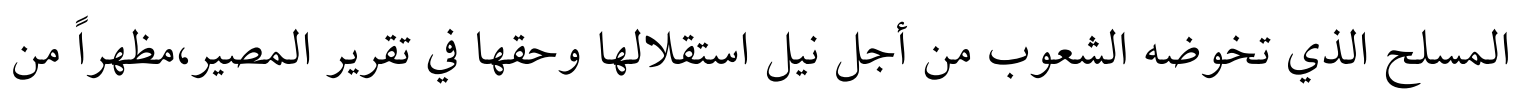
مظاهر المقاومة الشعبية المسلحة بمداها الواسع · (1) وقد عرفت المقاومة الشعبية المسلحة بأنها عمليات القتال التي تقوم بها عناصر وطنية

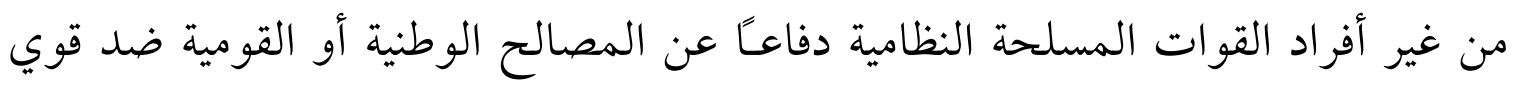
أجنبية سواء كانت تلك العناصر تعمل في إطار تنظيم يخضع لإشراف وتوجيه سلطة قانونية

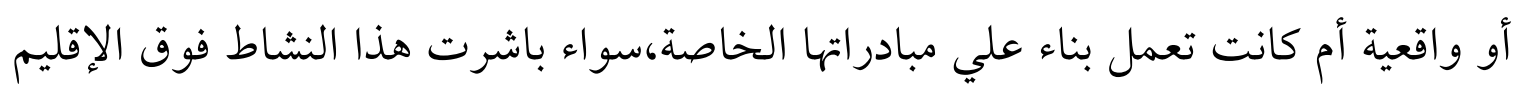

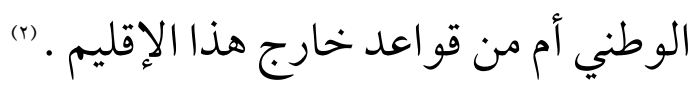

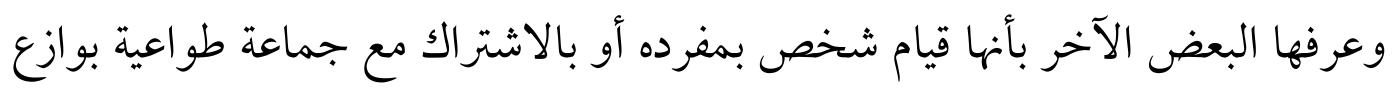

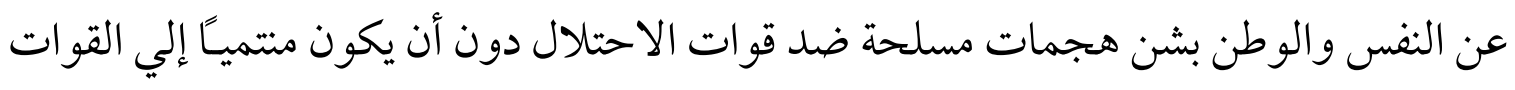

(1) انظر : د. راتـب ، عائشـة ، مشـروعية المقاومـة الشَعبية المسـلحة ، دراسـات في القـانون الـدولي ، المجلـة

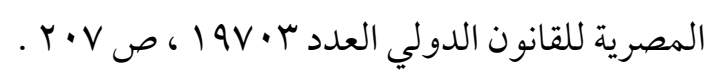

(Y) انظر : د. عامر، صلاح الدين، المقاومة الشعبية المسلحة في القانون الدولي العلم المرجع السابق، ص اع ـ. 
(1) المسلحة النظامية

وتسند المقاومة الشعبية المسلحة إلي حق تقرير المصير وهذا الأخير استمد شرعيته

$$
\text { من قرارات الأمم المتحدة . (r) من }
$$

ومن هذه القرارات قرار الجمعية العامة للأمم المتحدة رقم (ع اسب) الصادر عام

سو9 ا بشأن تعريف العدوان،فقد أشارت الفقرة السابقة من هذا القرار إلي أن ليس في هذا التعريف ولا سيما الفقرة الثالثة ما يمكن بأي وجه أن يمس ما هو مستقر في الميثاق من حق تقرير المعير والحرية والاستقلال للشعوب المحرومة من هذا الحق بالقوة والمشار إليها في إعلان مبادئ القانون الدولي المتصلة بالعلاقات الودية والتعاون بين الدول وفقا لميثاق الأمم المتحدة و لا سيما للشعوب الخاضعة لنظم استعمارية أو عنصرية أو الأشكال أخري من السيطرة الأجنية أو أن يمس حق هذه الشعوب في الكفاح من أجل هذا الهدف وفي طلب الدعم وتلقيه وفقا لمبادى الميثاق . إن)

(1) د. فـوده ، عـز الـدين، شـرعية المقاومـة المختلفـة ، در اسـات في القـانون الــولي ، المجلـة المصـرية للقـانون

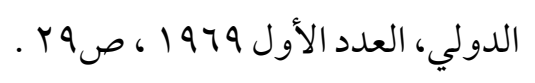

(Y) حق تقرير المصير هو حق كل شعب في تحديد مستقبلة السياسي ونظام الحكم الذي يوفقه وحق الشعب في

السيادة علي ثرواته وموارده الطبيعية وحقه في اختيار الأنظمة الاقتصادية والاجتماعية الملائمة .

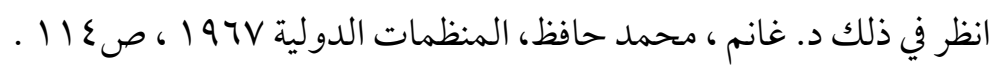

لذلك لا نجد وثيقة دولية تصدر عن الأمـم المتحدة تعني تنظيم جو انـب العلاقات الدولية ، وميثاق الحقـوق و الو اجبات الاقتصادية للدول وقرار تعريف العدوان وغير ذلك من الوثائق العديـدة انظر في ذلك د. العنـني ، إبر اهيم ، الأمـم المتحـدة ، دراسـة في ضـوء النظام القـانوني للمنظمـات الدولية وأهـم المشكلات العملية التي

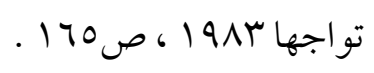

(r) انظر د. العربي ، نبيل عبد الله ، الآثار القانونية لقرارات الجمعية العامـة ، المجلة المصرية للقـانون الدولي ،

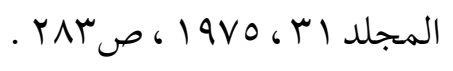


وبعد استعر اض ماهية المقاومة الشعبية المسلحة،واعتبارها عملاً مشروعَّا إستادا إلي قرارات الأمم المتحدة وأنها مبناها هو حق تقرير المصير من أجل نيل الشعوب المستعمرة

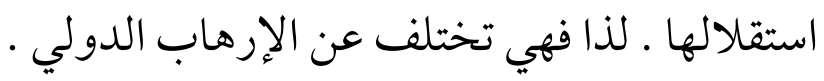
1 - تتميز أهداف المقاومة الشعبية الذي تمارسه حركات التحرير الوطني بأنها ذات صبغة عالمية،ويظهر جليًا في مساندة المنظمات الدولية لها والاعتراف بها،وإعطائها بعض الحقوق الدولية أهمها شرعية أعمالها وكفاحها المسلح طبقًا لأحكام ومبادئ القانون الدولي والحق في طلب وتلقي المساعدات الدولية من كافة الأشخاص الدولية وحقها في التمثيل الدبلوماسي"(1)،ما أهداف جرائم الإرهاب الدولي فإنها أيضا تتميز بالعالمية ولكنها عالمية في الاستنكار والمقاومة والردع لمثل هذه الأفعال التي تتسم بالوحشية وأنها جرائم

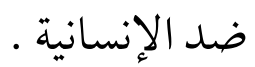

r - العنف المستخدم في المقاومة الشعبية للحصول علي حق تقرير المصير له أساس قانوني مستمد من قواعد القانون الدولي وهو حق الشعب في استعادة إليه المستعمر الذي يستند لحقوق الشعوب في تقرير مصيرها دونما تدخل أجنبي،وهذا من أهم المبادئ التي يقوم عليها ميثاق الأمم المتحدة . (1) أما العنف المستخدم في جر ائم الإرهاب فلا يتسم بالشرعية بل إنه يعد جريمة دولية

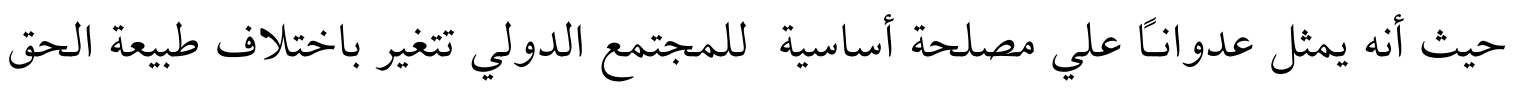

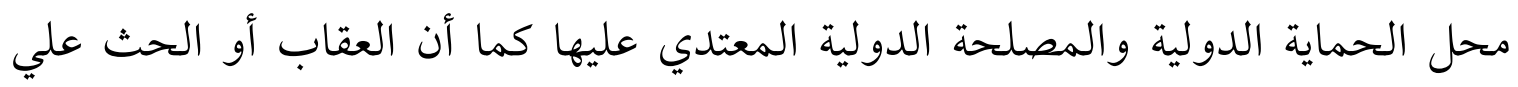

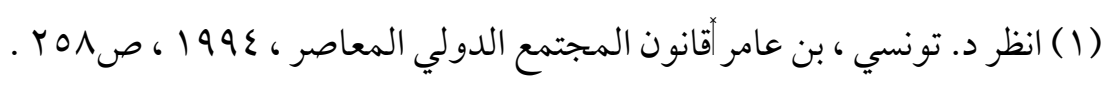

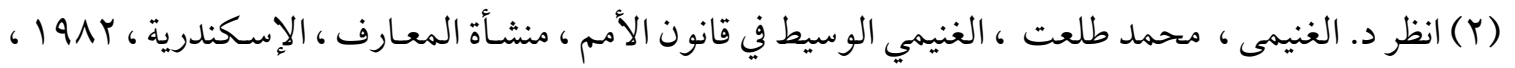

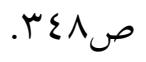




$$
\text { العقاب مقرر بمقتضي قو اعد القانون الدولي الجنائي · }
$$

وهكذا يختلف الإرهاب الدولي الذي يهدد أمن واستقرار الدول عن المقاومة

الشعبية المسلحة المشروعة دوليا من أجل نيل الشعوب المستقرة استقلالها وحرياتها .

\section{المطلب الثاني \\ تميز الإرهاب الدولي عن المقاومة الشعبية المسلحة في الغقه الفيقا الإسلامني}

إن حق تقرير المصير بمفهومه الحديث وسياقه التاريخي بأن شعوبًا استضعفت إلتلميل واستعمرت من قبل الدول الاستعمارية فإن النضال حق مشروع لهذه الشعوب المستضعفة وهو فرض عين على كل مسلم في هذه الديار بل وعلى الشعوب الإسلامية العمل على نصرتها وانتمائها وهذا ضمن مفهوم رد الاعتداء الذاتي أورد الاعتداء عن الغير كما هو في تئي الشريعة الإسلامية.

فالإسلام حينما انتشر وقام كدين ودولة تناول القرآن الكريم القواعد الكلية والأسس

الثابتة التي يقوم عليها كيان الدولة ولم يتعرض للتفصيلات سواء كان ذلك على الصعيد الداخلي أو الصعيد الخارجي.

فالدولة الإسلامية دولة عقائدية رابطتها واحدة هي الإسلام ويمكن أن يدخل فيها

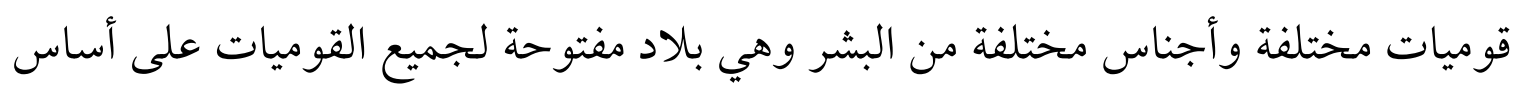
الانضواء تحت لو ائها فهي عالمية في إطارها ويمكن أن تنطلق من قومية واحدة ولكن على على أساس الرابطة العقائدية بل هي اتحاد لعدة قوميات ويتألف أفراد هذه القوميات باعتبارهم مسلمين وما يربطهم رابطة الانتماء للإسلام" (1). ونرى أن مبادئ القانون الدولي العام تتفق مع مبادئ الشريعة الإسلامية في حق الشعوب من التحرر من الاستعمار ، والحق له في تقرير مصيرها .

(1) انظر: : محمد المبارك، نظام الحكم، الحكم والدولة، الطبعة الرابعة، دار الفكر 19191 (1) صه. 


\section{المبحث الثالث}

تميز الإرهاب الدولي عن الدفاع الشرعي في القانون الدولي والفقه الإسلامي

الدفاع الشرعي هو القيام بتصرف مشروع دوليًا للرد على تصرف غير مشروع وقع ابتداء وفي كلتا الحالتين -الفعل ورد الفعل - يتم باستخدام القوة المسلحة. ويستهدف الدفاع الشرعي دفع الخطر الجسيم من قبل المعتدي والعمل على إيقافه لحماية أمن الدولة

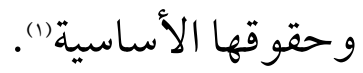

ومن ثم فقد نظر إلى هذا الحق باعتباره صورة لأخذ الحق بذات اليد. واستمر ذلك

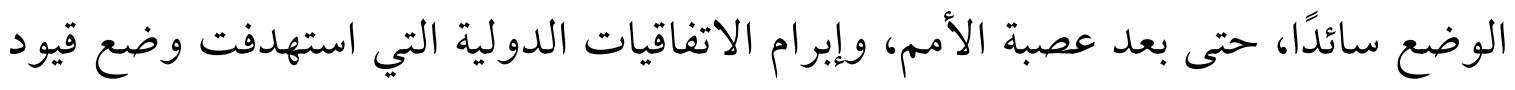

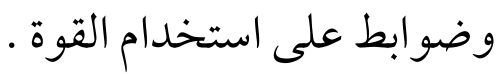
وعلى ذلك سوف نقسم هذا المبحث إلى مطلبين : المطلب الأول : تميز الإرهاب الدولي عن الدفاع الشرعي في القانون الدولي . المطلب الثاني : تميز الإرهاب الدولي عن الدفاع الشرعي في الفقه الإسلامي . لمدري

\section{المطلب الأول \\ تميز الإرهاب الدولي عن الدفاع الشرعي في القانون الدولي}

فكرة الدفاع الشرعي ارتبطت لدرجة التلازم مع مبدأ حظر استخدام القوة في العلاقات

الدولية وتطورت،مع ملاحظة أن هذا التلازم لا يعني انتفاء لفكرة الدفاع الشرعي في القانون

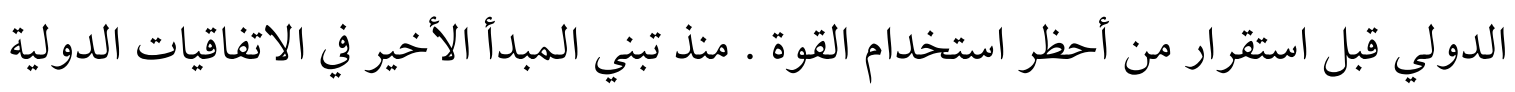

(1) انظر : د. سعيد سـالم جـويلي، استخدام القوة المسلحة في القانون الدولي وقت السلم، المجلة القانونية

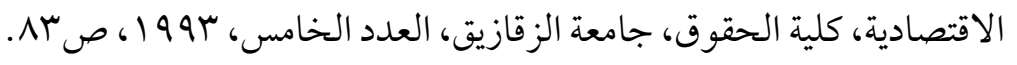


أثثير التساؤل بشأن ما إذا كان للدولة الحق في الدفاع عن نفسها باستخدام القوة إذا ما تعرضت لعدوان من قبل دولة أخري ـ وهذا ما تم الاعتراف به في ظل عصبة الأمم وميثاق بريان كيلوج

$$
\text { (1) رغم عدم وجود نص صريح }
$$

وجاء ميثاق الأمم المتحدة ليضع قاعدة عامة بحظر استخدام القوة أو التهديد بها

$$
\text { في العلاقات الدولية إلا في حالة الدفاع الشرعي · }
$$

حيث نصت المادة اه من ميثاق الأمم المتحدة علي أنه ليس في هذا الميثاق ما يضعف أو ينتقص الحق الطبيعي للدول فرادي أو جماعات في الدفاع عن أنفسهم إذا اعتدت قوة مسلحة علي أحد أعضاء الأمم المتحدة وذلك إلي أن يتخذ مجلس الأمن التدابير اللازمة لحفظ السلم والأمن الدولي والتدابير التي يتخذها الأعضاء استعمالا لحق الدفاع الشرعي عن النفس تبلغ إلي مجلس الأمن فوراً ولا تؤثر تلك التدابير بأي حال في ما للمجلس بمقتضي سلطاته ومسؤولياته المستمدة من أحكام الميثاق من الحق في أن يتخذ في أي وقت ما يري ضرورة لاتخاذه من الأعمال لحفظ السلم والأمن الدولي أو إعادته إلي نصابه. يتضح من هذا النص يجوز لأي دولة اللجوء إلي استخدام القوة لرد العدوان الواقع عليها دون حاجة إلي تفويض مجلس الأمن · ولتو افر حالة الدفاع الشرعي لابد من تو افر شروط في العدوان وشروطا في الدفاع .

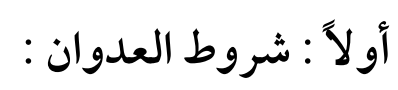
فلابد أن تكون الأعمال المرتكبة لكي يكون هناك عدوان أن تكون تلك الأعمال باستخدام القوة المسلحة ضد الدولة مثل قيام القوات البرية بغزو إقليم دولة مجاورة أو قيام

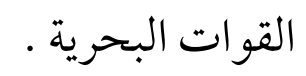

(1) انظر د. العناني، إبر اهيم ، المنظمات الدولية ، المطبعة الحديثة ، 199V ، القاهرة ، صع ع . 
بحصار مواني دولة أخري أو قيام القوات الجوية بعلميات قصف ضد المنشآت المدنية أو العسكرية فوق إقليم دولة مجاورة ويدخل في ذلك تدريب العصابات المسلحة وإمدادها بالمؤن والمساعدة عبر حدود دولة مجاورة لإثارة الفتن والاضطرابات أو لقلب نظام الحكم فيها أو غير ذلك فكل هذه الفروض تشكل عدوانًا مسلحكَ يبيح حق الدفاع (1). الشرعي للدولة التي تكون ضحية لذلكل

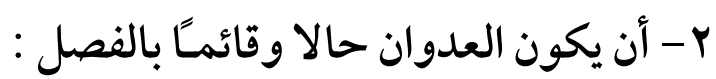
يشترط في العدوان المسلح الذي يبيح اللجوء لحق الدفاع الشرعي،أن يكون حالاً،أي أن العدوان بدأ أو لم ينته،فالمادة إن من الميثاق لم تستخدم تعبير عدوان ولكن استخدم تعبير الهجوم المسلح،وهذا يعني أن الهجوم الوشيك الوقوع أو أي فعل عدواني أخر ليس له صفة الهجوم المسلح لا يبرر اللجوء للقوة .) (")

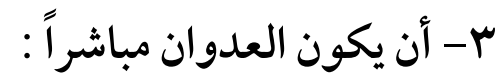

وذلك بأن تقوم الدولة المعتدية بعدوانها بصفة مباشرة مستخدمة في ذلك قواتها المسلحة،ويقصد بالعدوان المباشر في هذا الصدد استعمال الدولة لقواتها المسلحة بطريقة غير مشروعة ضد دولة أخري.

\section{ع - أن يكون فعل العدوان علي قدر من الجسامة والخطورة :}

لابد أن يمثل فصل الاعتداء خطر جسيم،فالخطر البسيط يكفي لرده الطرق الودية لحل

: (1)

Kelsen $(\mathrm{H})$ international law studiee ce fecundity un der international washingytor 1957 p p .59 .

: ( r) (r)

Kelsen (h) the principle of international law - new york .1966 . p 702

KELSQN (H) princi pler OF INTEQNATIONA LAW ‘NEW YOrK 1952 . P . 700. 
النزاع،فهناك حالات كثيرة استندت فيها الدول إلي حوادث حدودية بسيطة لتبرير عدوانها علي الدول المجاورة تحت ذريعة استخدام الحق في الدفاع الشرعي مثال ذلك رفض الأمم المتحدة الشكوى المقدمة من إسرائيل الخاصة بعمليات الفدائين داخل أراضيها والمنطلقة من الأراضي المصرية وكونها أدني من مستوي الهجوم المسلح الذي أدعته إسرائيل ورفضت للأمم المتحدة

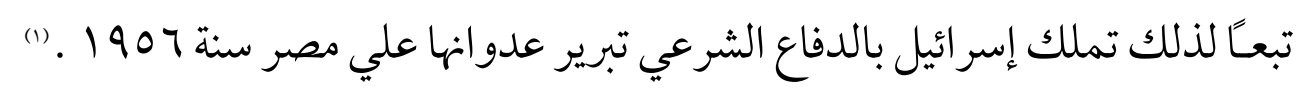
ه- أن يكون فعل العدوان غير مشروع :

أي أنه يشكل جريمة دولية،وذلك بأن تثبت الصفة غير المشروعة طبقًا لقواعد التجريم الدولية للاعتداء الذي يهدد الخطر بوقوعه .

فإذا انتفت عنه هذه الصفة فلا مجال عندئذ للتمسك بحق الدفاع الشرعي . (r)

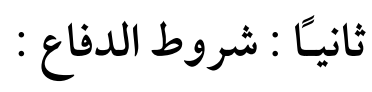
1 - أن يكون الدفاع الوسيلة الوحيدة لرد العدوان : بمعني أن لا تكون هناك وسيلة أخري غير اللجوء للقوة لرد العدوان،وإذا ما وجدت وسيلة أخري تحقق الغرض ذاته فلا يكون فعل الدفاع مباحا بل عدوانا يبيح للطرف الأخر حق الدفاع

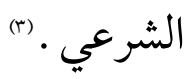
من ذلك مثلا إمكانية الاستعانة في الوقت المناسب بالمنظمة الدولية وكانت قادرة علي توفير الحماية . ع)

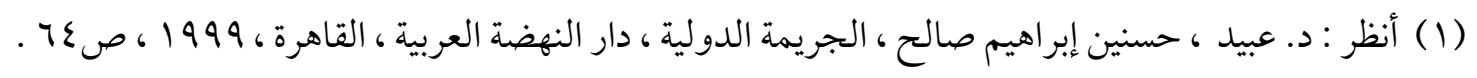

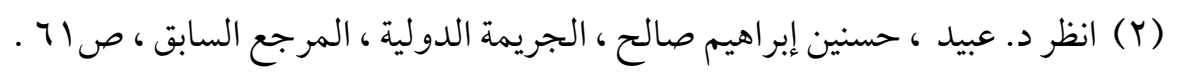

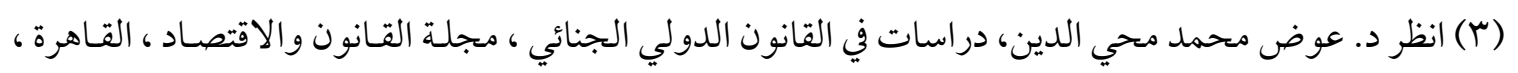

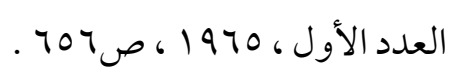

(ع) انظر د. حسني ، محمود نجيب ، دروس في القانون الجنائي الدولي ، القاهرة ، •97 197 ص9 ـ . 


\section{ب - توجيه الدفاع إلي مصدر العدوان :}

لكي يؤدي الدفاع الشرعي الغايات التي من أجلها شرع،لابد من توجيه فعل الدفاع

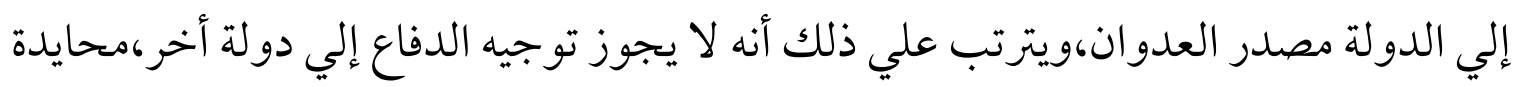

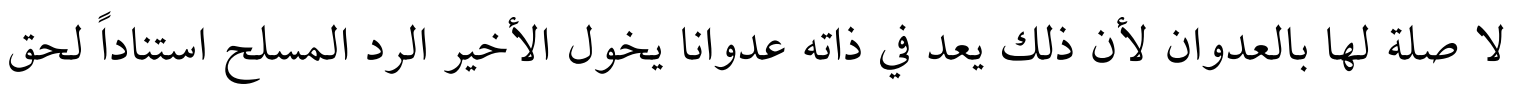
الدفاع الشرعي • ومثل هذا ما حدث في الحرب العالمية الأولي حينما انتهكت ألمانيا حياد

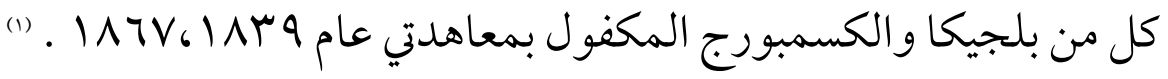
r- أن يكون الدفاع ذا صفة مؤقتة :

ومقضي هذا الشرط أن حق الدولة في الدفاع الشرعي حق مؤقت ينتهي بمجرد اتخاذ مجلس الأمن التدابير الملائمة لرد العدوان وهذا ما أشارت إليه صراحة المادة اه من ميثاق الأمم المتحدة (... إلي أن يتخذ مجلس الأمن الثدابير اللازمة لحفظ السلم والأمن

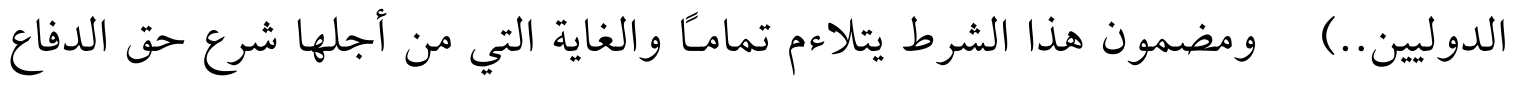
الشرعي . فهذا الحق لم يشرع إلا حماية للدولة المعتدي عليها . وبالتالي فإنه لا يعني بحال من الأحوال حلول الدول محل مجلس الألس الأمن في رد العدوان،ولكنه إجراء مؤقت ينتهي باضطلاع المجلس بدوره في حماية الأمن والسلم

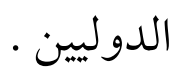

\section{ع - أن يتناسب فعل الدفاع مع فعل الاعتداء :}

وينصرف معني التناسب هنا إلي أن يكون فعل الدفاع من حيث الحجم والسلاح

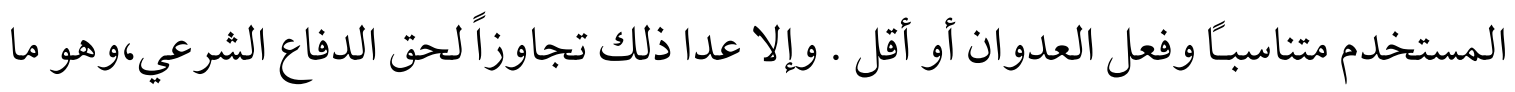

(1) انظر : د. عبيد ، حسنين، القضاء الجنائي الدولي ، تاريخه وتطبيقه ومشروعيته ، دار النهضة العربية القاهرة

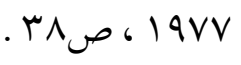




$$
\text { يعني تحول التكييف القانوني للفعل من الدفاع إلي العدوان . }
$$

ومعيار التناسب في القانون الدولي الجنائي،هو المعيار ذاته المتبع في القانون الداخلي،وهو معيار موضوعي قوامه سلوك الشخص المعتاد إذا وضع في نفس الظروف (1) المحيطة بالمدافع وبعد استعراض الدفاع الشرعي كأحد استثناءات استخدام القوة في العلاقات الدولية والتي جاء ميثاق الأمم المتحدة بتحريم استخدام القوة في العلاقات الدولية طبقا لنص المادة الثانية في فقرتها الرابعة ويستند الدفاع الشرعي إلي نص المادة اه من ميثاق الأمم المتحدة ولا بد من أن يكون هناك عدوانا لكي يتم الدفاع الشرعي ولابد أن يكون هناك شروطا للرد كما تناولت سلفًا وبالمقارنة بين الدفاع الشرعي والإرهاب الدولي نرى أن الدفاع الشرعي يستند إلي الشرعية الدولية طبقا لميثاق الأمم المتحدة وهو لرد العدوان فقط أما الإرهاب الدولي فهو جريمة ليس لها سند قانوني وإنما تهدد أمن الدول داخليًا وخارجيَّاوتقتل لأشخاص وتتلف الممتلكات العامة والخاصة بل أكثر من ذلك تفتت

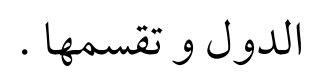

\section{المطلب الثاني \\ تميز الإرهاب الدولي عن الدفاع الشرعي في الغقه الإسلامي}

ما يقع على المسلمين بطريق مباشر أو غير مباشر، أنفسهم أو أمو الهم أو بلادهم،

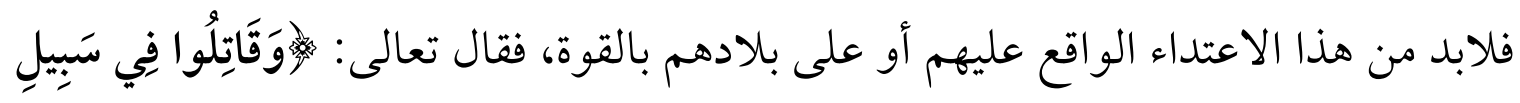

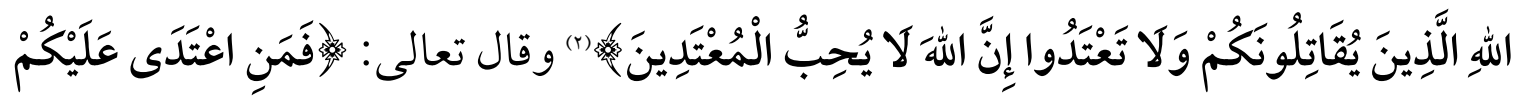

(1) انظر : د. صالح، ويصا ، العدوان المسلح في القانون الدولي ، الجوانب القانونية الأساسية لاستخدام القوة

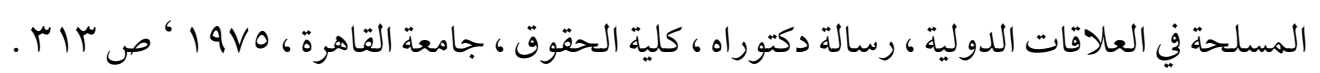

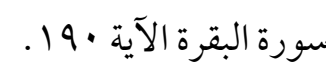




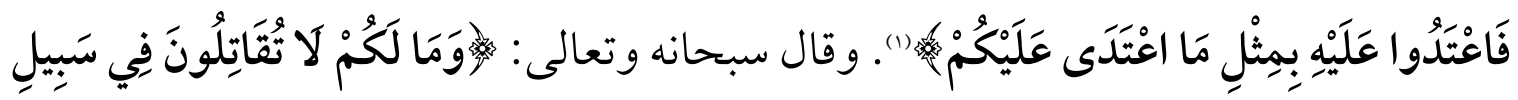

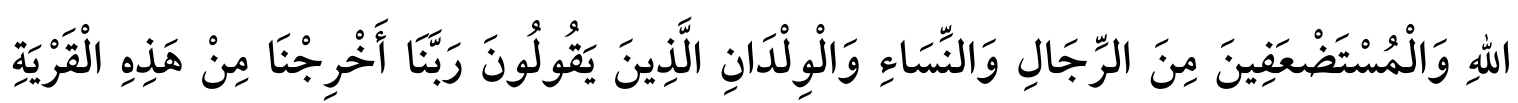

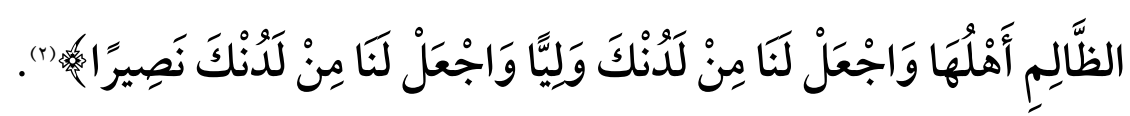

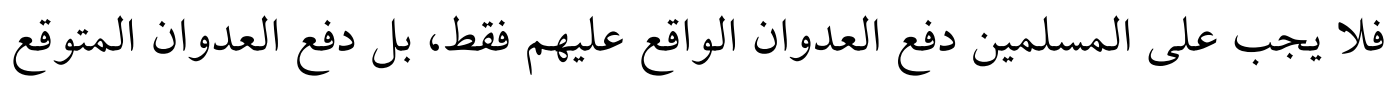

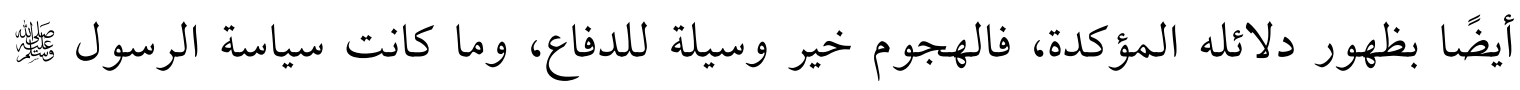
الحربية مع الفرس والروم إلا من هذا القبيل، عندما ظهرت بو ادر العدوان من الفرس بتمزيق كتاب رسول اله رسول رسول الله

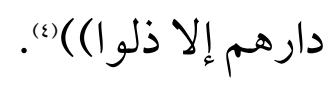

فلولا ما شرعه الله تعالى للأنبياء والمؤمنين من قتال الأعداء، لعلى أهل الشرك

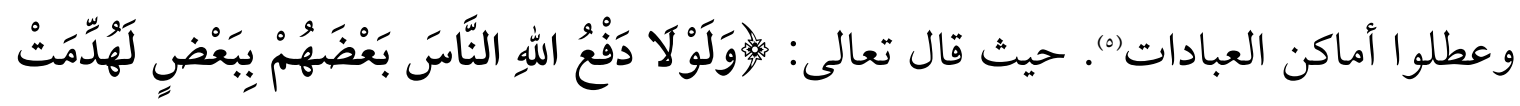

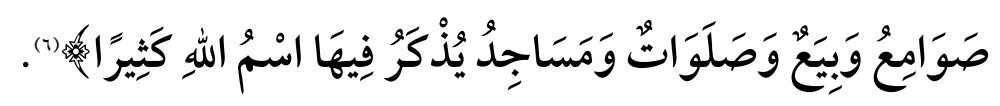
ومن هذا يتضح أن القتال في الإسلام، لم يكن مقصودًا لذاته، كتوسيع سلطان

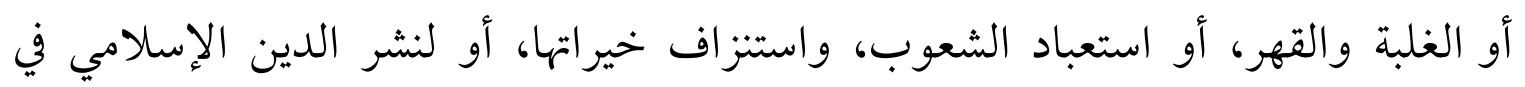

$$
\begin{aligned}
& \text { (1) سورة البقرة الآية £91. } \\
& \text { (Y) سورة النساء الآية Vo. }
\end{aligned}
$$

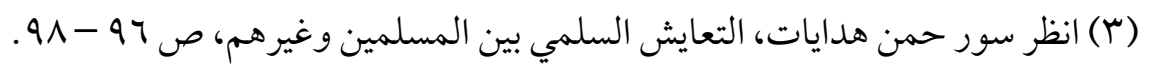

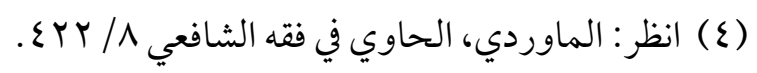

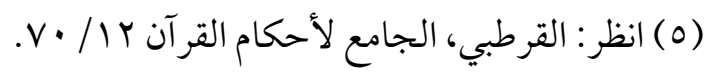

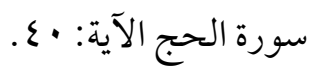




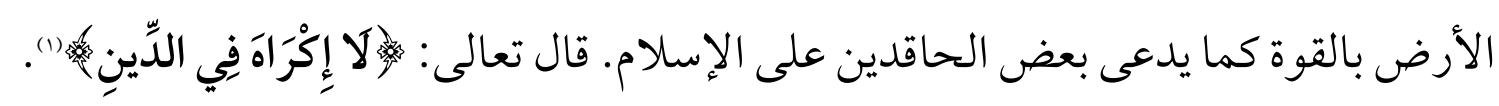

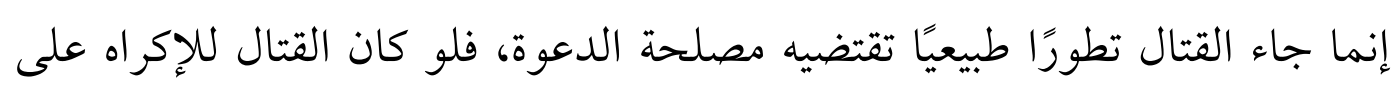

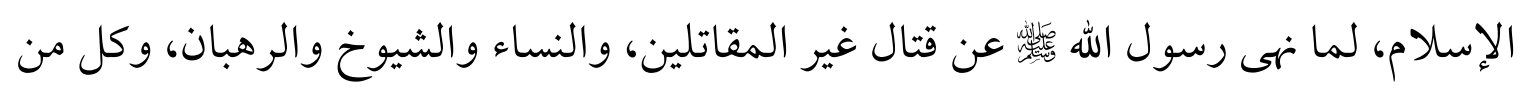
سالمfم. فاستخدام القوة لرد الاعتداء يضع الأمم الأخرى بالامتناع عن اللجوء إلى القوة

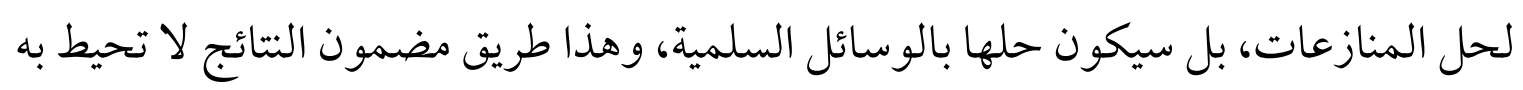

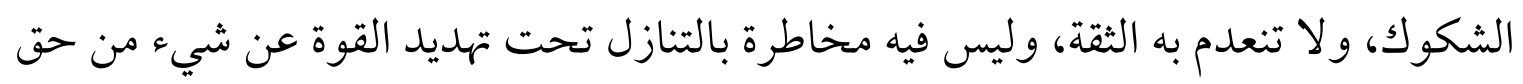

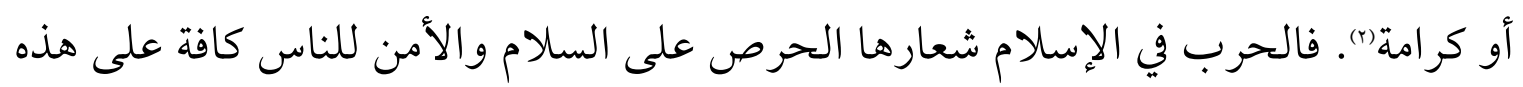

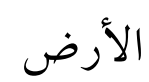
ومن هنا نرى أن الدفاع الشرعي في القانون الدولي العام يتفق مع الدفاع الشرعي في الشريعة الإسلامية من حيث رد للعدوان ، بل رد العدوان المتوقع وهو ما يعرف في القانون الدولي العام بالدفاع الشرعي الاستباقي

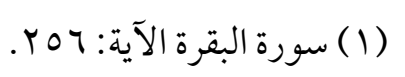

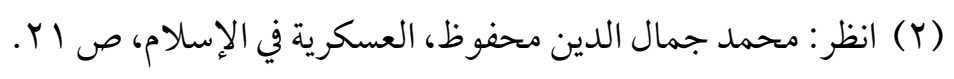




\section{الفصل الثاني \\ أسباب الإرهاب الدولي في القانون الدولي والققه الإسلامي}

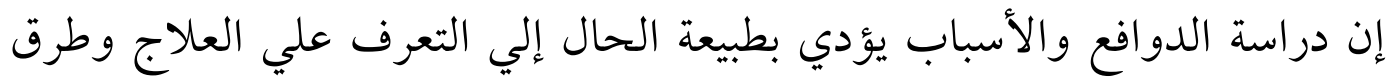

الوقاية وأسباب الإرهاب الدولي متعددة ومتنوعة فمنها السياسية ، ومنها الاقتصادية ،ومنها لهابيا

الإعلامية ، ومنها العقائدية والشخصية .

كما أنه يو جد أسباب للحرابة ( الإرهاب ) في الفقه الإسلامي منها أخذ المال ، وقتل

النفس ، دافع إخافة الطريق · ماكن

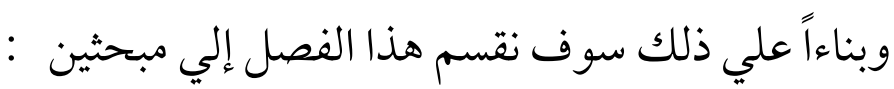

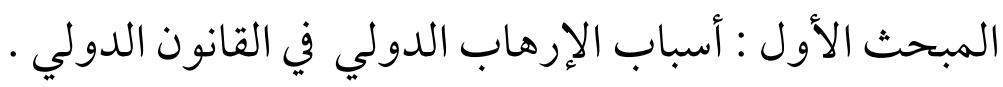

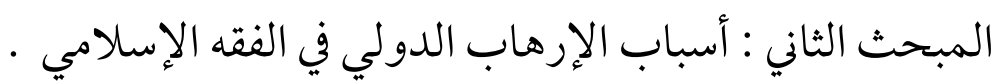




\section{المبحمث الأون \\ دوافع وأسباب الإرهاب الدولي في القانون الأدلي}

كما أسلفنا القول بأن للإرهاب الدولي دوافع وأسباب مختلفة ومتنوعة منها السياسية

والاقتصادية ، والدينية ، و الإعلامية ، و التاريخية ،و الشخصية

ويناءا علي ذلك سوف تقسم هذا المبحث إلي :

المطلب الأول : الدو افع السياسية .

المطلب الثاني : الدوافع الاقتصادية .

المطلب الثالث : الدو افع الدينية

المطلب الرابع : الدوافع الإعلامية

المطلب الخامس : الدوافع التاريخية

المطلب السادس : الدوافع الشخصية.

\section{المطلب الأول \\ الدوافع السياسية السولية}

الأسباب السياسية تنقسم إلي نوعين،أسباب داخلية وخارجية وربما كانت الأسباب

(1) الخارجية هي وليدة الأسباب الداخلية

فالقهر السياسي الداخلي غالبًا ما يدفع الأفراد والطو ائف المضطهدة التي لا تستطيع

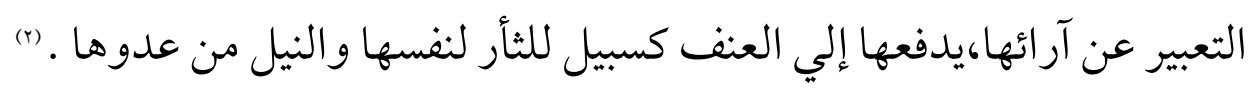

فالعمليات الإرهابية ذات الدافع السياسي هدفها في النهاية هو الوصول إلي قرار

(1) انظر د. شكري، علي يوسف، الإرهاب الدولي في ظل النظام العـالمي الجديد ، الطبعة الأولي ، دار اينز اك

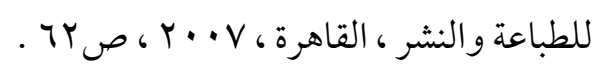

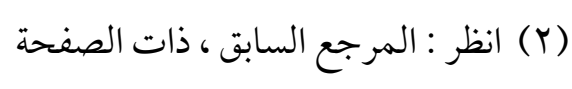


سياسي بمعني إرغام دولة أو جماعة سياسية علي اتخاذ قرار معين أو الامتناع عن قرار تراه في (1). مصلحتها،لما كانت تتخذه أو تمتنع عنه إلا بضغط العمليات الإرهابية

وقد تهدف العمليات الإرهابية إلي إنزال الضرر بمصالح دولة معينة،أو برعاياها نظراً لمو اقفها السياسية من قضية معينة ويمعني أوضح الاعتداء علي سيادة الدول والتخاذل الدولي هما الشرارة التي تشعل نار الإرهاب . (ل)

\section{المطلب الثاني الدوافع الاقتصادية}

قد يكون الدافع وراء العمليات الإرهابية هو الإضرار باقتصاد دولة معينة كتدمير المنشآت الصناعية،أو التجارية أو مهاجمة مكاتب شركات الطيران أو المنشآت السياحية

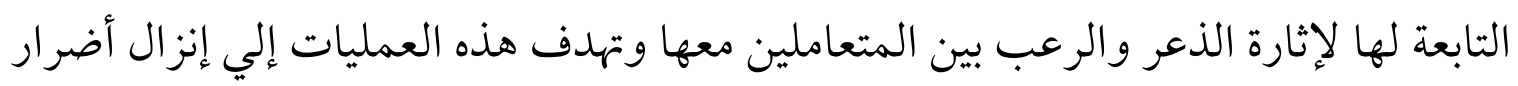

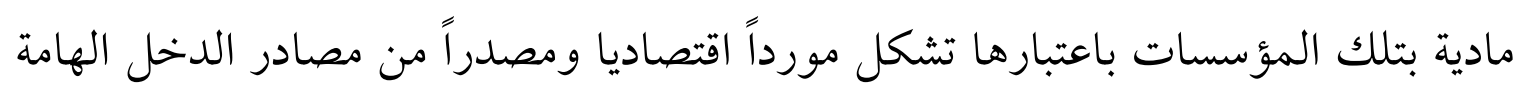

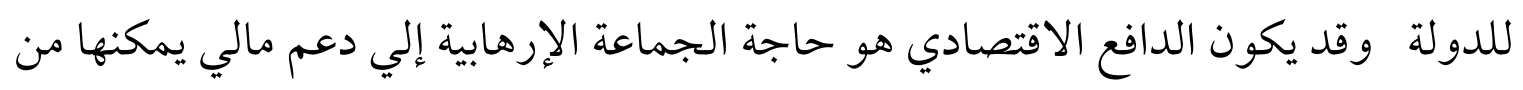

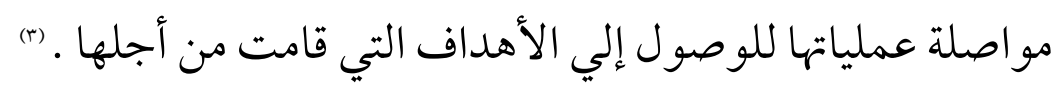

(1) انظر د. حلمي، نبيل أحمد ، الإرهاب الدولي وفقا القانون الدولي العام ، مرجع سابق ، صع ا ـ .

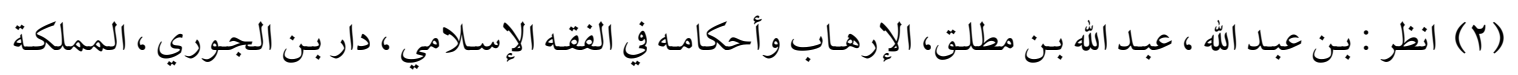

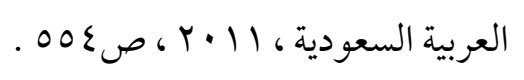

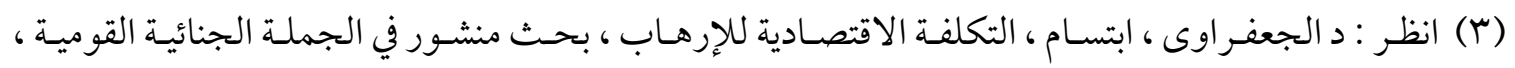

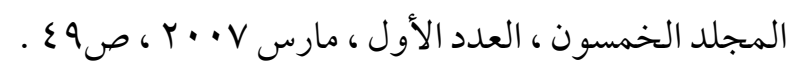




\section{المطلب الثالث الدوافع الدينية}

مما لا يخفي علي أحد،ما للدين والعقيدة والمذهب من تأثير بحياة الأفراد،ومن

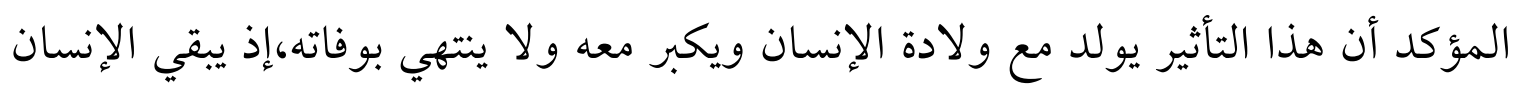

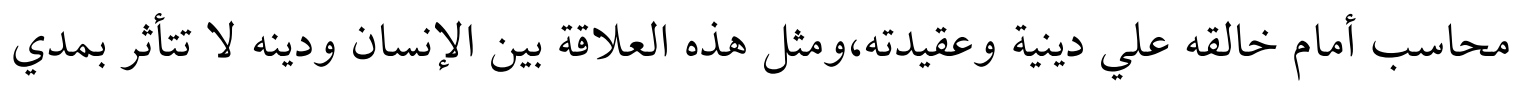

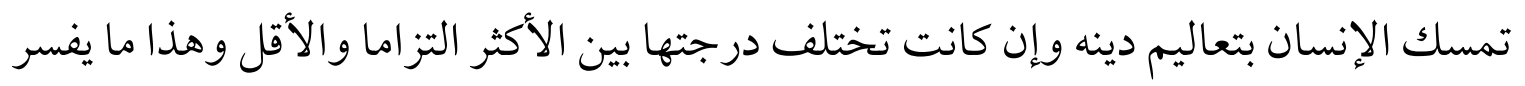

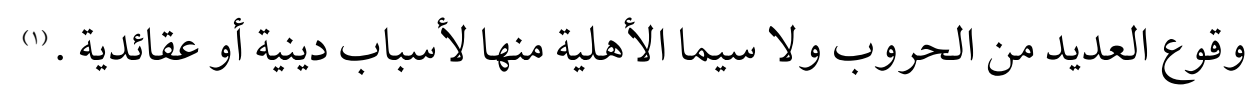
فعدم فهم مقاصد الشريعة والجهل بالدين،وتلقي الخطاب الديني من غير

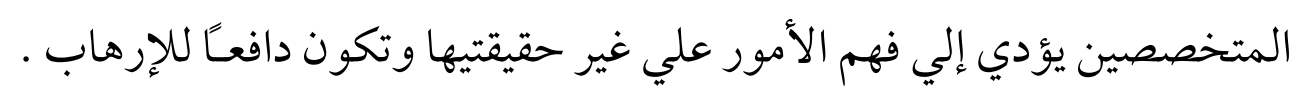

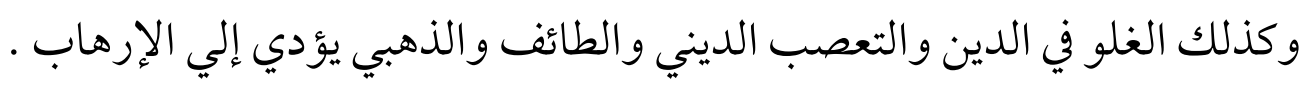
ونري الحل في هذه المشكلة بأن يكون دور للمؤسسات الدينية في توصيل الفهم الصحيح للدين سواء في المساجد أو عن طريق ندوات بالجامعات والمدارس ووضع رقابه

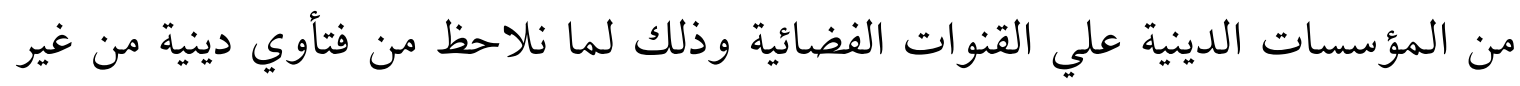
المتخصص مع تطوير المناهج الدراسية في الدراسات الدينية بالمدارس ووضع مادة للثقافة الإسلامية كمادة عامة في التعليم الجامعي .

\section{المطلب الرابع الدوافع الإعلامية المرابة}

ساهمت الثورة الإعلامية الهائلة في العالم في نشر الفكر المتطرف،والمظاهر

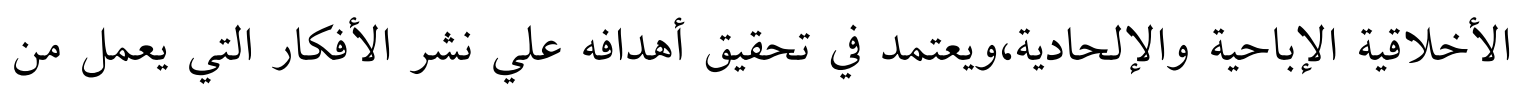
(1) () انظر : د. الشكري ، علي يوسف، الإرهاب الدولي في ظل النظام العالمي الجديد، المرجع السابق ،صV0 
أجلها،وطرحها أمام الرأي العام العالمي،و المنظمات الدولية للحصول علي دعمها وتأييدها لقضية،فقد تري احدي المنظمات الثورية أن هناك تجاهلاً من الرأي العام لقضيتها فتلجأ إلي تنفيذ بعض العمليات الإرهابية المثيرة بقصد لفت الانتباه العالمي إلي القضية التي تتبناها وتدافع عنها،وخلف نوع من التعاطف مع من يدافعون عنها،وإجبار الحكومات والدول علي

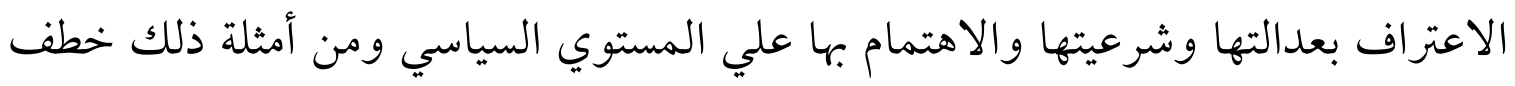
الطائرات وتفجير السفارات والقنصليات،حيث نجحت في خلق نوع من التعاطف علي مستوي الرأي العام العالمي مع مرتكبي تلك الأفعال من خلال ما تناقله وسائل الأعلام بكافة صورها وأشكالها من تقارير ومتابعات تفصيلة عن مدي الظلم الذي يتعرضون له

ومدي المعاناة التي تعيشها شعوبهم · (1) ونري أن لابد من محاربة هذا الإعلام عن طريق وضع رقابة علي هذه الوسائل من

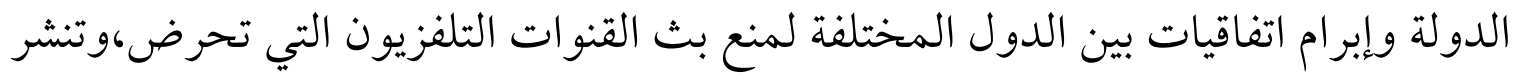
الأخبار الكاذبة،وتعمل علي ثبت الأفكار الخاطئة .

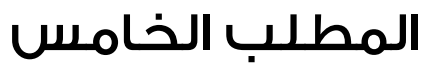 الدوافع التاريخية}

الصراع التاريخي أو الصراع التاريخي له دور كبير كسبب للإرهاب الدولي فعلي سبيل المثال نجد الصراع بين العرب وإيران فهذا الصراع ليس كما يظن البعض صراع شيعي

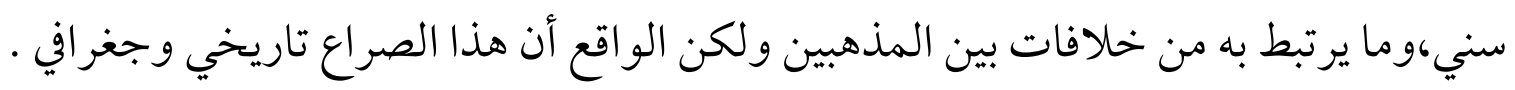
فإما عن الصراع التاريخي،فنجد أن تاريخ العلاقات العربية الإيرانية زاخر بالصراع من منذ بند

(1) انظر : د. عز الدين ، أحمد جلال، الإرهاب والعنف السياسي، كتابة الحرية ، 1919 ، ص101 . 
مرحلة ما قبل الإسلام ـ فمعركة القاسية لا تزال تمثل حرجـا نازفًا بالنسبة إلي كثير من القوميين الإيرانية ـ ممن ينظرون إليها من منظور قومي عنصر،صرف بعيداً عن دوافعها وأبعادها وكيف أنها تمثل شرارة للثقافتين العربية والفارسية فمن حضارة إسلامية مزدهرة وقتذاك.

أما حسابات الجغرافيا فلها هي الأخرى نصيب لا يقل تأثيراً عن دور التاريخ في علاقات الجانبين،فالجغرافيا وضعت الجانبين علي محك الصراع بشكل شبه دائمًا تاريخيـا،وإيران تتعامل مع الجغرافيا والتاريخ من منظور مغاير للحرب،فهي في حالة جنبين دائم إلي استفادة مجدها الإمبر اطوري،وتشعر بفدان الهوية،شأنها في ذلك شأن تركيا،لذا فهي تسعي بكل الطرف للسيطرة علي الدول المجاورة ومحاولة تشكيل الخارطة السياسية فيها بما يتماشي مع مصالح طهران وأهدافها الإستراتيجية في الإقليم،وتستخدم في ذلك قائمة طويلة من الوكلاء ابتداء من حزب الله اللبناني وصولاً إلي جماعة الحوثي في اليمين،مروراً بميشيات الحد الشيعي في العراق،وعناصر وتيارات طائفية من دول عربية أخري عديدة . (r)

(1) انظر : الكتبي، سالم، مقال بعنو ان صراع التاريخ والجغر افيا بين العرب وإيران، صحيفة العرب بتـاريخ

$$
\begin{aligned}
& \text { (10/9/19 } \\
& \text { (Y) انظر : الكتبي ،سالم ، المرجع السابق ، ذات الصفحة . }
\end{aligned}
$$




\section{المطلب السادس الدوافع الشخصية}

قد ترجع الجرائم الإرهابية بدوافع شخصية،ولتحقيق أهداف معينة شخصية فقد تكون الجرائم الإرهابية للابتزاز الأموال من شركات الطير ان المختلفة ـ ففي عام IVVY قام بعض الزنوج الأمريكيين بخطف طائرة أمريكية،وطلبوا فدية قدرها مليون دولار للإفراج عن (1) المسافرين،وهبطو ا بالطائرة ذلك في مطار الجزائر العاصمة وقد تكون الجرائم الإرهابية التي تستند إلي دوافع شخصية يكون مرتكبيها مصابون بخلل عقلي أو مرض نفسي وهذا ما حدث عام 9VY (19 ،عندما قامت سيدة بخطف طائرة إيطالية كانت طريقها لميلانو قادمة من روما وأجبرت قائدها علي التوجه لمبونخ بألمانيا الغربية،ثم سلمت نفسها للسلطات الألمانية التي كشفت عن وجود خلل عقلي لديها،ويتميز هذا النوع من الإرهابيين بعدة صفات مشتركة وهي الطفولة المضطربة التي أدت للعزلة،ثم إلي الشذوذ وفقدان الاتصال بالأصدقاء،وعلاقات غير طبيعية بالو الدين . (r) ونرى لحل لهذه المشكلة تفعيل وظيفة الأخصائي الاجتماعي سواء كان في المدرسة أو الجامعة أو الهيئات والمصالح الحكومية لمعرفة مشاكل هؤلاء الأشخاص لمعالجتهم . وكذلك يكون هناك دور للأسرة إذا ما لاحظت أن هناك خلل في سلوك أحد الأبناء فعليها بالمسار عة لعرضه على طبيب نفسي •

(1) انظر : محمد، البخدوي بحث نطق الطائرات منشور في مجلة معهد البحوث والدراسات العربية ع 19V )

$$
\begin{aligned}
& \text { ص. } \\
& \text { (r انظر : د. نبيل أحمد حلمي ، الإرهاب الدولي ، المرجع السابق ، صVI . . }
\end{aligned}
$$




\section{المبحث الثاني \\ دوافع الإرهاب في الققه الإستلامي}

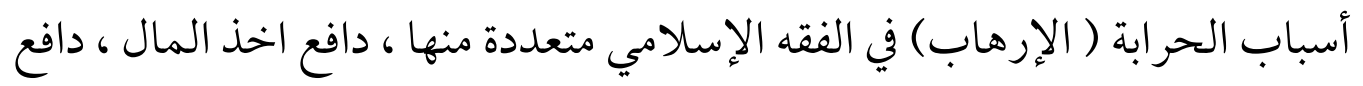

قتل النفس ، دافع إخافة الطريق .

وبناء على ذلك سوف نقسم هذا المبحث إلى ثلاثة مطالب :

المطلب الأول : دافع اخذ المال . مال.

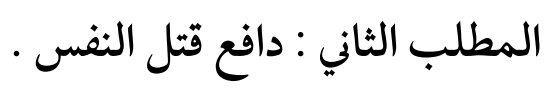

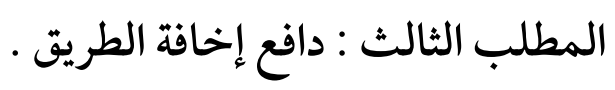

\section{المطلب الأول \\ دافع اخذ المال}

الدافع الرئيسي للمحاربين هو أخذ مال المسلمين ، ومن في حكمهم وهو يطابق

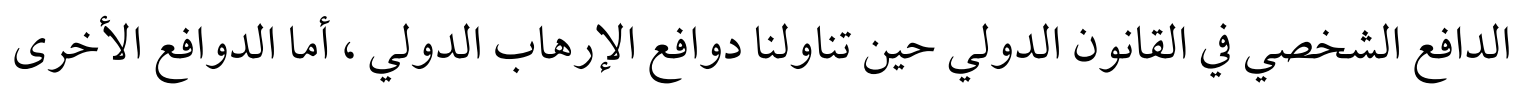

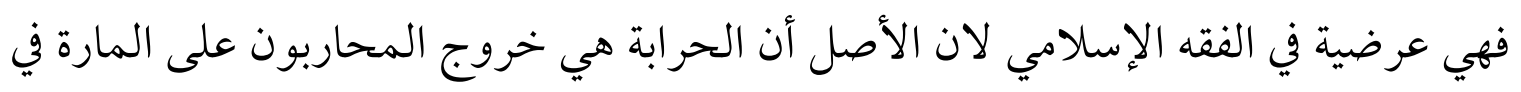
الطريق بدافع سرقة أمو الهم بواسطة القوة ، والشوكة مع كون هؤلاء المارة بعيدين عن المنع ،

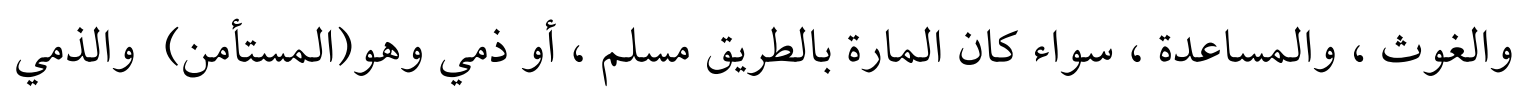

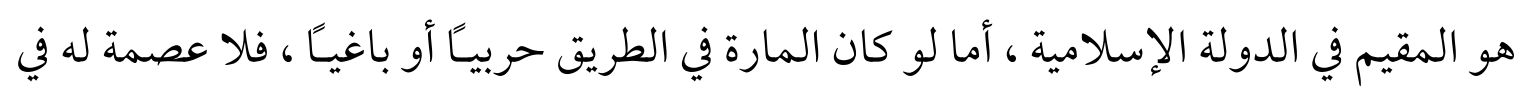

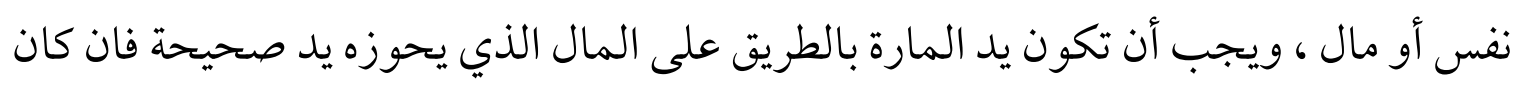

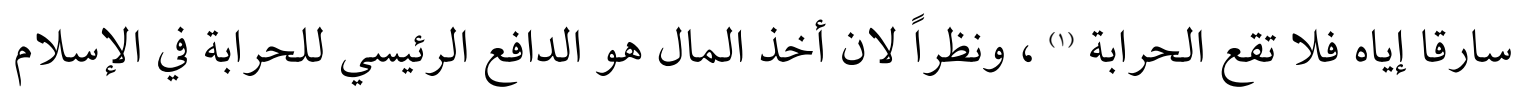
لذلك سميت (بالسرقة الكبرى ) .

(1) انظر : بدائع الصنائع ، الجزء السابع ، ص 19. 


\section{المطلب الثناني \\ دافع قتل النغس النس}

القتل ليس من دوافع الحرابة الرئيسية ، ولكنه قد يحدث أثناء أخذ المال لذلك فهو

دافع عرضي قد يصاحب جريمة الحرابة وهنا يخرج المحاربون على المارة بالطريق بهدف أخذ مالهم فيقتلون مع السرقة ، أو يقتلون دون القدرة على سرقة المال وفى هذه الحالة ينتج عن الحرابة فزع وخوف شديدين للمارة بالطريق ، وبذلك يكون المحاربون قد ارتكبوا عدة صور لجريمة الحرابة ربما بفعل إجرامي واحد وهو السرقة ، والقتل وإخافة الطريق ، وإن كان في وقوع أي من هذه الجرائم ما يكفى لإسناد الحر ابة إليهم ، ولذلك ذهب معظم الفقهاء إلى القول بأن القتل لا يسقط عن المحاربين بعفو ولى الدم ، أو بعفو الحاكم في حالة القتيل الذي لا وارث له (") حيث إن العقاب في هذه الحالة يعد حداً من حدود الله عز وجل ، وهى لا تسقط إلا بالتوبة النصوح قبل قدرة الحاكم عليهم ·

\section{المطلب الثالث دافع إخافة الطريق}

يلاحظ أن سلوك المحاربين الإجر امي فيه إخافة للمارة بالطريق وترويعهم ، وإن لم يأخذوا مالاً ، ولم يقتلوا نفستا ، ورغم أن هذه الصورة هي أقل صور الحرابة ضرراً إلا لها أثار سلبية على كافة مناحي الحياة في الدولة الإسلامية السياسية و الاقتصادية والاجتماعية لأنه سوف تسود الفوضى والاضطر اب ، والجرائم ، والسرقة ، والبغض والكراهية .

(1) انظر : د أحمد ، هلالي عبد الله ، أصول التشريع الجنائي الإسلامي 1990، ص 197. 


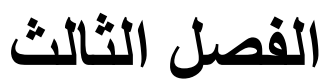

\section{طرق مكافحة الإرهاب في القانون الدولي والفقه الإسلامي}

أدى انتشار ظاهرة الإرهاب إلى وجود حركة دولية نشطة لعلاج هذه الظاهرة

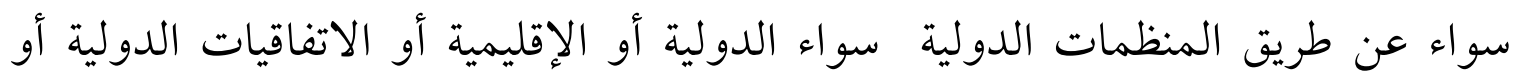

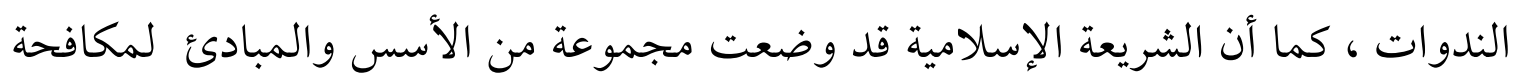

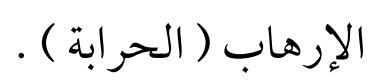

وبناء على ذلك سوف نقسم هذا الفصل إلى ثلاثة مباحث :

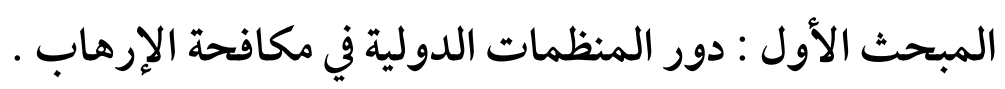

المبحث الثاني : المنظمات الإقليمية ودورها في مكافحة الإرهاب .

المبحث الثالث : مكافحة الإرهاب في الفقه الإسلامي .

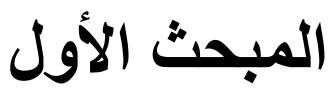

دور المنظمات الدولية في مكافحة الإرهاب المباب

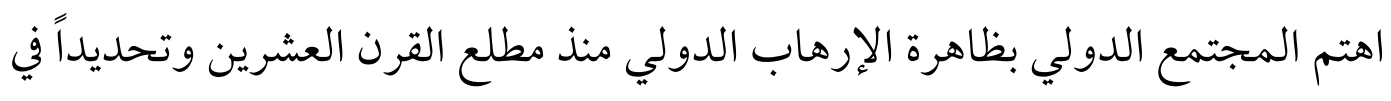

أعقاب الحرب العالمية الأولي نتيجة لما خلفته هذه الحرب من آثار مدمرة أتت علي العالم كله.

ومع تزايد عمليات الإرهاب الدولي اهتمت الكثير من المنظمات الدولية بمناقشتها

ودراستها،وذلك للقضاء عليها أو التقليل من حدتها،فظاهرة الإرهاب تنتهك حقوق الإنسان

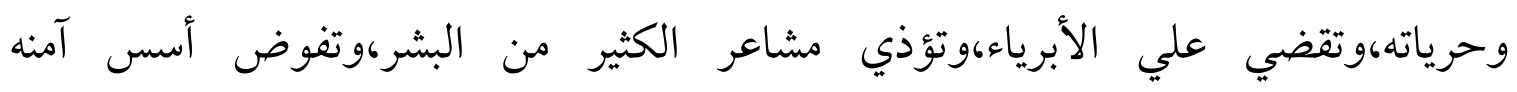

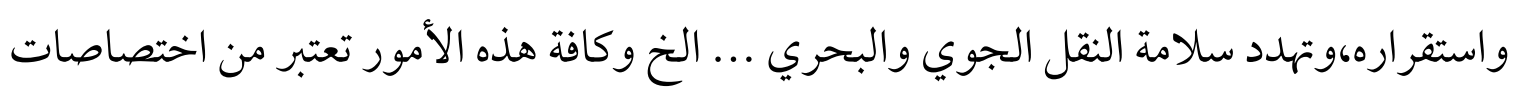

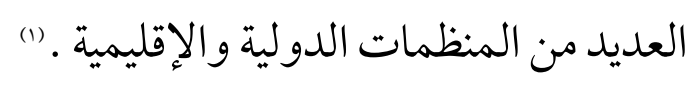

(1) انظر د. عبد الهادي، عبد العزيز مخيمر، الإرهاب الدولي مع دراسته للاتفاقيات الدولية والقرارات الصادرة 
فالمنظمات الدولية والإقليمية لها دور كبير في مكافحة الإرهاب وبناءاً علي ذلك

$$
\begin{aligned}
& \text { سوف نقسم هذا الفصل إلي مطلبين : } \\
& \text { المطلب الأول : الأمم المتحدة ودورها في مكافحة الإرهاب . } \\
& \text { المطلب الثاني : المنظمات الإقليمية ودورها في مكافحة الإرهاب . } \\
& \text { المطلب الأول } \\
& \text { الأمهم المتحدة ودورها في مكافحة الإرهاب الاب }
\end{aligned}
$$

اهتمت منظمة الأمم المتحدة بالبحث في ظاهرة الإرهاب،وكيفية القضاء وذلك عندما بدأت عمليات خطف الطائرات في الزيادة في بداية السبعينيات واحتجاز المبعوثين الدبلوماسيين وتفجير مقار البعثات الدبلوماسية ووضعت في حباتها بأن هذه الظاهرة تعتبر أحد الأسباب الرئيسية التي تهز أمن واستقرار المجتمع الدولي وذلك عن طريق محاولة وضع تعريف مناسب للإرهاب والأسباب التي تؤدي إليه وكيفية علاجه،كذلك اهتمت وذلك بتشكيل اللجان اللازمة لإعداد اتفاقيات دولية منظم إطار من التعاون الدولي لمنع وقع (1). بعض أشكال الإرهاب

وقد قامت منظمة المتحدة بجهودها في مكافحة الإرهاب عن طريق أجهزتها المختلفة سو اء مجلس الأمن أو الجمعية العامة للأمم المتحدة . وبناءاً علي ذلك سوف نقسم هذا المطلب إلى فروع . الفرع الأول : دور مجلس الأمن في مكافحة الإرهاب الفرع الثاني : الإجر اءات المتخذ من قبل الجمعية العامة للأمم المتحدة بشأن مكافحة

$$
\begin{aligned}
& \text { عن المنظمات الدولية ، المرجع السابق ، ص9YY . }
\end{aligned}
$$

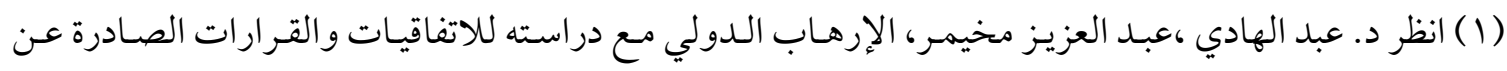

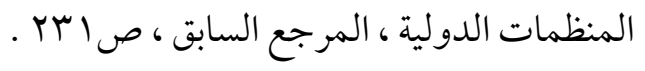




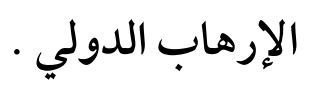

الفرع الثالث : الجهود الدولية لمكافحة تمويل الإرهاب

$$
\text { الفرع الأول }
$$

دور مجلس الأمن في مكافحة الإرهاب الأول

يتمتع مجلس الأمن الدولي بأهمية خاصة نظراً لأنه الجهاز الوحيد في منظمة الأمم

المتحدة الذي يتحمل تبعات حفظ السلم والأمن الدولي .

وفي هذا تنص المادة ع Y / من ميثاق الأمم المتحدة علي أنه رغبة في أن يكون العمل

الذي تقوم به الأمم المتحدة سريعا وفعالا،يعهد أعضاء تلك الهيئة إلي مجلس الأمن بالتبعات الرئيسية في أمر حفظ السلم والأمن الدولي،ويوافقون علي أن هذا المجلس يعمل نائبًا عنهم في قيامه بو اجباته التي تفرضها عليه هذه التبعات .

وقبل أحداث Iل سبتمبر r... كان موضوع الإرهاب الدولي لا يشغل حيزاً كبير في

منظمة الأمم المتحدة ولكن بعد هذه الأحداث ظهر موضوع الإرهاب الدولي وشغل حيزاً

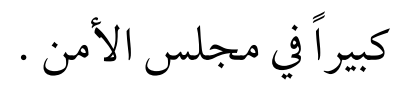

\section{أولا : دور مجلس الأمن في مكافحة الإرهاب قبل سبتمبر Y...}

بعد تفكك الاتحاد السوفيتي السابق عام 1991 الحدث الأبرز في القرن العشرين . فلم تعد هناك ثنائية قطبية وتوازن قوي وعدم انحياز ـ وسادت مفاهيم جديدة في العالم من بينها الأحادية القطبية والعولمة والنظام العالمي الجديد . وفي خضم هذا التحول والتغير الذي طرأ علي العالم برز الإرهاب باعتباره الحظر الأكبر المهدد لأمن الدول الكبرى هذه المرة بعد أن تمكن من الدول الأصغر والأقل استقراراً في العالم . (1)

(1) انظر : د. الشكري ،علي يوسف، الإرهاب في ظل النظام العالمي الجديد ، المرجع السابق ، ص ○ ب 
وبعد أن التغير في النظام العالمي رافض ذلك تطور في القرارات الصادرة عن مجلس

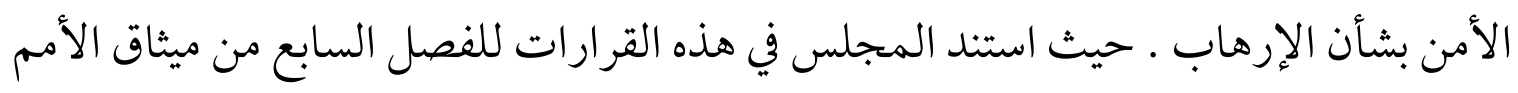

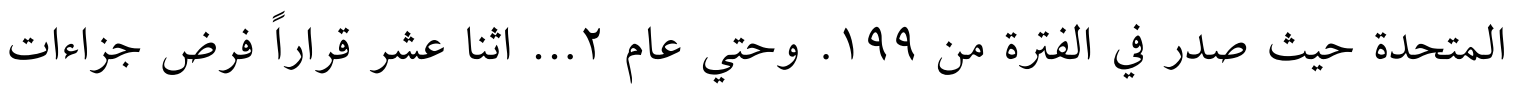

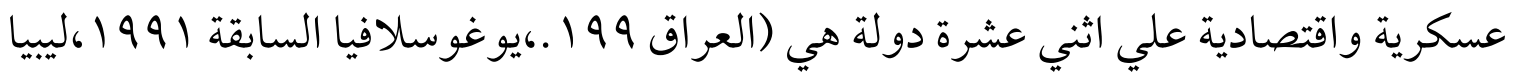

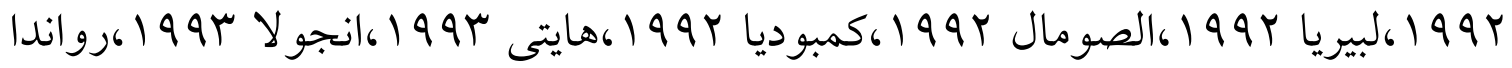
ع991،السودان 1997(6سير اليون 1997، (أفغانستان 1999) وحيث أن اللجوء للفصل السابع من الميثاق محكوم بالضرورة بوقوع عدوان أو التهديد به أو حدث ما يهدد السلم

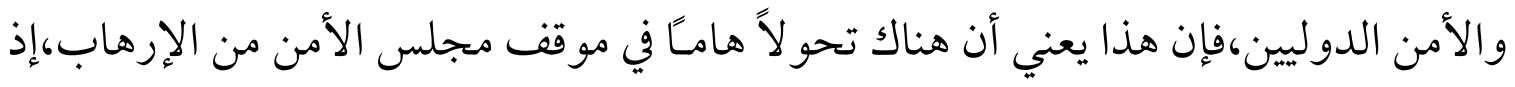

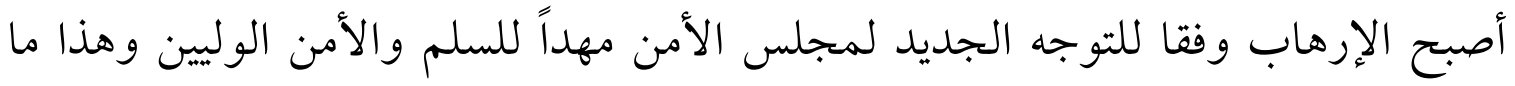
أشارت إليه بعض القرارات صراحة ومن بينها القرار تقاعس لبيا عن الالتزام بمضمون القرار

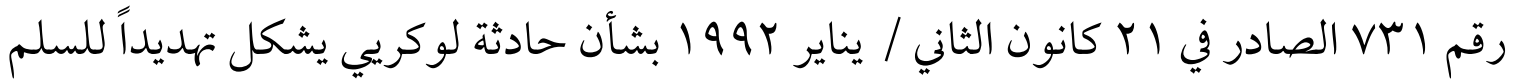

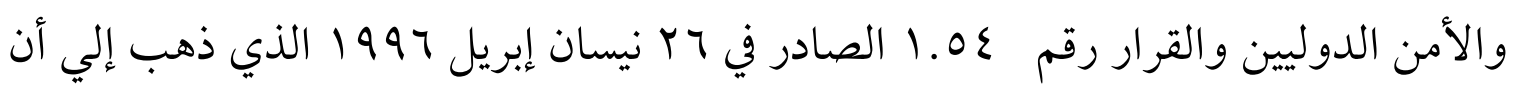

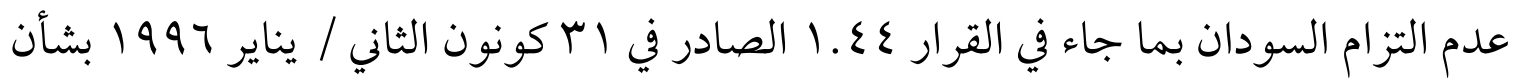

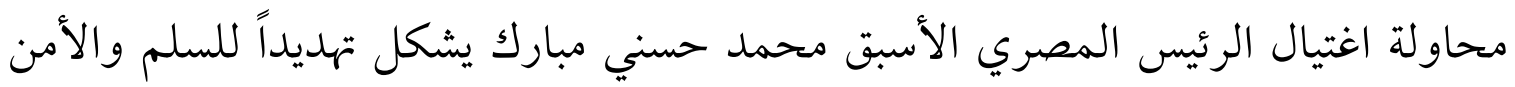

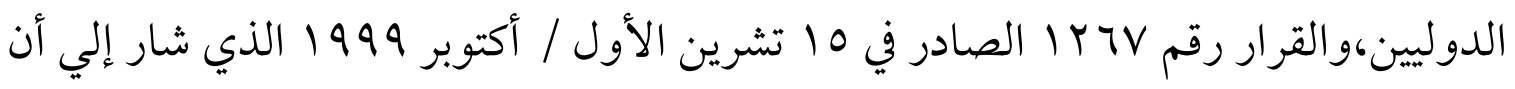

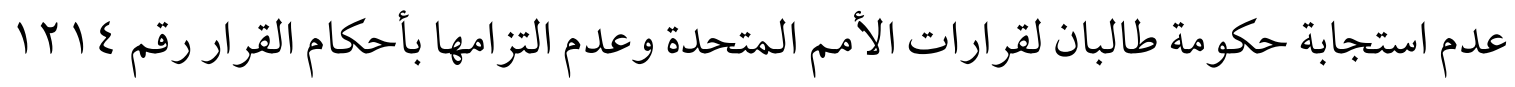

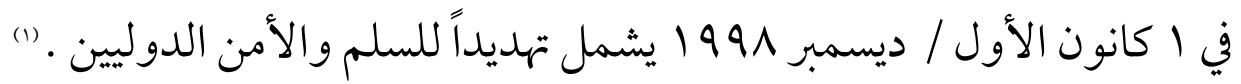

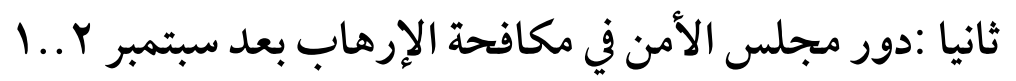

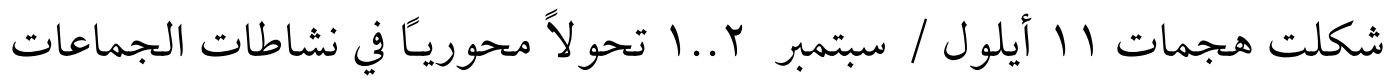

$$
\text { (1) (انظر : د. الشكري ،علي يوسف، المرجع السابق ، ص7·r. }
$$


الإرهابية والإرهاب بصفة عامة ـ فقد كانت هذه الهجمات واحدة من الدول الأكثر استقراراً وأمنا في العالم ليس هذا فحسب،ولكنها استهدفت رموز هذه الدولة ممثلة بالبيت الأبيض ووزارة الدفاع وبرج التجارة العالمية . (1) وبعد سبعة عشر يومـا من وقوع هذه الهجمات الإرهابية أصدر المجلس القرار رقم

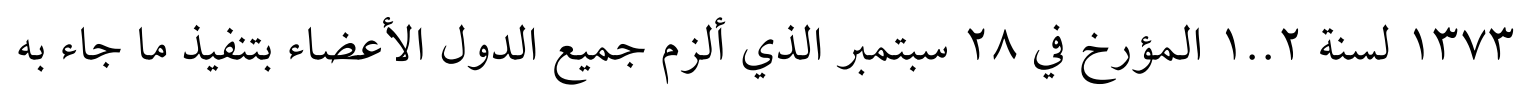
حيث نص علي تدابير يجب علي الدول القيام بها مقرراً إنشاء لجنة تابعة له لمراقبة تنفيذ القرار مطالبًا جميع الدول بتقدير تقاريرها إلي اللجنة عن الخطوات الذي تم اتخاذها تنفيذاً لهذا القرار ويذلك نجد أن مجلس الأمن منذ صدور هذا القرار يضطلع بدور قيادي في توحيد الجهود العالمية لمكافحة الإرهاب،وبدأ تصرف بقوة ليرقي إلي مستوي مسؤولياته فيما يتعلق بالتهديد العالمي الذي يشكله الإرهاب(() وذلك لان قرار اته تحمل الصيغة التشريعية و التنفيذية،وبالتالي فإن آثار خطيرة وبالذات علي دول العالم الثالث التي لا يتو افر لها حماية من قبل احدي الدول الكبرى التي تتمتع بحث الفيتو سواء قبل أو بعد || سبتمبر r .. (،حيث تعرضت العديد من الدول لقرارات بغرض الحصار والحظر الاقتصاد والدبلوماسي عليها مما أدي ذلك إلي إصابتها بالعديد من الخسائر،وهذه العقوبات لا توقع إلا علي الدول الضعيفة والتي حاولت الخروج من الهيمنة التي تمارسها الدول الكبرى عليها .

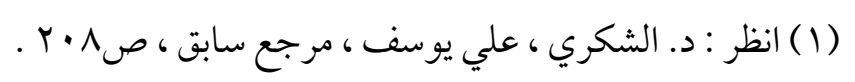

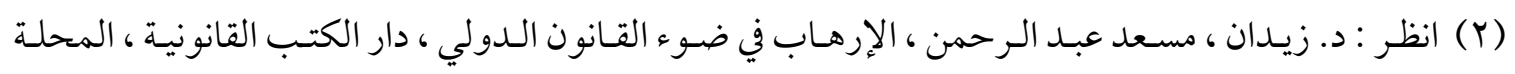

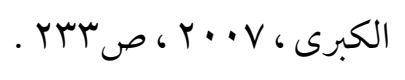




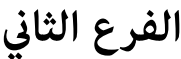 \\ الإجراءات المتخذة من قبل الجمعية العامة

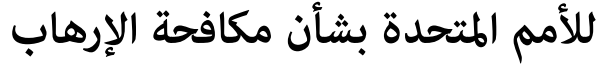

تختص الجمعية العامة") بموجب المادة العاشرة من ميثاق الأمم المتحدة بمناقشة أي

أمور وكل الأمور التي تهم الأعضاء مع تحفظ واحد وهو عند مباشرة مجلس الأمن نظر نزاع

أو موقف ما فليس للجمعية العامة أن تقدم أية توصية في شأن هذا النزاع أو الموقف إلا إذا

(") طلب منها ذلك

ولذا فإن الجمعية العامة للأمم المتحدة قد أصدرت قرارات عديدة بشأن الإرهاب

$$
\text { الدولي و كان لها موقف بالنسبة لحركات التحرير الوطنية . أولا :الجمعية العامة وموقفها من الإرهاب الدولي }
$$

صدر إعلان الجمعية العامة للأمم المتحدة في دورتها الخامسة والعشرين في أكتوبر

19V ا ـ حيث تضمن واجب كل دولة بالامتناع عن تشجيع الأعمال الإرهابية علي إقليم دولة

أخري أو تقديم المساعدة للإرهابيين أو السماح لهم بالعمل علي إقليمها أو من خلاله . (r)

وفي الدورة السابعة والعشرين عام 19VY تناولت الجمعية العامة موضوع الإرهاب

الدولي تحت بند التدابير الرامية إلي منع الإرهاب الدولي الذي يعرض للخطر أرواحا بشرية

بريئة ويهدد الحريات الأساسية،وانتهي الأمر بإصدار الجمعية العامة للقرار رقم ع ب.r لسنة Y T ا و الذي نص علي قلق المنظمة الشديد إزاء تزايد الأعمال الإرهابية الدولية،وحث

$$
\begin{aligned}
& \text { (1) انظر : د. زيدان ، مسعد عبد الرحمن ، الإرهاب في ضوء القانون الدولي ، المرجع السابق ، صبه1 . }
\end{aligned}
$$

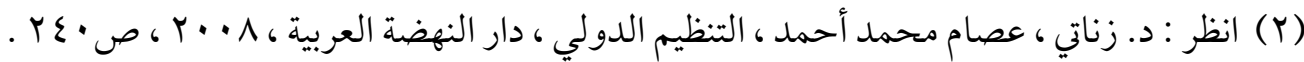

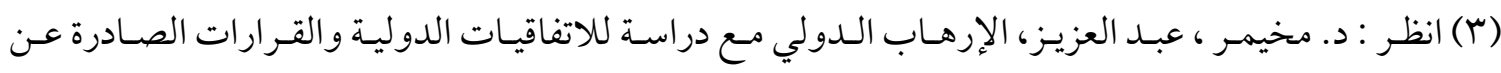

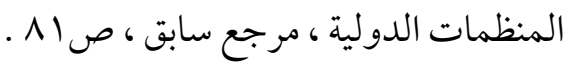


الدول الأعضاء علي ضرورة إيجاد حلول عادية وسلمية للأسباب التي تقف وراء الأعمال الإرهابية،وأضاف بأنه يجب احترام حقوق الشعوب جمعيًّ في مناهضة الأنظمة الاستعمارية والعنصرية،وتلك التي تخضع للسيطرة الأجنبية وحق تقرير المصير وشرعية كفاحها لنيل استقلالها كما قررت الجمعية العامة') إنشاء لجنة خاصة تعني بدراسة الإرهاب الدولي وتتألف من خمسة وثلاثين عضواً يعنيهم رئيس الجمعية العامة مع مراعاة مبدأ التمثيل الجغرافي،وتقوم بدراسة الملاحظات التي تقدمها الدول،وتقوم بإعداد تقريرها متضمنا

$$
\text { (r). التوصيات }
$$

كما تم إبرام اتفاقيتين دوليتين لمواجهة بعض الأعمال الإرهابية واتفاقية خاصة بحماية الأشخاص المتمتعين بحماية من الدبلوماسيين لسنة سلو الووالثانية تتعلق باختطاف الرهائن لسنة 9 ( 9 ، لكنها لم تتوصل لوضع تعريف للإرهاب لاختلاف وجهات نظر الدول واقتصرت علي حث الدول في قراراتها علي التعاون من أجل القضاء السريع علي الإرهاب..(r)

\section{ثانيا :الأمم المتحدة وموقفها من حر كات التحرير الوطنية:}

أوضحت دول العالم الثالث عن رأيها داخل الأمم المتحدة من خلال اجتماعات الجمعية العامة بشأن التمييز بين الإرهاب والكفاح المسلح،حيث كان رأيها أن التحرير الوطني ومقاومة المحتل من القيم النبيلة التي لا يمكن أن توصم بالإرهاب،لأن أي خلط في

(1) انظر : د. حلمي ، نبيل أحمد، الإرهاب الدولي وفقا لقواعد القانون الدولي العام المرجع السابق، ص ؟ +1 . .

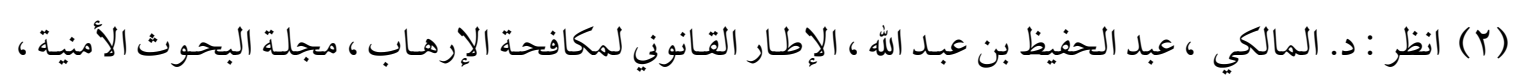

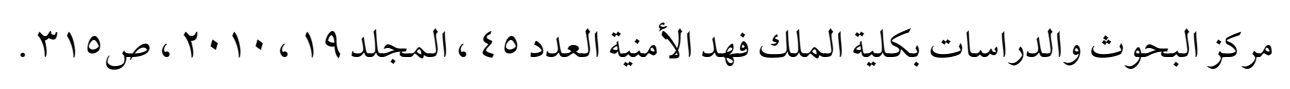

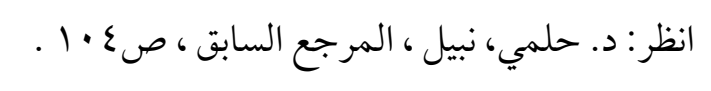

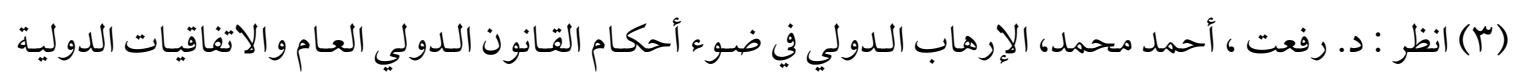

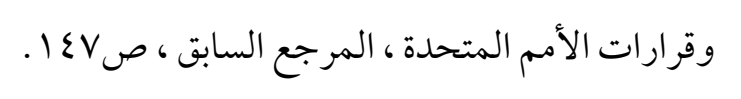


هذا الصدد يعني الاستهانة بالقيم الإنسانية،والحقوق التي أكدت عليها الأمم المتحدة،وأكدت علي أن جميع الاتفاقيات الخاص بالإرهاب لن تؤتي ثمارها إلا إذا تم

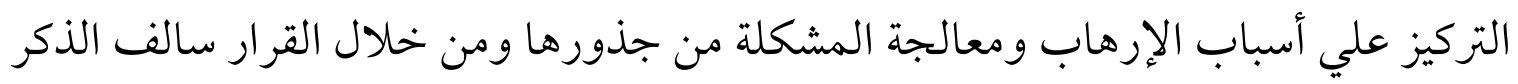

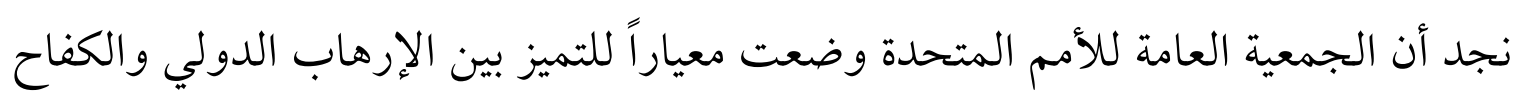

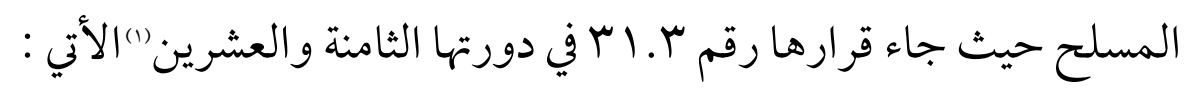
1 - أن نضال الشعوب الو اقعة تحت السيطرة الاستعمارية والأنظمة العنصرية لتحقيق حقها في تقرير المصير والاستقلال هو نضال مشروع يتفق مع مبادئ القانون الدولي . r- أية محاولة لقمع هذا النضال هو مخالفة لميثاق الأمم المتحدة ومبادئ القانون

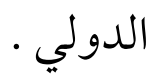
r- هذا النضال ضد الاستعمار يعد نزاع ذو طابع دولي وفقـَ لأحكام اتفاقيات جنيف لعام 9 19 وبروتوكو لات جنيف لسنة 9VV 16و الذي ينظم الوضع القانوني للمتحاربين في حروب التحرير ولا مجال في هذا الصدد للخلط بين هذه المقاومة التي تقوم بها الشعوب التي تخضع للاحتلال والأنظمة العنصرية . وبذلك نجد أن حق التحرر الوطني وتقرير المصير قد مر بثلاثة مر احل رئيسية هي: المرحلة الأولي : كان يستخدم فيها الحق لأغراض استعمارية ولتوسيع المجالات

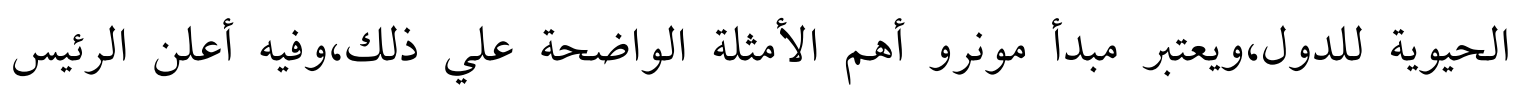

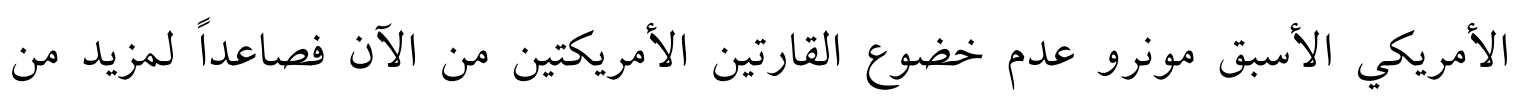

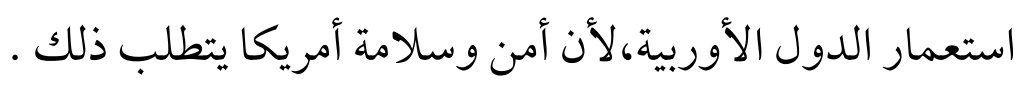
المرحلة الثانية : استخدام حق تقرير المصير للمحافظة علي الوضع الفعلي للدولة (1) انظر : د. حلمي، نبيل أحمد، الإرهاب الدولي وفقا لقواعد القانون الدولي العام ، المرجع السابق، ص99. 
التي اكتسب وضعا سياسيكا محدداً وتريد الإبقاء علي هذا الوضع،وفي العصر الحديث نبين أن الدول قد رسخت في أذهانها فكرة الاستقلال السياسي والسلامة الإقليمية،وتأيدت بفقه وقواعد القانون الدولي وبصفة خاصة ما يتعلق بمفهوم السيادة للدولة والمساواة بين الدول

$$
\text { وتحريم العدوان وحق الدفاع الشرعي · }
$$

المرحلة الثالثة : في هذه المرحلة استخدمته الشعوب التي فقدت استقلالها السياسي

و السيطرة علي مواردها الطبيعية،واستقر هذا الشكل بالنسبة للشعوب التي تقع تحت سيطرة

$$
\text { الاحتلال الأجنبي أو أي سيطرة أجنبية . }
$$

\section{الفرع الثالث الثمالث}

\section{الجهود الدولية لمكافحته تمويل الإرهاب الثاب}

من الأسباب التي تعوق عملية القضاء علي الإرهاب،وجود تمويل مالي للتنظمات الإرهابية تساعدها علي الاستمرار وتشجعها علي التقدم فيه .

وعلي الرغم من الجهود الكبيرة المبذولة دوليًا أوداخليًا لمكافحة الإرهاب إلا أن ظاهرة تمويله مازالت تثير جدلاً عالميًا واسعً لما تمثله من خطورة في دوام الإرهاب واستمراره،ولكن الضعف الواضح في تحقيق مصادر تمويله قد أثر بشكل كبير علي مدي فعالية مكافحته،ولذلك قامت الأمم المتحدة بجميع أجهزتها بمو اجهة هذه الظاهرة وإصدار (1) القرارات والاتفاقيات الدولية للقضاء عليها أولا :تعريف جريمة تمويل الإرهاب

فقد عرفت اتفاقية 1999 تمويل الإرهاب وسعت فيه فلم تقيده بتقديم الأموال بنيه

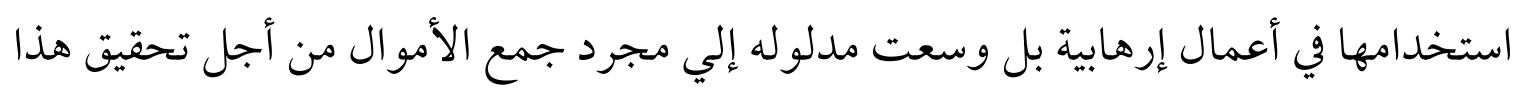

(1) انظر : د. بجبوج ،عمار تيسير، التعاون الدولي في مكافحة جر ائم الإرهـاب ، رسالة دكتوراه مقدمة إلي كلية

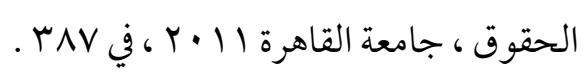


الغرض ويستوي لوقوع السلوك الإجرامي أن يتم تقديم الأموال أو جمعها بأية وسيلة كانت مباشرة أو غير مباشرة،وبشكل غير مشروع ويستوي أن تكون مصادر الأموال محل الجريمة

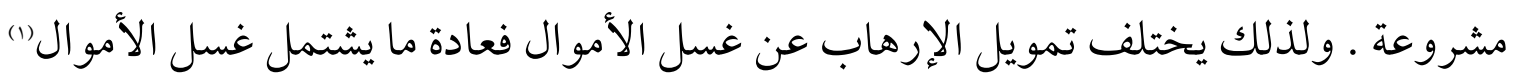

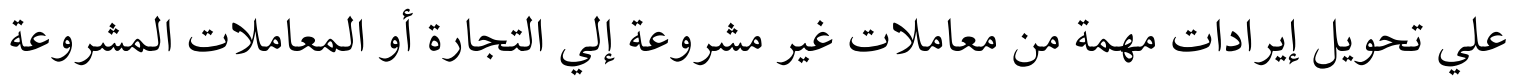
وهو ما لا يشترط في جريمة تمويل الإرهاب إذ يمكن أن يشتمل تمويل الإرهاب علي جمع

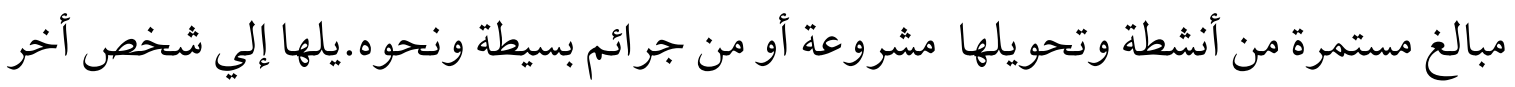

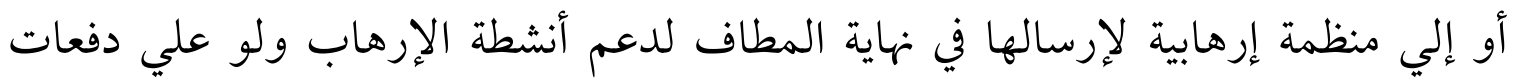
صغيرة ويستوي أن يصدر التمويل من أشخاص طبيعيين أو أشخاص معنويين وقد ثبت أن

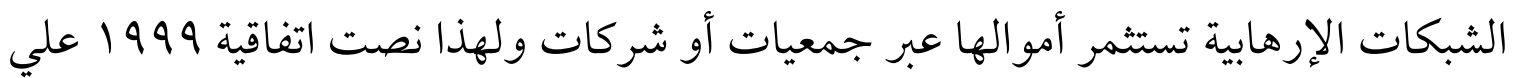
التزام الدول الأعضاء باتخاذ التدابير لانعقاد المسئولية الجنائية والمدنية والإدارية

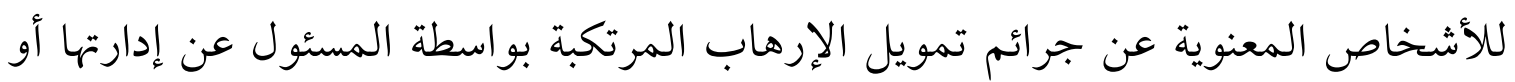

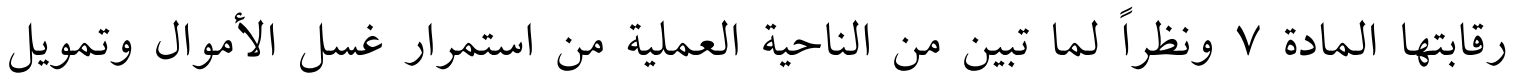

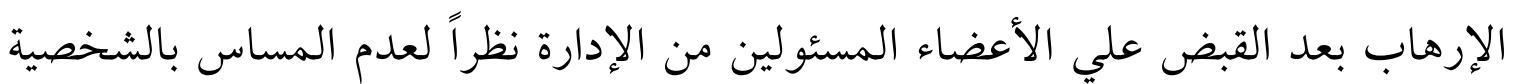
المعنوية للمشروع،فإن تدابير تجميد الأرصدة وضبطها ومصادرتها تحول دون تحقيق هذا

(r). الغرض

كما بذلت جهود إقليمية في هذا المضمار،فوضعت منظمة الدول الأمريكية اتفاقية

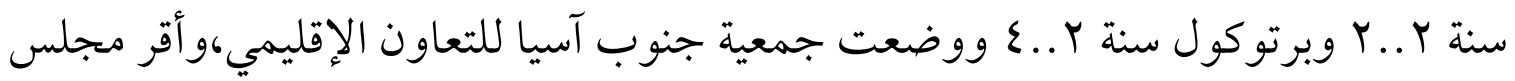

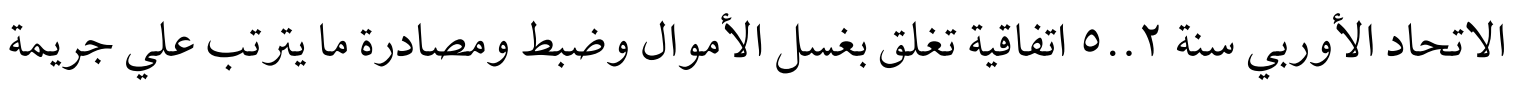

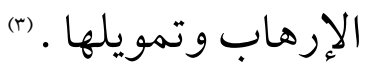

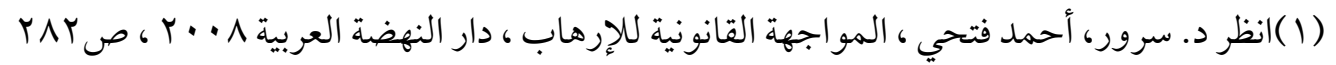

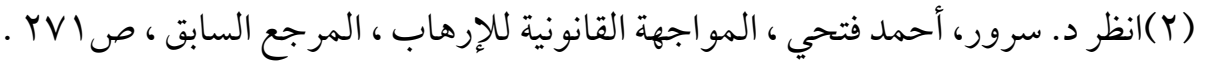

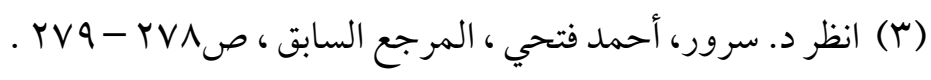




\section{المبحث الثاني \\ المنظمات الإقليمية ودور ها في مكافحة الإرهاب الإني}

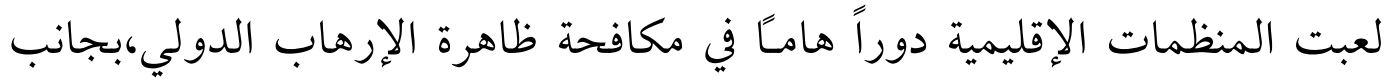

منظمة الأمم المتحدة،حيث أن المنظمات الإقليمية تستخدم دول العالم كافة،حيث أنها

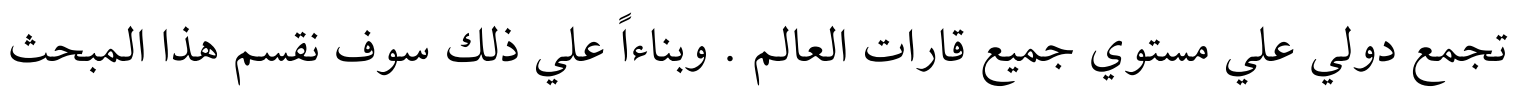

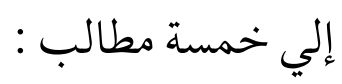

المطلب الأول : دور الاتحاد الأوربي في مكافحة الإرهاب .

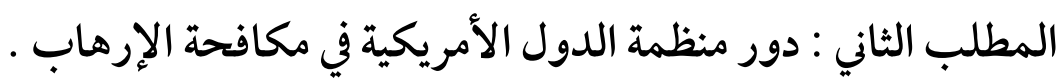

المطلب الثالث : موقف الاتحاد الأفريقي في مكافحة الإرهاب .

المطلب الرابع : موقف جامعة الدول العربية من مكافحة الإرهاب .

المطلب الخامس : موقف مجلس التعاون الخليجي من مكافحة الإرهاب .

\section{المطلب الأول}

\section{دور الاتحاد الأوربي في مكافحة الإرهاب}

بذلت الدول الأوربية جهوداً عديدة في مكافحة الإرهاب وقد أسفرت هذه الجهود

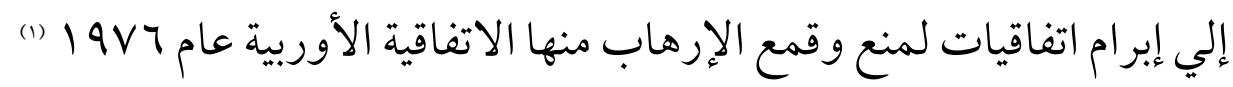

وقد نصت المادة الأولي منها علي تعريف الجرائم الإرهابية ـ ذلك بالنص علي

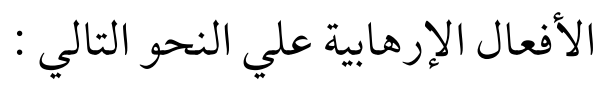

1- ما جاء من جرائم في اتفاقية لاهاي لسنة 9 الم بشأن الاستيلاء غير المشروع

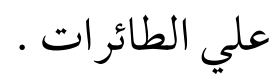

ץ - ما جاء ذكره من جرائم في اتفاقية مونتريال سنة الو 19Vا الخاصة بقمع الأعمال غير

(1) انظر د. زيان، مسعد عبد الرحمن، الإرهاب في ضوء القانون الدولي، مرجع سابق ، ص10. 
المشروعة ضد الطير ان المدني .

ץ- ما جاء ذكره من جرائم خطيرة تتضمن الاعتداء علي الحياة والسلامة الجسدية أو الحرية التي تكون موجهة ضد أشخاص يتمتعون بالحماية الدولية،وكذا الجرائم التي تشمل الخطف وأخذ الرهائن أو احتجازهم تعسفـًا.

\section{المطلب الثاني \\ دور منظمة الدول الأمـريكية في مكافحة الإرهاب}

أدي تزايد الأعمال الإرهابية في دول أمريكا اللاتينية وزيادة حالات العنف السياسي الموجهة ضد البعثات الدبلوماسية من اغتيال واعتداء وخطف حيث اتخذت الجمعية العامة لمنظمة الدول الأمريكية قراراً بإصدار اتفاقية لمنع وقمع الأعمال الإرهابية التي تأخذ شكل الجرائم ضد الأفراد وأعمال الابتزاز المتعلقة بها في دورتها الثالثة غير العادية في واشنطن عام 19V1) الشعوب الأمريكية وتشكل جرائم ضد الإنسانية،وأن الأهداف الأيدلوجية والسياسية لا

(1) يمكنها أن تنفي صفتها الإجرامية باعتبارها تمثل خرفًّا لحقوق الإنسان الأساسية وقد نصت المادة الثانية من هذه الاتفاقية علي أن الأعمال الإرهابية ضد الأفر اد تعتبر من أهم الجرائم التي يجب أن يكون هناك عقاب عليها لأنها تؤدي إلي آثار ذات طبيعة دولية أيا كان السبب في ارتكابها.(r) كذلك تنص المادة السابعة منها علي قيام الدول المتعاقدة . (r)

(1) انظر د. قطب، طارق محمد ، مكافحة الإرهـاب وتعويض ضحايا الحو ادث الإرهابية في النطاق الدولي

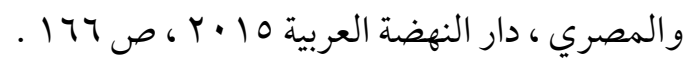

(Y) انظر : د. عبد الهادي، عبد العزيز مخمير، الإرهاب الدولي مع دراسة للاتفاقيات الدولية والقرارات الصادرة

$$
\begin{aligned}
& \text { عن المنظمات الدولية ، مرجع سابق صه بr؟. } \\
& \text { (r) انظر : المرجع السابق ، صعهץ . }
\end{aligned}
$$


بإدراج هذه الجرائم الإرهابية ضمن الجرائم الخاضعة للتسليم أثناء التوقيع علي معاهدات تسليم المتهمين القائمة أو اللاحقة ـ كما أكدت المادة الثامنة أنه علي الدول واجب اتخاذ التدابير الممكنة لمنع إعداد الجرائم المشار إليها في المادة سالفة الذكر فوق الإقليم الوطني ضد دولة أخري متعاقدة وأنه واجب علي الدول التعاون لمنع الجرائم السابقة وتبادل المعلومات وتنسيق الإجراءات . - المات

كما تضمنت المادة الخامسة من الاتفاقية بأنه لا يتم منع التسليم المطلوب بسبب احدي الجرائم المنصوص عليها في المادة الثانية نظراً لكون الشخص موضوع الطلب أحد رعايا الدول المطلوب إليها التسليم ولها الامتناع لأي مانع أخر دستوري أو قانوني ـ ولذلك فإن الدول المطلوب إليها تكون ملتزمة بعرض القضية علي السلطات الوطنية المختصة بهدف الملاحقة القضائية كما لو كان الفعل قد ارتكب في إقليمها،وتشمل هذه الجرائم الخطف والقتل ضد أشخاص وأفعال الابتزاز المرتبطة بهذه الجرائم وقرت الاتفاقية الحماية

للأشخاص المتمتعين بالحماية الخاصة وفقـا لقو اعد القانون الدولي . (1)

\section{المطلب الثالث}

موقف الاتحـاد الأفريقي مـن الإرهاب

أنشئت منظمة الوحدة الأفريقية الاتحاد الإفريقي حاليا في مايو عام ب7 9 (،وتم إعداد مشروع ميثاق للمنظمة في تلك الفترة حيث يتكون من ديباجة و بس مادة ولغاتها هي العربية والانجليزية والفرنسية،وتعتبر أديس أبابا عاصمة أثيوبيا مقراً لها ـ. وتقوم علي مجموعة من المبادئ التي تحقق وحدة وتضامن الشعوب الأفريقية (r) وعدم تعكير صفو العلاقات

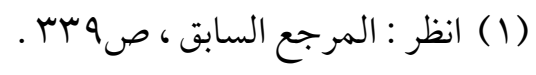

(Y) انظر :د زناتي ،عصـام محمـد أحمـد ، حماية حقوق الإنسـان في إطار الأمسم المتحـدة ، دار النهضـة العربية

$$
.790 \text {. } 1991
$$


بينها،وعدد أعضائها 7 ع دولة .

وقد لاقت وقاست دول الاتحاد من جراء العمليات الإرهابية من المآسي سواء من

الناحية المادية أو البشرية واقتصر الاهتمام بمكافحته داخليًا فقط دون أن يكون التنسيق علي المستوي الدولي علي الوجه المطلوب،"(1) ولكن التنسيق الإقليمي ظهر واضحَّ وبطريقة توافقيه وفقا لكل منظمة إقليمية من ناحية ومدي التنسيق والتعاون بين الأعضاء من ناحية أخري حيث نتج عن ذلك مؤتمر محاربة الإرهاب ومخاطر تصفية الشرعية الدولية مع انعكاساتها العربية والأفريقية في مارس r...r بمعهد البحوث والدراسات الأفريقية بجامعة القاهرة،وتم الاتفاق فيه علي ضرورة مواجهة الإرهاب وفقا للشرعية الدولية،وكذا الهيمنة التي تحاول أمريكا نصب شباكها علي جميع دول العالم بحجة محاربة الإرهاب وبصفة خاصة بعد أحداث سبتمبر Y... ا م والذي قرر فيه رئيسها جورج بوش بأنه من ليس مع أمريكا فهو ضدها،و لابد من محاربته لاعتباره أحد العناصر الإرهابية التي يجب محاربتها. وقد أصدرت منظمة الوحدة الأفريقية الكثير من القرارات لمكافحة الإرهاب . 1 - في عام ب999 كان القرار دعم التعاون والتنسيق بين البلدان الأفريقية من أجل

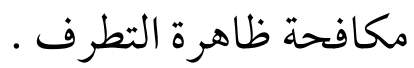
Y - عام ع999 انعقاد القمة الثلاثية لمنظمة الوحدة الأفريقية في تونس وصدر إعلان تحت عنو ان قانون السلوك حول العلاقات الأفريقية والتصدي للأعمال الإرهابية . r(r) عام 999 19 صدور اتفاقية الجرائر للوقاية من الإرهاب ومكافحته

(1) انظر د. قطب ، طـارق محمـد ، مكافحـة الإرهاب وتعويض ضـحايا الحـوادث الإرهابية في النطاق الدولي

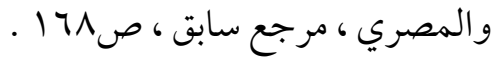

$$
\begin{aligned}
& \text { (Y) انظر : د زيدان، مسعد عبد الرحمن، الإرهاب في ضوء القانون الدولي المرجع السابق ، ص؟^ . }
\end{aligned}
$$


ع - عام r... إعلان بعض التجمعات الفرعية في القارة الأفريقية داكار مثل لاكوميا والساداك الإيكواس،والإيجاد،وغيرها عن شاجبيها وإدانتها للإرهاب الذي تعرضت له

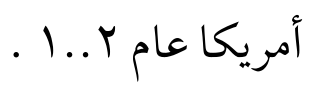

\section{المطلب الرابع موقف الجـامعة العـربية مـن الإرهاب الراب}

قامت جامعة الدول العربية في عام 19 1 بإصدار وثيقة إطار (1) العمل المشترك خلال الدور الحادي عشر لوزراء خارجية دول إعلان دمشق في البحرين حيث أكدت هذه الوثيقة علي : 1 - احترام الدول العربية مبادئ سيادة ووحدة الأراضي والسلامة الإقليمية .

$$
\text { r ץ - عدم جواز الاستيلاء علي أراضي الغير بالقوة }
$$

وفي عام 1990 جاء إعلان دمشق الصادر عن اجتماع وزراء الخارجية العرب عن الإدانة الكاملة للإرهاب،وضرورة التعاون الوثيق بين هذه الدول في مو اجهة ظاهرة التطرف والعنف لأنها تهدد الاستقرار والتنمية،وتتناقض مع جوهر الإسلام السمح،وخير مثال علي ذلك إدانة العمليات الإرهابية التي وقعت في المملكة العربية السعودية،ودولة البحرين آنذاك والذي خلف وراءه العديد من الأرواح البريئة . و الكثير من الجر في بالإضافة إلي ترويع الآمين،كما تضمن إعلان دمشق الدعوة إلي توحيد الجهود العربية لاستئصال هذه الظاهرة من جذورها .مؤكدين أن التطرف والعنف والإرهاب ظواهر عالمية غير مقصورة علي شعب

(1) انظر : د. إبر اهيم، حسين توفيق ، ظاهرة العنف السياسي في النظم العربية ، مركز دراسات الوحدة العربية ،

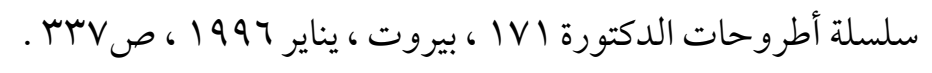


أو منطقة بعينها وعلي ضرورة التمييز بين المقاومة الوطنية المشروعة للاحتلال والعدوان

$$
\text { وبين العمليات الإرهابية . (1) }
$$

ورغبة في تعزيز التعاون بين الدول العربية لمكافحة الجرائم الإرهابية التي تهدد أمن

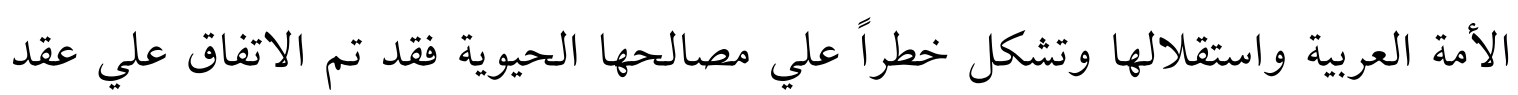
الاتفاقية العربية لمكافحة الإرهاب عام 991 (،داعية كل دولة عربية لم تشارك في إبرامها للإرهاب يمسح باستيعاب كافة الصور للعنف أو التهديد به،ولكنها استعدت من نطاق جرائم الإرهاب كافة حالات الكفاح المسلح ضد الاحتلال الأجنبي والعدوان من أجل التحرر وتقرير المصير وفقا للمبادئ القانون الدولي .

كما نصت علي عدم اعتبار الجرائم الإرهابية الواردة بالاتفاقية من قبيل الجرائم

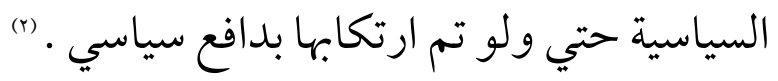
كما جاء بالاتفاقية أن الدول تتعهد بعدم تنظيم المتهمين أو المحكوم عليهم في الجرائم الإرهابية المطلوب تسليمهم من أي من هذه الدول وتعد هذه الاتفاقية من أهم إنجازات مجلس جامعة الدول العربية علي الإطلاق .) وفي نوفمبر Y..ع تم انعقاد المؤتمر العرب السابع لمكافحة الإرهاب،لوزراء الداخلية العرب والذي نوقشت فيه الإجراءات الواجب إتباعها لمكافحة الإرهاب وهي : 1 - متابعة قرارات الأمم المتحدة المتعلقة بمنع الإرهابيين من حيازة أسلحة الدمار

(1) انظر : مركز دراسات الوحدة العربية ، يوميات وثائق الوحـدة العربية ، بيروت ، لبنـان ، 1997 ، صبحج $.7 \Lambda$

(Y) انظر :د. قطب ، طارق محمد ، مكافحة الإرهاب وتعويض ضحايا الحوادث الإرهابية في النطاق الدولي

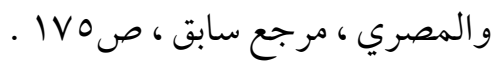

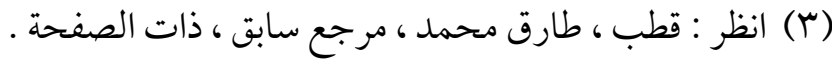




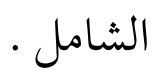

r - إحداث هيكل تنظمي عرب لمكافحة الإرهاب .

ب- إدانة الإرهاب الذي يستهدف بعض الدول العربية وخاصة السعودية وأحداث

$$
\text { الرياض الإرهابية . مابة }
$$

ع- التأكيد علي التميز بين الإرهاب والكفاح المسلح لمحاربة الاحتلال

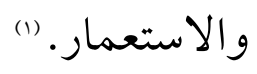

\section{المطلب الخامس \\ موقف مجلس التعاون الخليجي مـن الإرهاب الـابل}

في عام Y..T تم تشكيل لجنة أمنية دائمة مختصة بمكافحة الإرهاب تعقد اجتماعاتها

بشكل دوري ، وفى مجال تعزيز التعاون والجهود بين دول المجلس مع حالات النزوح

البشرى عند الحروب أو الكوارث الطبيعية فقد تم فى الاجتماع السابع والعشرين لوزراء

الداخلية بدول المجلس إقرار الخطة المشتركة لمواجهة حالات النزوح البشرى الطارئة ،

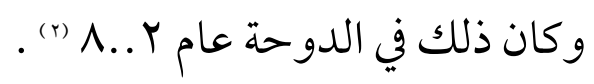

وانطلاقا من النظام الأساسي لمجلس التعاون الخليجي بشان مكافحة الإرهاب والذي يدعو إلى نبذ العنف والإرهاب بكل أشكاله وصوره ، وفى إطار المسؤولية الجماعية في المحافظة على الأمن والاستقرار واقتناعا بان الإرهاب لا يمكن تبريره ولابد من مكافحته والقضاء عليه فقد اتفقت هذه الدول على عقد اتفاقية لدول مجلس التعاون لدول الخليج

( ) وثائق المؤتمر العرب السابع لوزراء الداخلية العرب لمكافحة الإرهـاب المنعقد في تونس خلال الفترة من

$$
\text { . }
$$

(Y) انظر د قطب، طارق محمد ، مكافحة الإرهاب وتعويض الحوادث الإرهابية وتعويض ضحايا الإرهابية في

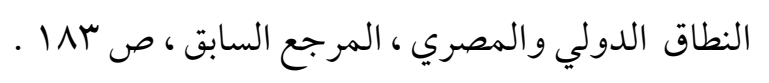


العربية لمكافحة الإرهاب مكونة من خمسون مادة حيث قامت بتعريف كل من الإرهاب والجريمة الإرهابية (') . حيث جاء بها أن الإرهاب (هو كل فعل من أفعال العنف أو التهديد

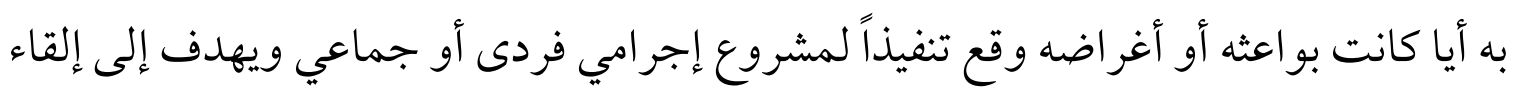

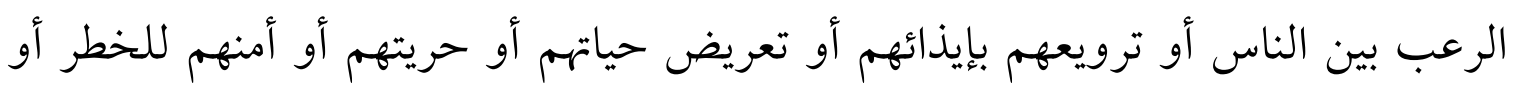

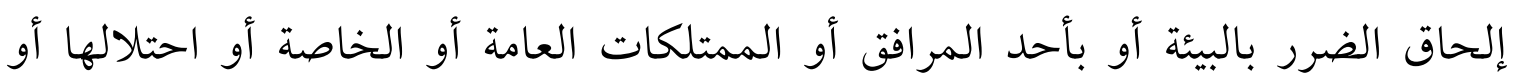
الاستيلاء عليها أو تعريض احد الموارد الوطنية للخطر .

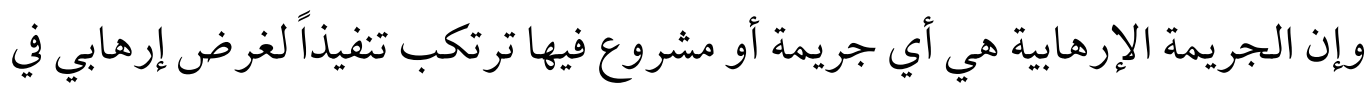

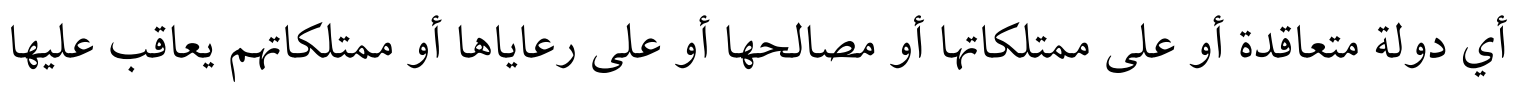

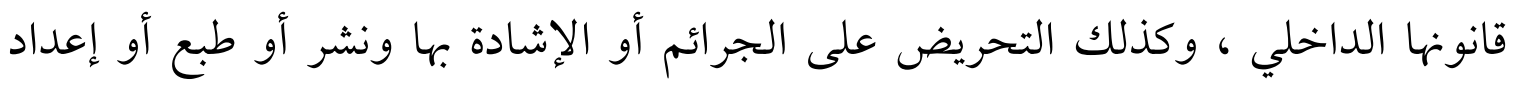

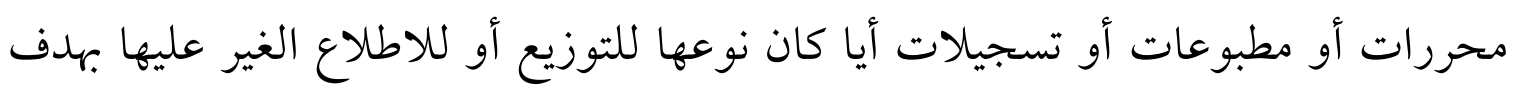
تشجيع ارتكاب تلك الجرائم ، ويعد جريمة إرهابية تقديم أو جمع الأموال أيا كان نوعها لتهيا لتمويل الجرائم الإرهابية مع العلم بذلك . 


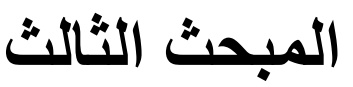 \\ مكافحة الإز هاب في الفقه الإسلامهي}

إذا كان من المتفق عليه أن الإرهاب يحمل في طياته عنصري الترويع والتخويف ، الهي التهي

فإن الإرهاب في الشريعة الإسلامية لا يخرج عن كونه عمليات عنف منظمة ينفذها أفراد ، أو جماعات ، أو دول للوصول إلى أهداف محددة مسبقًا - وبما أن الدين الإسلامي يرفض العنف والإرهاب ، ويحارب الجريمة ، باعتبارها مفسدة في الأرض تستوجب العقاب الدنيوي والأخروي .فانه يمكن ومنع الحرابة في الإسلام عن طريق القضاء على الأسباب التي تؤدى لإرهاب ، حيث أن الوقاية خيراً من المعالج - ويكون ذلك عن طريق .

وبناء على ذلك سوف نقسم هذا المبحث إلى سبع مطالب : المطلب الأول : تحقيق العدل والأنصاف بين كافة الأجناس .

المطلب الثاني : تعميق الاستنارة الدينية والتفكير العلمي في نفوس المسلمين · المطلب الثالث : الدور الإعلامي في الدولة الإسلامية في منع الإرهاب .

المطلب الرابع : تطبيق الشريعة الإسلامية في الجرائم الواقعة داخل الدولة الإسلامية. المطلب الخامس : قمع جر ائم الحرابة في الإسلام . المطلب السادس : تحقيق الأمن. المطلب السابع : حماية الضروريات الخمس •

\section{المطلب الأول \\ تحقيق العدل والأنصاف بين كافة الأجناس الون}

إن تحقيق العدل والمساواة بين كل البشر أيا كان دياناتهم أو جنسياتهم أو لغاتهم يساعد بشكل فعال ومؤثر في القضاء على مسببات ودوافع الإرهاب الدولي ، ويل والقضاء على التطرف بشكل عام ولعل ابلغ دليل على إن العدل يحقق الأمن والأمان بين ربوع الدولة 
الإسلامية قصة أمير المؤمنين الفاروق عمر بن الخطاب عندما جاءه رسول من ملوك إحدى

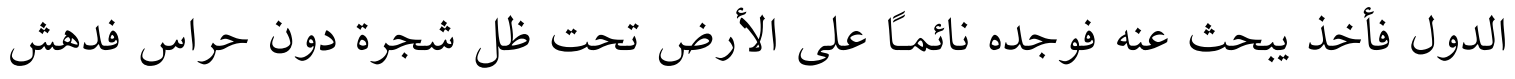
الرجل وقال لعمر ( حكمت فعدلت فأمنت فنمت يا عمر ) والعدل الذي مارسه سيدنا عمر رضي الله عنه كان بين الناس مسلمين وغير مسلمين ولقد قال الله عز وجل عن العدل ( إن الله يأمر بالعدل والإحسان وإيتاء ذي القربى وينهى عن الفحشاء والمنكر والبغي ) ولقد قال

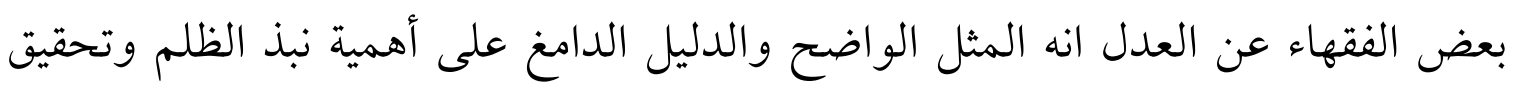

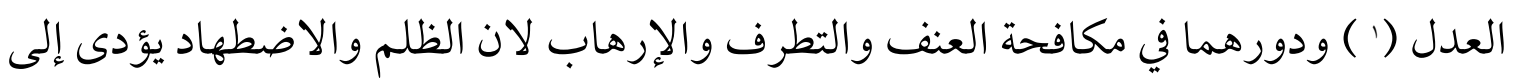

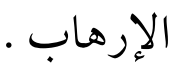

\section{المطلب الثاني تعميق الاستنارة الدينية والتفكير العلمي في نفوس المسلمين} ترجع كلمة الاستنارة في اللغة العربية إلى كلمة (النور ) ويعد العقل الإنساني مثل

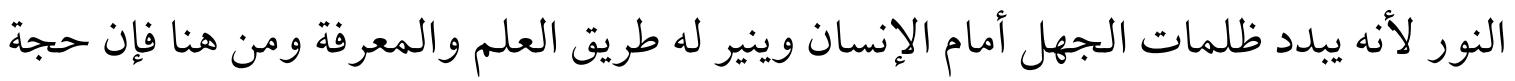
الإسلام الإمام الغزالي وصف العقل بأنه ( أنموذج من نور الله ) ( ) وعلى ذلك فالمقصود بالاستنارة الدينية هو أن نعمل العقل في فهم الدين وان نقرأ الدين في ضوء فهم العقل السليم ، والدين الإسلامي لا يتعارض مع مفهوم الاستنارة الدينية بل العكس يتطابق معها ويؤيدها

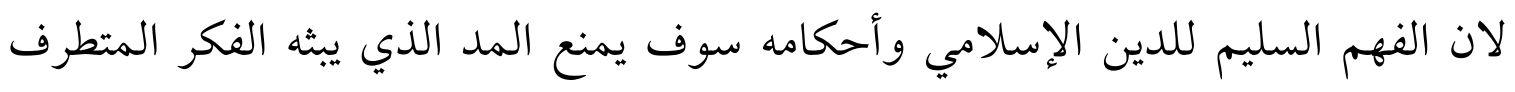
الداعي للعنف والإرهابي عقول المنغلقين الذين لا يعملون عقولهم في إدراك حقيقة الدين الإسلامي النابذ للعنف والإرهاب والحرابة وقد قال الشيخ محمد عبده عن العلاقات بين العقل والدين أن ( العقل يجب أن يحكم كما يحكم الدين فالدين عرف بالعقل ولابد من

(1) انظر : الماوردى ، أدب الدنيا والدين ، الجزء الثاني ، مطبعة دار الشعب ، القاهرة ، ص ع ؟Y.

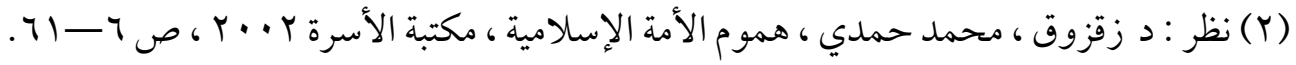


اجتهاد يعتمد على العقل والدين حتى نستطيع أن نواجه المسائل الجديدة في المدنية

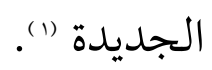

وقال عنها أيضا حجة الإسلام الإمام الغزالي أن ( العقل كالأساس والشرع كالبناء ولن يغنى أساس ما لم يكن هناك بناء ، ولن يثبت بناء ما لم يكن له أساس ، فالشرع عقل من خارج و العقل شرع من داخل ، وهما متعاضدان بل متحدان )(r) . أما التفكير العلمي فيعنى إرجاع الظواهر إلى أسبابها الحقيقية لا الأسباب الوهمية وذلك عن طريق التفكير الجاد المنظم الذي يسير وفق منهاج علمية للوصول إلى غاية علمية محددة والإسلام بوجه عام حث المسلمين على التفكير العلمي يوم القيامة ( إن السمع و البصر كل أولئك كان عنه مسئولاً ) (م) بل جعل عدم استعمال العقل ذنب من الذنوب يسال

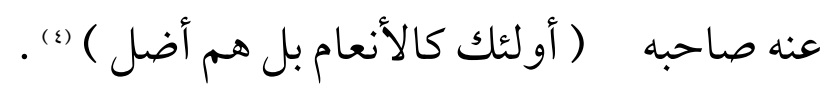

\section{المطلب الثالث الدور الإعلامي في الدولة الإسلامية في منغ الإرهاب}

يجب على وسائل الإعلام المختلفة في الدول الإسلامية أن تلعب دوراً أكثر حيوية جدية في توعية المسلمين بخطورة جرائم الحرابة والإرهاب على كافة صورها على المجتمع الإسلامي وعلى المجتمع الدولي بصفة عامة وان تذكرهم بشكل دائم ومستمر بمدى جسامة العقوبة على المحاربين في الإسلام ومدى انتهاك المحاربين لأوامر الله عز وجل وسنة سيدنا محمد صلى الله عليه وسلم لابد أن تعلم وسائل الإعلام المختلفة سواء المسموعة والمرئي

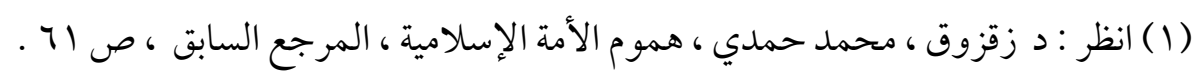

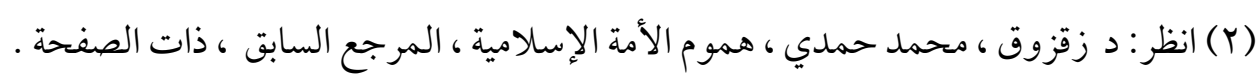

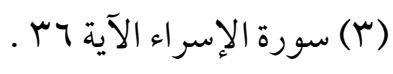

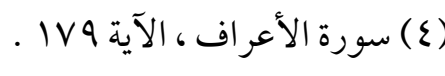


والمقروءة منها المسلمين في كل بقاع الدول الإسلامية أن المحاربين ينتهكون بجرائمهم عقود الذمة وعقود الأمان التي اقرها الإسلام لصالح غير المسلمين المقيمين إقامة دائمة (- عامة أهل الذمة ) أو إقامة مؤقتة ( المستأمنين ) بها لابد أن يبذل رجال الدين ورجال الدعوة الإسلامية جهوداً مضاعفة لتوضيح وبيان جزاء من ينتهك حرمات الله سبحانه وتعالى ويتعدى على حدوده ( ومنها حد الحرابة ) ويوضحو اللحاكم والسلطات في الدولة الإسلامية ضرورة إقامة حدود الله عز وجل على المحاربين لان عقوبتهم من الحدود التي لا يجوز العفو فيها لان فبإقامتها عبادة لله سبحانه وتعالى وفى تركها وإهمالها معصية وان هذه الحدود هي حمى الله عز وجل شأنه ومن حام حول الحمى أوكأن يقع فيه ، لكن الواقع للأسف الشديد على عكس ذلك حيث بالغت وسائل الإعلام المختلفة في الدول الإسلامية ولا سيما التلفاز في مسلسلاته المتعددة رسم صورة الإرهاب المحارب ( الإرهابي ) من حيث إطلاق اللحية وارتداءه الجلباب الأبيض القصير ومن تحته السروال الأبيض الطويل بحيث أنها جعلت من يطبق سنة رسول الله صلى الله عليه وسلم إنما هو الإرهابي ( المحارب ) فكان ذلك تأكيداً دون قصد وبجهل من جانبهم بما يدعيه الغرب وأعداء الإسلام على المسلمين بأنهم الإرهابيون وهم وراء جرائم الإرهابي في كل بقاع العالم لابد من تصحيح مسار الدور الإعلامي في الدولة الإسلامية واستخدامه في توعية المسلمين بالإرهاب وخطورته على الأمن والسلام في الدولة الإسلامية وبالأعم لابد من تصحيح مسار الإعلام الإسلامي لاستخدامه بشكل يكون منافعه أكثر من مضاره وهذا ما لا يحدث الآن ، فالأعلام على اختلاف أشكاله وصوره يقدم أسوأ مثل للمسلمين في الدولة الإسلامية من كافة صنوف وأنواع الانحلال الخلقي والفكري وإهمال بشكل مطلق للبرامج الإسلامية بل وتعمد إذاعة 


\section{هذه البرامج في مواعيد متأخرة من الليل فلا يشاهدها إلا القليل من المسلمين "( .

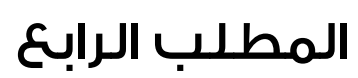 \\ تطبيق الشـريعة الإسلامية في الجـرائم الواقعة داخل الدولة إلـة الإسلامية ميجة المرية}

إن تطبيق شرع الله عز وجل أتى به الإسلام هو أمر واجب بحكم الكتاب والسنة النبوية على الحاكم المسلم ، وقد وصف جل شأنه الذين لا يحكمون بما أنزل الله تارة بأنهم الظالمون وتارة أخرى بأنهم الفاسقون وتارة ثالثة بأنهم الكافرون ولا شك أن تطبيق حد الحرابة على المحاربين كما ورد في كتاب الله عز وجل وذلك كعقوبة سماوية هي حماية للمجتمع ووسيلة من وسائل منع الحرابة لدى كثير ممن يفكرون فى محاربة الله ورسوله بإشاعة الرعب والفزع في العالم ، وتعد هذه العقوبة نوع من تدابير حماية المجتمع الإسلامي وغيره من المجتمعات لا سيما عندما نكون بصدد تطبيقها على المحاربين الذين لهم خطورة إجرامية وخطر اجتماعي على المجتمع الإسلامي بأسره (' ) وبذلك يكون الهدف من تطبيق العقوبات ( الحدود) على المحاربين من قتل وقطع للأيدي والأرجل من خلاف وصلب ونفى ( حبس ) حسب كل حالة من حالات الحرابة ليس فقط تطبيق حدود الله عز وجل التي لا شفاعة فيها ولا عفو وإنما أيضا تحقق المنع والوقاية من وقوع هذه الجرائم مستقبلاً في الدولة الإسلامية التي ينبسط عليها حكم الإسلام وسلطان الحاكم المسلم وفى هذا الصدد قال ( مارك انسل )أن القانون الإسلامي منذ بداية الإسلام فيما عدا الجرائم الخمسة الكبرى التي حددها الإسلام في القرآن الكريم اهتم بتدابير حماية المجتمع وأعطى للمحاكم الحرية

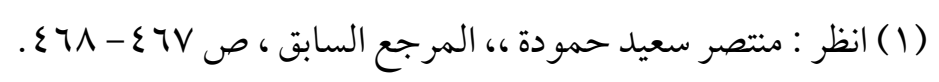

(r) انظر :على عزت بيجوفيتش ، الإسلام بين الشرق والغرب ، مجلة النور الكويتية ، مؤسسة بافاريا ، بدون

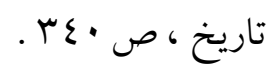


في بعض الجرائم بحيث تأخذ فى اعتبار ها الجريمة وظروف ارتكابها وشخصية مرتكبها (1) .

\section{المطلب الخَامس قمع جـرائمم الحـرابة في الإسلاهم}

لقد جاء الإسلام بأروع تشريع جنائي في مجال معاقبة المحاربين وجعل من الحرابة أشد جريمة في الإسلام لأنها تتضمن محاربة الله سبحانه وتعالى ورسوله سيدنا محمد صلى الله عليه وسلم ، واعتداء على حدوده ، وإثاعة الفزع و الرعب في ربوع العالم ، وهدماً للكليات الخمس التي دعا الإسلام للحفاظ عليها وهى النفس، والدين ، والعقل ، والنسل ، لذلك جاء الجزاء من جنس العمل ومتناسباً مع خطورة الإرهاب والإرهابيين · لذلك لابد أن يعاقب الحاكم المسلم هؤلاء المحاربين ولا يجب أن تأخذه بهم شفقة لأنهم يرتكبون أبشع الجرائم ، وأقساها في الإسلام ، وبذلك يكون من ضمن أهداف قمع الحرابة وتوقيع هذه العقوبات على الإرهابيين هو إعادة ما يسمى بالتوازن الأخلاقي الذي أخل به ارتكاب المحاربين لجرائهم ، فالعقوبة وان لم تنفى الإثم والذنب كما قال (هيجل )(r) فأنها تعد استجابة أخلاقية ودينية ضد عمل غير أخلاقي وغير ديني ، كما ان الحرابة تعد اعتداء على حدود الله ونو اهيه وهذا يستدعى غضبة ، وبالتالي فان تطبيق عقوبتها على المحاربين والتي نادي به الإسلام يعد جزءاً ثابتاً في مفهوم العدالة في الشرع والقانون(م) كما أن توقيع العقاب على المحاربين هو إعادة للحقوق المالية لأصحابها التي نهبها وسلبها

(1) انظر : على عزت بيجوفيتش ، الإسلام بين الشرق والغرب ، مجلة النور الكويتية ، مؤسسة بافاريا ، المرجع

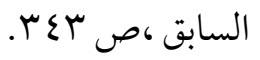

(Y) انظر : على عزت بيجوفيتش ، الإسلام بين الشرق والغرب ، مجلة النور الكويتية ، مؤسسة بافاريا ، المرجع السابق ، ذات الصفحة . (r) انظر : المرجع السابق ،ص r r r. 


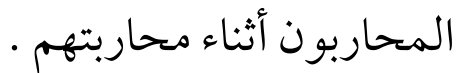

\section{المطلب السادس تحقيق الأمـن}

من أجل القضاء على أشكال الإرهاب ، وتحقيق الأمن والاستقرار ، نجد أن لإسلام يعمم الأمن ويوسع مساحته ، ويمد ظلاله ليشمل كل نواحي الحياة البشرية ، اجتماعيا واقتصاديا وسياسيا ، فيجب تحقيق الأمن من الخوف في المسكن كما في الطريق ، وفى مكان العمل وهكذا ، ويجب أن يكون الفرد أميناً على ممتلكاته أيضا فضلا عن تحقيق أمنه في غذائه ، إذ لا قيمة لتحقيق الأمن على الأرواح ، دون تحقيق الأم نفي غذاء الناس ومعاشهم (1)

فالإسلام قد ربط بين ظاهرتين متلازمتين ، تكمل أحداهما الأخرى ، هما سد الاحتياجات الاقتصادية للإنسان ، وتوافر الطمأنينة والسكينة والاستقرار ، فانتشار الأمن في بلد ما يكون مدعاة إلى تحقيق التنمية الاقتصادية ، كما أن توافر التنمية الاقتصادية ، يعد عاملاً أساسياً من عوامل السكينة والأمن ، لذلك قال الصحابي الجليل أبو ذر الغفاري : ( عجبت لمن لا يجد القوت في بيته ، كيف لا يخرج على الناس شاهر ا سفيه ) (r) . والإرهاب المعاصر قد تكون له أنماط أخرى ، ويحارب ضحاياه ويستهدفهم بوسائل عديدة ،لذلك فان الإسلام يقرر شمولية الأمن ، وتغطيته لجميع تلك الأنماط ، وسد

(1) انظر : د محمد بن محمد سعيد الشعيبى ، الإرهاب في الإقليم البرى وفقَّ للاتفاقيات الدولية والقانون اليمنى وأحكام الشريعة الإسلامية ، مجلة بحوث جامعة تعز ، سلسلة الآداب والعلوم الإنسانية ، العدد الرابع ، . IVA

(Y) انظر : د أبو الوفا ، احمد ، الشريعة الإسلامية وظاهرة الإرهاب الدولي ، مجلة البحوث والدراسات العربية ، البهات

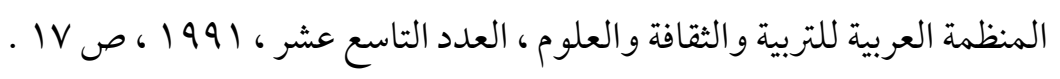


جميع الأبواب بوجه الإرهاب (1) ، فالرسول محمد صلى الله عليه وسلم يقول ( من أصبح

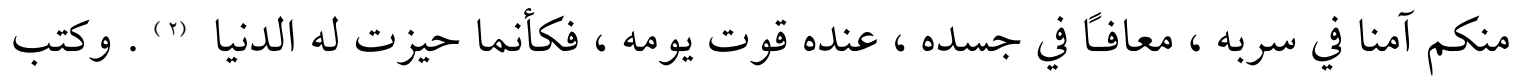
الإمام ابن حزم في رسائله ( الوجع والفقر والنكبة والخوف ، لا يحس آذاها إلا من كان فيها ، ولا يعلمها من كان خارجا عنها .. الأمن والصحة والغنى ، لا يعلمها من كان خارجا عنها ،

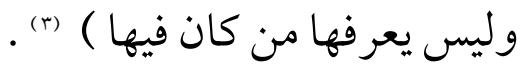

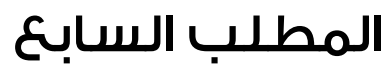 حماية الضروريات الخمس الغس}

والضروريات الخمس هي ـ حفظ الدين وحفظ النفس وحفظ العقل وحفظ العقل وحفظ العرض وحفظ المال ،فأحكام الشريعة الإسلامية تدور جول تحقيق هذه الضروريات() ، التي لا يمكن حمايتها ، أو صيانتها إلا بمحاربة الأفعال أو الجرائم التي تنال

(1) انظر : : د محمد بن محمد سعيد الشعيبى ، الإرهاب في الإقليم البرى وفقًا للاتفاقيات الدولية والقانون

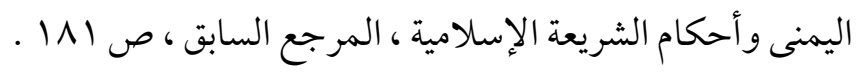

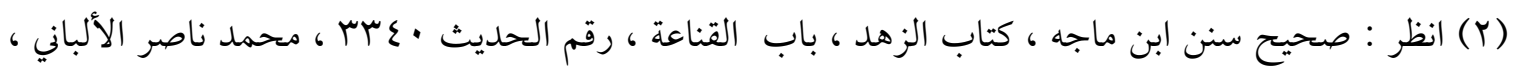

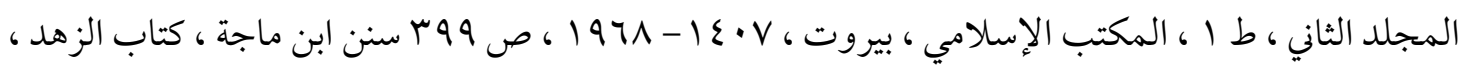

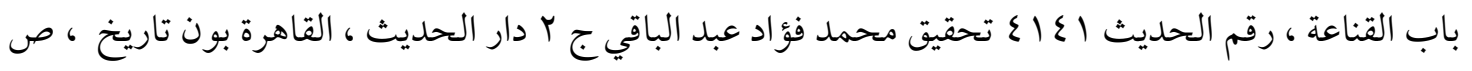
. ITNV

(r) انظر : رسائل ابن حزم الأندلسي، ج ا تحقيق د إحسان عباس ، المؤسسة العربية للدراسات والنشر ، بيروت، . $r \leqslant q ص$

(ع) انظر : الإمام أبى حامد محمد بن محمد بن محمد الغزالي ، المستصفى من علم الأصول ، جا ،ط ، 1 ، كال

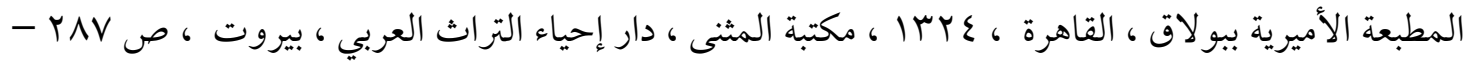


منها (1) . فجرائم التخريب التي تستهدف الناس في عقائدهم ، أو في أرواحهم ، أو في عقولهم ، أو أعر اضهم ، جميعا من الفساد في الأرض الذي يحرمه الإسلام ، قال تعالى ( ومن الناس من سن يعجبك قوله في الحياة الدنيا ويشهد الله على ما في قلبه وهو ألد الخصام وإذا تولى سعى فى الأرض ليفسد فيها ويهلك الحرث و النسل والله لا يحب الفساد ) (r) . فهذه الآيات الكريمة ، تجعل حب الفساد صفة دميمة مبغوضة لمن لا خلق له ، ومما يبغضه الله سبحانه وتعالى ، فهو أحرى بأن تجند له النصوص والأحكام والزواجر (r) .

ومعنى المحافظة على كل ما تقدم ، وحمايته وشجب الاعتداء عليه ، أن الإسلام

يسلب الإرهاب موضوعه الذي ينصب عليه في خرقه ، أو تهديده للضروريات الخمس ، ومن ثم ، فهو أي الإسلام لا يقره ولا يشجعه ، ولا يدعو إليه () . وكيف لا يكون كذلك ، إذا كان من أساليبه في مكافحة الجريمة ، حثه الناس على ضرورة أخذ العبر والنظر فيمن يقوم بارتكاب أفعال إجر امية ، أو إرهابية قال تعالى : ( قل سيروا في الأرض فانظر كيف كان عاقبة

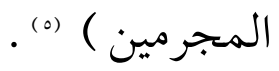

(1) انظر : دزيدان ، عبد الكريم ، المدخل لدراسة الشريعة الإسلامية ، ط V ، مؤسسة الرسالة ، ، به ابيروت،

$$
\begin{aligned}
& \text { ص ص }
\end{aligned}
$$

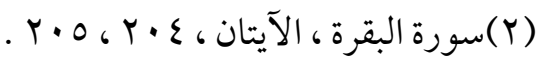

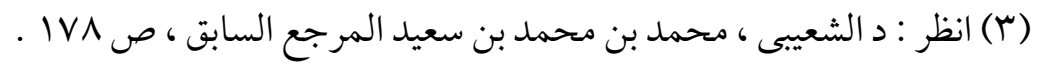

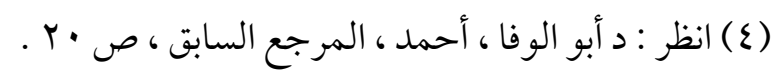

$$
\begin{aligned}
& \text { (0) سورة النحل ، الآية ، } 79 .
\end{aligned}
$$




\section{الخاتمـــة}

وهكذا قد انتهينا من موضوع البحث تحت عنوان الإرهاب الدولي أسبابه وطرق مكافحته في القانون الدولي العام والفقه الإسلامي "دراسة مقارنة". وقد قسمنا هذا البحث إلى ثلاثة فصول تناولنا في الفصل الأول ماهية الإرهاب وتميزه في القانون الدولي والفقه الإسلامي، من خلال ثلاثة مباحث تناولنا في المبحث الأول تعريف الإرهاب في القانون الدولي والفقه الإسلامي ، وتناولنا في المبحث الثاني تميز الإرهاب عن المقاومة الشعبية المسلحة في القانون الدولي والفقه الإسلامي ، وتناولنا في المبحث الثالث تميز الإرهاب الدولي عن الدفاع الشرعي في القانون الدولي والفقه الإسلامي . ثم انتقلنا إلى الفصل الثاني تناولنا فيه أسباب الإرهاب الدولي في القانون الدولي والفقه الإسلامي من خلال مبحثين تناولنا في المبحث الأول أسباب الإرهاب الدولي في القانون الدولي ، كما تناولنا في المبحث لمث لفي الثاني أسباب الإرهاب الدولي في الفقه الإسلامي ثم انتقلنا إلى الفصل الثالث وتناولنا فيه طرق مكافحة الإرهاب في القانون الدولي والفقه الإسلامي من خلال ثلاثة مباحث تناولنا في المبحث الأول دور المنظمات الدولية في مكافحة الإرهاب ، وتناولنا في المبحث الثاني المنظمات الإقليمية ودورها في مكافحة الإرهاب ، كما تناولنا في المبحث الثالث مكافحة

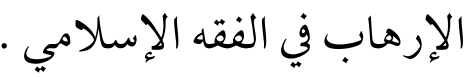

\section{وقد انتهينا إلى النتائج والتوصيات الآتية:}

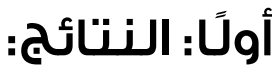

1- أن الإرهاب الدولي ظاهرة عالمية ولا يقتصر على أعمال العنف فقط وإنما هناك

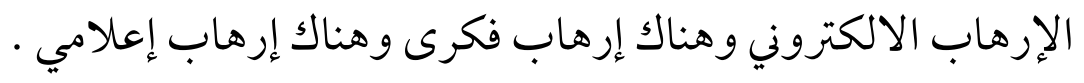

r - أن الإرهاب يختلف عن بعض الأفعال الأخرى التي قد تختلط به وهى المقاومة المسلحة من اجل تقرير المصير والتخلص من الاستعمار ،وعن الدفاع الشرعي للرد الاعتداء. 
r- هناك أسباب ودوافع مختلفة تؤدى إلى الإرهاب وهذه الأسباب والدوافع قد تكون

$$
\text { سياسية أو اقتصادية أو دينية أو إعلامية أو تاريخية أو شخصية . }
$$

0 - تتعدد صور وأشكال الإرهاب مثل اختطاف الطائرات والسفن ، والأعمال التخريبية ،

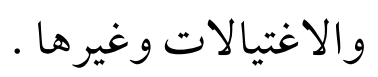

7 - يوجد جهود دولية عديدة لمكافحة الإرهاب من المنظمات الدولية مثل الأمم المتحدة متمثلة في القرارات التي تصدر من مجلس الأمن أو من الجمعية العامة للأمم المتحدة . أو المنظمات الإقليمية مثل الاتحاد الأوربي أو الاتحاد الأفريقي أو جامعة الدول العربية

$$
\text { أو مجلس التعاون الخليجي · }
$$

V - إبرام العديد من الاتفاقيات الدولية سواء الثنائية أو الجماعية أو متعددة الأطراف و الخاصة بمكافحة الإرهاب . وكذلك سن التشريعات الوطنية للمكافحة الإرهاب . V- أن جريمة الحرابة في الفقه الإسلامي تتفق مع جريمة الإرهاب في الوقت الحاضر ، ومن عدة أوجه وهى بالطبع تحمل صفات الأعمال الإرهابية في غالبيتها. ^ أن الدفاع الشرعي في القانون الدولي العام يتفق مع الدفاع الشرعي في الشريعة الإسلامية

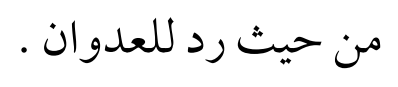
9 - أن الشريعة الإسلامية قد وضعت مجموعة من الأسس والمبادئ لمكافحة الإرهاب

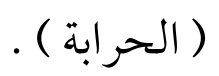

\section{ثانياً : التوصيات :}

1- تفيل دور المؤسسات الدينية في توصيل الفهم الصحيح للدين سواء في المساجد أو عن طريق ندوات بالجامعات والمدارس ووضع رقابه من المؤسسات الدينية علي القنوات الفضائية وذلك لما نلاحظ من فتأوي دينية من غير المتخصصين مع تطوير المناهج الدراسية في الدراسات الدينية بالمدارس ووضع مادة للثقافة الإسلامية كمادة 


$$
\text { عامة في التعليم الجامعي . }
$$

r- إنشاء مر اكز بحثية خاصة لمكافحة الإرهاب وذلك للتعرف على أسباب ودوافع

$$
\text { الإرهاب ووضع طرق لمكافحته . }
$$

ب- إبرام الاتفاقيات بين مختلف الدول وذلك بشأن تسليم المجرمين مرتكبي الجرائم

$$
\text { الإرهابية ، وكذلك للتبادل المعلومات عن الجرائم الإرهابية . }
$$

ع - وضع تشريعات وطنية للجرائم الإرهابية ، ووضع عقوبات مشددة وصارمة للقضاء

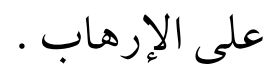

0- القضاء على البطالة ، ووضع برامج تثقفيه للشباب عن طريق وزراه الشباب للتوعية

للسعي على إيجاد أعمال لهم بعيداً عن الوظائف الحكومية التي تثقل أعباء الدولة ،

وإرشادهم بكيفية إقامة مشروعات خاصة . 


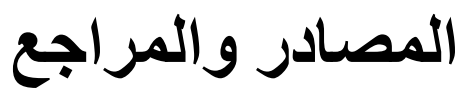

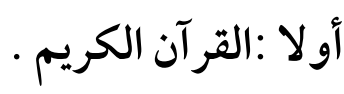

ثانيًاً : المعاجم :

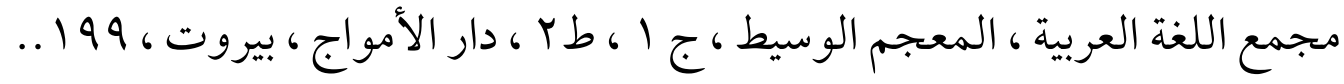

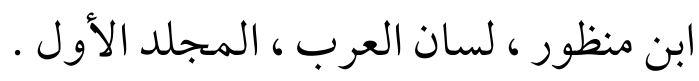

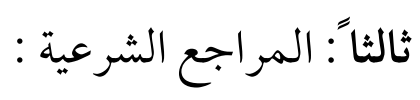

الإمام علاء الدين أبى بكر مسعود الكاسانى ، بدائع الصنائع في ترتيب الشرائع ، الجزء

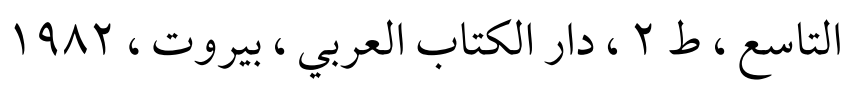

شرح الشيخ محمد الخطيب الشربينى على متن منهاج الطالبين للإمام أبى زكريا بن شرف النووي ، مغنى المحتاج إلى معرفة معاني ألفاظ المنهاج ، الجزء الرابع ، دار الفكر

$$
\text { بيروت، عYع ا - ب... }
$$

شمس الدين محمد بن أبى العباس احمد بن حمزة شهاب الدين الرملي المنوفي

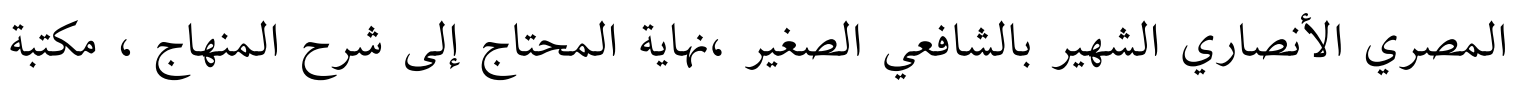

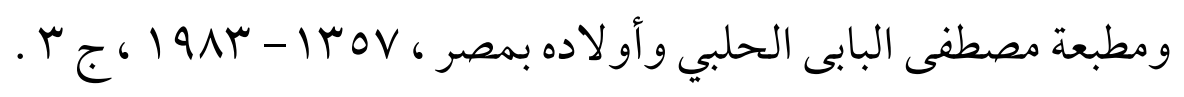

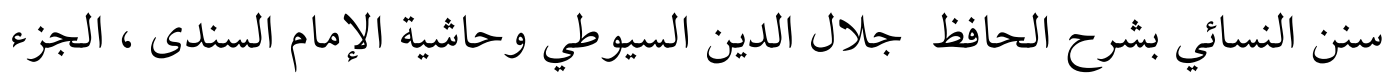

السابع ، دار البشائر الإسلامية ، بيروت ع 199 ، كتاب تحريم الدم ، باب التغليظ ، فيمن قاتل

تحت راية

$$
\begin{aligned}
& \text { سنن أبو دود ، كتاب السنة ، باب قتل الخوارج ، ، ج ع } \\
& \text { صحيح مسلم ، الجزء الأول ، كتاب الإيمان . }
\end{aligned}
$$

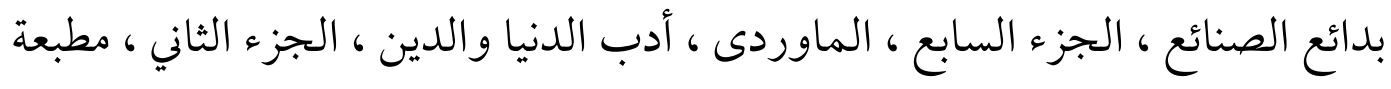

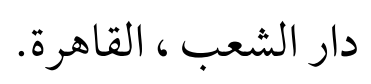


صحيح سنن ابن ماجه ، كتاب الزهد ، باب القناعة ، رقم الحديث ع سب.، محمد

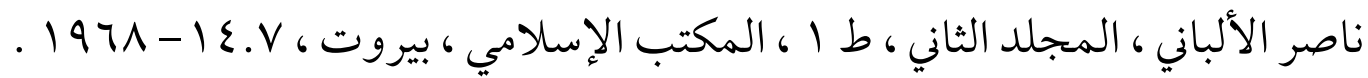

سنن ابن ماجة ، كتاب الزهد ، باب القناعة ، رقم الحديث إع إع تحقيق محمد فؤاد

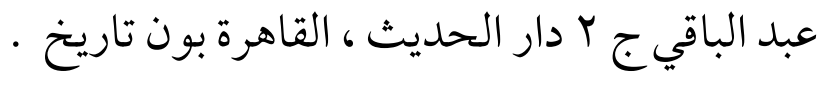

رسائل ابن حزم الأندلسي ، ج ا تحقيق د إحسان عباس ، المؤسسة العربية

$$
\text { للدراسات و النشر ، بيروت . }
$$

الإمام أبى حامد محمد بن محمد بن محمد الغزالي ، المستصفى من علم الأصول ،

ج) ،ط ، ا ، المطبعة الأميرية ببولاق ، القاهرة ، عبr| ، مكتبة المشنى، دار إحياء التراث

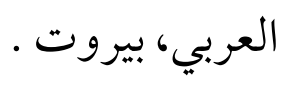

\section{رابعًا: الكتب العامة و المتخصصة :-}

د. العناني، إبراهيم،الأمم المتحدة،دراسة في ضوء النظام القانوني للمنظمات الدولية وأهم المشكلات العملية التي تواجها ب191ا. المنظمات الدولية،المطبعة الحديثةً 199V

د أحمد ، هلالي عبد الله ، أصول التشريع الجنائي الإسلامي 1990 1. د الجميلى ، خالد رشيد ، أحكام البغاة والمحاربين في الشريعة الإسلامية والقانون ،

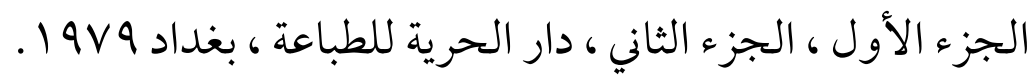
د الرشيدي ، أحمد،نحو مدخل موضوعي،لفهم ظاهرة الإرهاب وسبل التصدي لها،

$$
\text { مركز دراسات الشرق الأوسط،الأردن ؟..؟. }
$$

د. الشكرى ، علي يوسف ،الإرهاب الدولي في ظل النظام العالمي الجديد،الطبعة

$$
\text { الأولي، دار اينز اك للطباعة والنشر،القاهرة| }
$$

د الشعيبى ، محمد بن محمد سعيد ، الإرهاب في الإقليم البرى وفقـً للاتفاقيات 
الدولية والقانون اليمنى وأحكام الشريعة الإسلامية ، مجلة بحوث جامعة تعز ، سلسلة

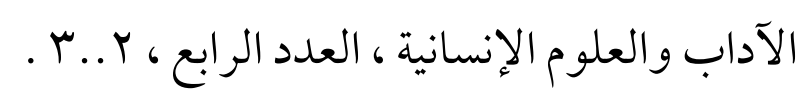

د.الغنيمى ، محمد طلعت ، الغنيمي الوسيط في قانون الأمم ، منشأة المعارف ،

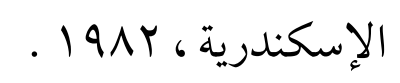

د المغربي ، عبد الحكيم على ، المشاركة في الحرابة وعقوبتها في الشريعة الإسلامية ، دار الطباعة المحمدية ، ط ا ، القاهرة ، س1919.

لواء دكتور / بوادي، حسنين المحمدي،الإرهاب الدولي تجريمًا ومكافحة،دار

$$
\text { المطبو عات الجامعية،الإسكندرية، الب..V. }
$$

بيجوفيش ، على عزت ، الإسلام بين الشرق والغرب ، مجلة النور الكويتية ، مؤسسة بافاريا ، بدون تاريخ

د بن عبد الله ، عبد الله بن مطلقُ الإرهاب وأحكامه في الفقه الإسلامي،دار بن

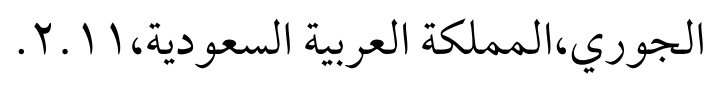

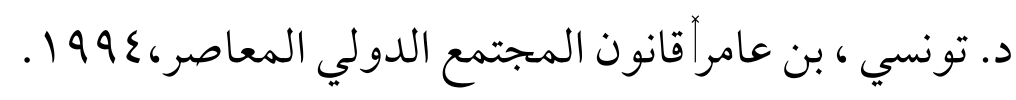

د. حسني ، محمود نجيب| دروس في القانون الجنائي الدولي،القاهرة، 197 ... د. . حلمي، نبيل أحمد ،الإرهاب الدولي وفقا لقواعد القانون الدولي العام،دار النهضة العربية،القاهرة،بدون تاريخ.

د. حمو دة ، منتصر سعيدا الإرهاب،جو انبه القانونية،وسائل مكافحته في القانون الدولي

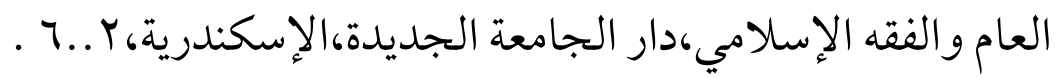
د. رفعت ،أحمد محمدا الإرهاب الدولي في ضوء أحكام القانون الدولي العام والاتفاقيات الدولية وقرارات الأمم المتحدة أدار النهضة العربية 1999 . د زناتي ، عصام محمد أحمدأحماية حقوق الإنسان في إطار الأمم المتحدة،دار النهضة 


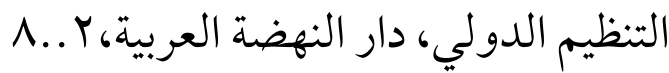

د زقزوق ، محمد حمدي ، هموم الأمة الإسلامية ، مكتبة الأسرة Y... Y.

د زيدان ، عبد الكريم ، المدخل لدراسة الشريعة الإسلامية ، ط V ، مؤسسة الرسالة،

$$
\text { (91 بيروت }
$$

د. زيدان ، مسعد عبد الرحمنج الإرهاب في ضوء القانون الدولي،دار الكتب

$$
\text { القانونية،المحلة الكبرى،Y. V. }
$$

د. سرور، أحمد فتحي،المواجهة القانونية للإرهاب،دار النهضة العربية Y.A ، ك.

p 1919

د.شكري، محمد عزيز،الإرهاب الدولي،دراسة قانونية نافذة،دار العلم للماليين،

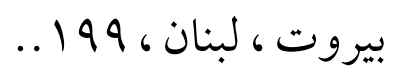

د. عبد الهادي ، عبد العزيز مخيمرا الإرهاب الدولي مع دراسة للاتفاقيات الدولية

والقرارات الصادرة عن المنظمات الدولية،دار النهضة العربية،القاهرة 1917

د. عبيد ، حسنين إبراهيم صالح،الجريمة الدولية،دار النهضة

العربية،القاهرة،9991القضاء الجنائي الدولي،تاريخه وتطبيقه ومشروعيته،دار النهضة

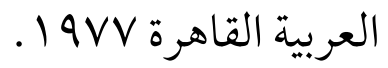

د. عز الدين ، أحمد جلال الإرهاب و العنف السياسي،كتابة الحريةج

د ـ غانم ، محمد حافظ، المنظمات الدولية $197 V$.

عودة ، عبد القادرة ، التشريع الجنائي الإسلامي مقارنًا بالقانون الوضعي ، الجزء

الثاني ، القسم الخاص ، ط Y، مكتبة دار العروبة .

د مصطفى الرافعي ، أحكام الجرائم في الإسلام ، الحدود و القصاص والتعزيز ، الدار 
الإفريقية العربية ، بدون تاريخ ·

الإمام محمد أبو زهرة ، الجريمة والعقوبة في الفقه الإسلامي ، الجريمة ، بدون تاريخ

محمد المبارك، نظام الحكم، الحكم والدولة، الطبعة الرابعة، دار الفكر 19191.

محمد بن حمد بن جزي الغرناطي المالكي ، قوانين الأحكام الشرعية ومسائل

$$
\begin{aligned}
& \text { الفروع الفقهية ، دار العلم للملايين ، بيروت ، } 1971 \text { ـ } \\
& \text { خامساً: رسائل الدكتوراه :- }
\end{aligned}
$$

د. إبراهيم ، حسين توفيقً ظاهرة العنف السياسي في النظم العربية،مركز دراسات

$$
\text { الوحدة العربية،سلسلة أطروحات الدكتورة IV I لبيروت،يناير } 1997 .
$$

د. بجبورج ،عمار تيسير،التعاون الدولي في مكافحة جرائم الإرهاب،رسالة دكتوراه

$$
\text { مقدمة إلي كلية الحقوق،جامعة القاهرة II ا. ب. . }
$$

د حسن ، عبد العزيز محمد محمد ، جريمة الحرابة وعقوبتها في الشريعة الإسلامية

والقانون الجنائي ، در اسة مقارنة ، رسالة دكتوراه ، كلية الحقوق ، جامعة القاهرة .

د. ـ صالح ، ويصا،العدوان المسلح في القانون الدولي،الجوانب القانونية الأساسية

لاستخدام القوة المسلحة في العلاقات الدولية،رسالة دكتوراهكلية الحقوق،جامعة

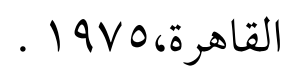

د.عامر، صلاح الدين،المقاومة الشعبية المسلحة في القانون الدولي العام،دار الفكر

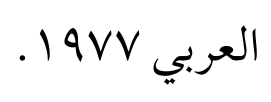

د.قطب ، طارق محمد،مكافحة الإرهاب وتعويض ضحايا الحوادث الإرهابية في

النطاق الدولي والمصري،دار النهضة العربية 10 ـ. .

$$
\text { سادساً: الدوريات والمجلات : }
$$

د أبو الوفا ، احمد ، الشريعة الإسلامية وظاهرة الإرهاب الدولي ، مجلة البحوث 
والدراسات العربية ، المنظمة العربية للتربية والثقافة والعلوم ، العدد التاسع عشر ، 1991 . د ابتسام، الجعفر اوي،التكلفة الاقتصادية للإرهاب،بحث منشور في الجملة الجنائية

القومية،المجلد الخمسون،العدد الأول،مارس Y...V.

د. المالكي ، عبد الحفيظ بن عبد اللهالإطار القانوني لمكافحة الإرهاب،مجلة البحوث الأمنية،مركز البحوث والدراسات بكلية الملك فهد الأمنية العدد مع،المجلد

د. العربي، نبيل عبد الله،الآثار القانونية لقرارات الجمعية العامة،المجلة المصرية للقانون الدولي،المجلد اسب، 19V0.

د.سرحان ،عبد العزيز محمد،حول تعريف الإرهاب الدولي وتحديد مضمومة -

$$
\text { المجلة المصرية للقانون الدولي - المجلد } 9 \text { ب - سVY 19. }
$$

د. راتب ، عائشة،مشروعية المقاومة الشعبية المسلحة،دراسات في القانون الدولي،المجلة المصرية للقانون الدولي ،العدد الثالث، 19V، . .

د. عوض، محمد محي الدين،دراسات في القانون الدولي الجنائي،مجلة القانون والاقتصاد، القاهرة،العدد الأول، 1970 ـ

د. فوده ، عز الدين،شرعية المقاومة المختلفة،دراسات في القانون الدولي،المجلة

$$
\text { المصرية للقانون الدول ي| العدد الأول } 1979 \text { ـ ـ }
$$

دمحمد ، البخدوي بحث نطق الطائرات منشور في مجلة معهد البحوث والدراسات

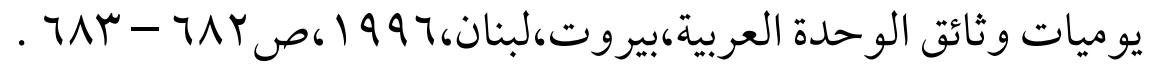

وثائق المؤتمر العرب السابع لوزراء الداخلية العرب لمكافحة الإرهاب المنعقد في 


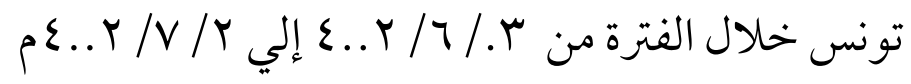

$$
\begin{aligned}
& \text { تاسعاً:المقالات : n } \\
& \text { الكتبى، سالم ،مقال بعنوان صراع التاريخ والجغرافيا بين العرب وإيرانا صحيفة } \\
& \text { العرب بتاريخ }
\end{aligned}
$$

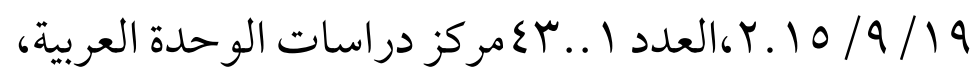

$$
\begin{aligned}
& \text { عاشراً: المراجع الأجنبية : }
\end{aligned}
$$

- Kelsen (h) the principle of international law - new york . 1966

- KELSQN (H) princi pler OF INTEQNATIONA LAW،NEW YOrK 1952 . P . 7...

- Kelsen $(\mathrm{H})$ international law studiee ce fecundity un der international washingytor 1957.

- Sottile A .leterrorisne international R.C.A.O Vol 651938

- aldana le terrorisne, revue international de droit penal 1936.

- David eric le terrorisme reue droit in relexionss vr definition et la lepression du terois me editions de iuniversite de - bruxelles bmuxelle p. 25 .

- $\quad$ Wilkinsan p. three question terrorisme in coverment and oppositian val .8 na 3 londan 1973 p.292 .

- Kelsen (h) the principle of international law - new york . 1966

- KELSQN (H) princi pler OF INTEQNATIONA LAW،NEW YOrK 1952 . P . 7...

- GUILAUME (G) LA CoNVENTION DE LA HAoYE DU 16 DECEMGbr 197. pOUr LA rlepession DE IACAPYUrE ILLICITE D AE MANFS rEVUEFfra DE nce AErIE 4. EANNE 1986 


\section{فهرس الموضو عات}

$11 \cdot 7$

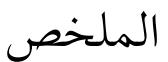

$11 \cdot 9$

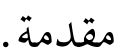

$111 \cdot$

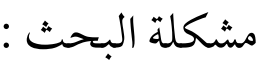

1111 أسباب اختيار الموضوع : ( )

1111 أهداف الدراسة : n

$111 r$ خطة البحث :

الفصل الأول ماهية الإرهاب وتميزه في القانون الدولي والفقه الإسلامي ..............

$111 \%$ تمهيد وتقسيم :

المبحث الأول تعريف الإرهاب الدولي في القانون الدولي والفقه الإسلامي ...... | 11 |...

1119 المطلب الثاني تعريف الإرهاب الدولي في الاتفاقيات الدولية .

$11 \mathrm{rr}$ المطلب الثالث تعريف الإرهاب في الفقه الإسلامي.

$11 r \mu$ الفرع الأول تعريف الحرابة في الفقه الإسلامي

$11 Y \varepsilon$ الفرع الثاني تعريف الحرابة في اللغة.

11 ro الفرع الثالث تعريف الحر ابة في الاصطلاح .

WYA الفرع الرابع جريمة الحرابة في الكتاب و السنة المبحث الثاني تميز الإرهاب الدولي عن المقاومة الشعبية في القانون الدولي والفقه ||$r \mid$ الإسلامي 
المطلب الأول تميز الإرهاب الدولي عن المقاومة الشعبية المسلحة في القانون الدولي ||$r \mid$

المطلب الثاني تميز الإرهاب الدولي عن المقاومة الشعبية المسلحة في الفقه الإسلامي 11ro.

المبحث الثالث تميز الإرهاب الدولي عن الدفاع الشرعي في القانون الدولي والفقه $111 \% 7$. الإسلامي

المطلب الأول تميز الإرهاب الدولي عن الدفاع الشرعي في القانون الدولي ........ بس | المطلب الثاني تميز الإرهاب الدولي عن الدفاع الشرعي في الفقه الإسلامي ......... الفصل الثاني أسباب الإرهاب الدولي في القانون الدولي والفقه الإسلامي........... ع \| المبحث الأول دوافع وأسباب الإرهاب الدولي في القانون الدولي ................. $11 \leqslant 0$ المطلب الأول الدوافع السياسية $11 \leqslant 7$ المطلب الثاني الدوافع الاقتصادية . $11 \varepsilon \vee$ المطلب الثالث الدوافع الدينية .... $11 \varepsilon V$. المطلب الرابع الدوافع الإعلامية .

$\| \varepsilon \wedge$ المطلب الخامس الدوافع التاريخية 110. المطلب السادس الدوافع الشخصية .

1101 المبحث الثاني دوافع الإرهاب في الفقه الإسلامي 1101 المطلب الأول دافع اخذ المال. 
$110 \mathrm{r}$ المطلب الثاني دافع قتل النفس - م

$110 r$ المطلب الثالث دافع إخافة الطريق

الفصل الثالث طرق مكافحة الإرهاب في القانون الدولي والفقه الإسلامي ........... 110 1104 المبحث الأول دور المنظمات الدولية في مكافحة الإرهاب

$110 \xi$ المطلب الأول الأمم المتحدة ودورها في مكافحة الإرهاب . 1100 الفرع الأول دور مجلس الأمن في مكافحة الإرهاب

الفرع الثاني الإجراءات المتخذة من قبل الجمعية العامة للأمم المتحدة بشأن

1101 مكافحة الإرهاب

1171 الفرع الثالث الجهود الدولية لمكافحته تمويل الإرهاب

$117 \varepsilon$ المبحث الثاني المنظمات الإقليمية ودورها في مكافحة الإرهاب

$117 \varepsilon$ المطلب الأول دور الاتحاد الأوربي في مكافحة الإرهاب

1170 المطلب الثاني دور منظمة الدول الأمريكية في مكافحة الإرهاب

1177. المطلب الثالث موقف الاتحاد الأفريقي من الإرهاب.

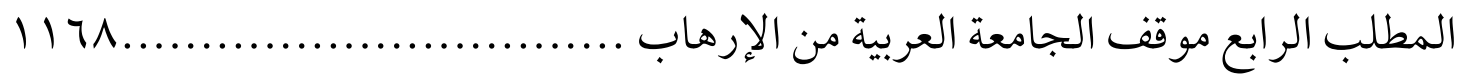
المطلب الخامس موقف مجلس التعاون الخليجي من الإرهاب ........................... IIVT المبحث الثالث مكافحة الإرهاب في الفقه الإسلامي

IIVY المطلب الأول تحقيق العدل والأنصاف بين كافة الأجناس المطلب الثاني تعميق الاستنارة الدينية والتفكير العلمي في نفوس المسلمين ........ IVY... 
IV المطلب الثالث الدور الإعلامي في الدولة الإسلامية في منع الإرهاب ....................

المطلب الرابع تطبيق الشريعة الإسلامية في الجرائم الو اقعة داخل الدولة الإسلامية IVT

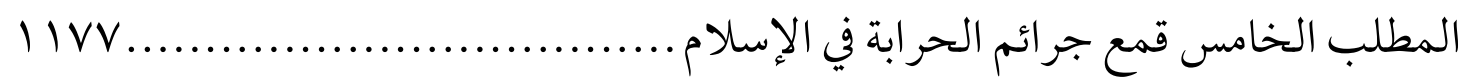

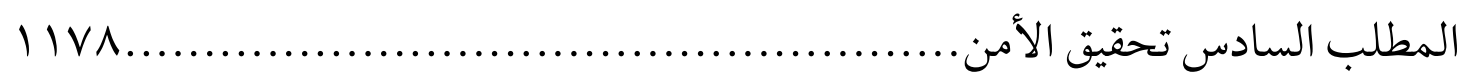

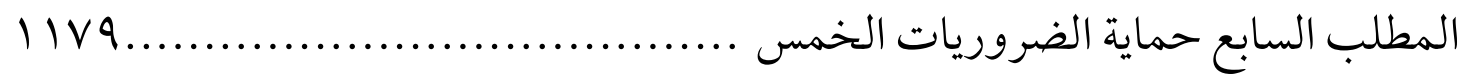

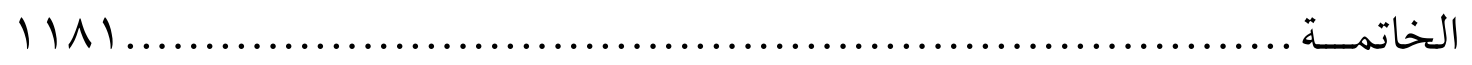

أو لاً: النتائج:

ثانيًا : التوصيات :

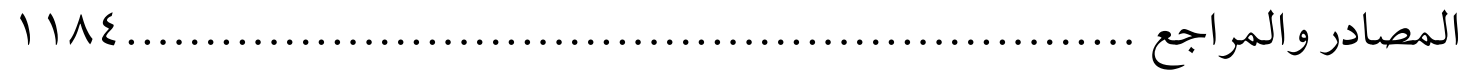

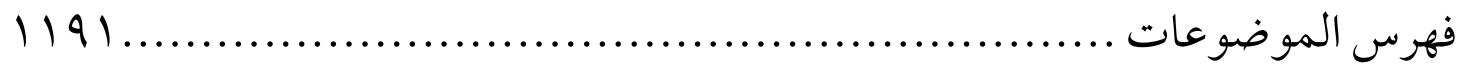

